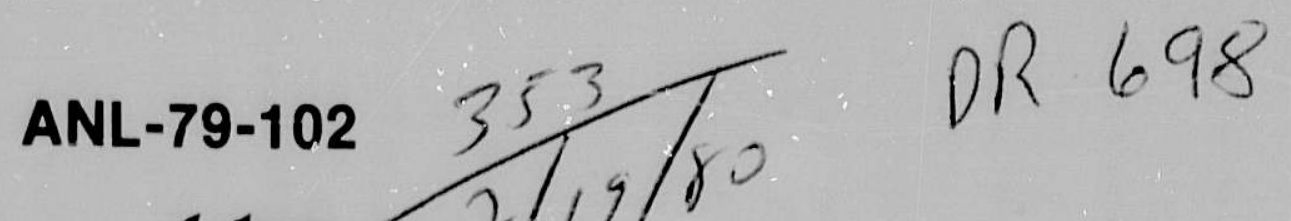

ANL-79-102

\author{
DESIGN OF A SYSTEM \\ USING CPC COLLECTORS \\ TO COLLECT SOLAR ENERGY \\ AND TO PRODUCE \\ INDUSTRIAL PROCESS STEAM
}

by

C. K. Hsieh
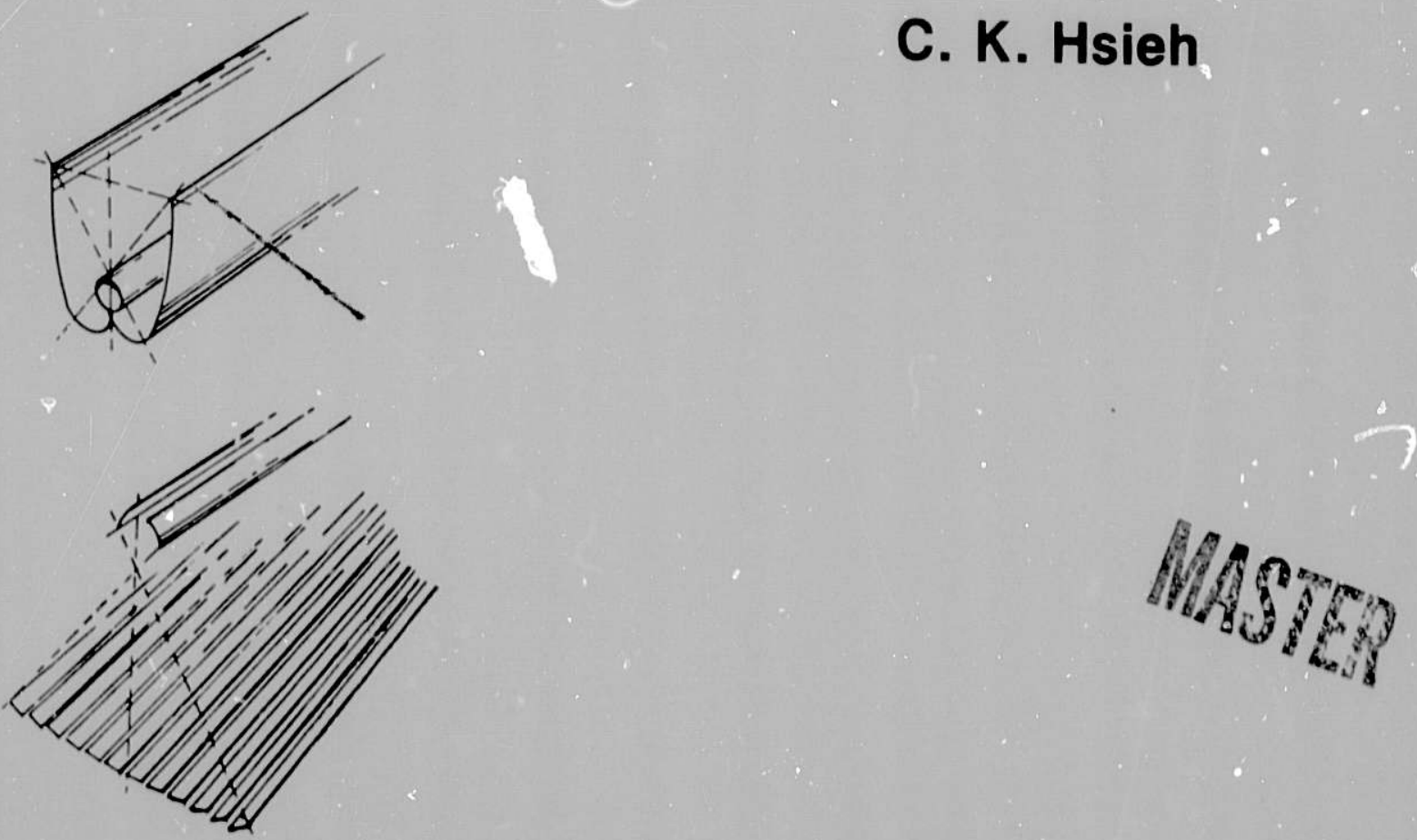

ARGONNE NATIONAL LABORATORY, ARGONNE, ILLINOIS Prepared for the Office of Solar Applications Assistant Secretary for Conservation and Solar Energy U. S. Department of Energy under Contract W-31-109-Eng-38 
ANL-79-102

ARGONNE NATIONAL LABORATORY

9700 South Cass Avenue

Argonne, Illinois 60439

DESIGN OF A SYSTEM USING CPC COLLECTORS

TO COLLECT SOLAR ENERGY AND

TO PRODUCE INDUSTRIAL PROCESS STEAM

by

C. K. Hsieh*

Solar Energy Group

August 1979

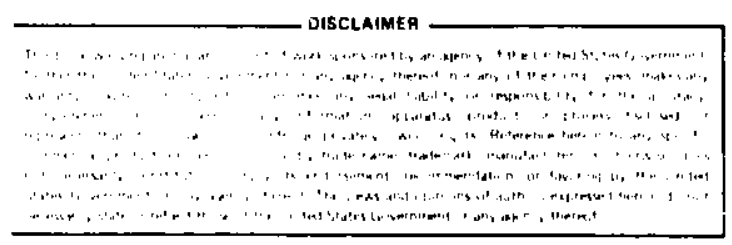

*Department of Mechanical Engineering,

University of Florida, Gainesville 
NOMENCLATURE . . . . . . . . . . . . . . . . . . . . . viii ABSTRACT . . . . . . . . . . . . . . . . . . . . . 1

CHAPTER I. INTRODUCTION . . . . . . . . . . . . . . . 2

CHAPTER II. ANALYSIS . . . . . . . . . . . . . . 7

1. Optical Analysis of CPC Collectors ........ 7

2. Thermal Analysis of CPC Collectors......... 10

3. Heat Pipe Design Theory ... . . . . . . . 27

CHAPTER III. DESIGN OF SYSTEM AND PREDICTION OF PERFORMANCE . . . . . . 38

1. Performance of Collectors in the Collector Loop . . 40

2. Boiler Loop Analysis .............. 49

3. Discussion................ 62

CHAPTFR IV. CONCLUSIONS . . . . . . . . . . . . . . . . 66

CHAPTER V. REFERENCES .................... 67

APPENDIX A. A COMPUTER PROGRAM TO ANALYZE THERMAL PROCESSES IN A SERIES OF CPC COLLECTORS FITTED WITH CTR TUBES , . . . . . 69

APPENDIX B. A COMPUTER PROGRAM TO ANALYZE THERMAL PROCESSES IN A SERIES OF CPC COLLECTORS FITTED WITH HEAT PIPES . . . . . 77 
1. Geographic Locations of Solar IPH Demonstration Projects . . . . . 4

2. A Schematic Diagram Showing a CPC Collector Fitted with a CTR Tube . . 8

3. A Diagram Showing Incidence Angles and Radii of Receiver Tubes . . . 11

4. Free Convection Coefficient for the Receiver Envelope . . . . . . 16

5. Electric Analog Circuit for a CPC Collector . . . . . . . . . . 18

6. Modelling of Heat Transfer through the Back Plate of a CPC Collector. 20

7. $\mathrm{F}_{\mathrm{R}} / \mathrm{F}^{\prime}$ Curves for CPC Collectors . . . . . . . . . . . . . . 24

8 Equivalent Electric Circuits for a Simplified Thermal Analysis of CPC Collectors....................... . . 24

9. Heat Exchanger Effectiveness Curves . . . . . . . . . . . . 28

10. Heat Exchanger Penalty Curves . . . . . . . . . . . . . 28

11. A Schematic Diagram Showing Heat Pipe Operations and Various Dimensions . . . . . . . . . . . . . . . . . . . . . 32

12. Diagram of a System Using CPC Collectors to Produce Process Steam . . 39

13. A Schematic Diagram Showing iroughs Lay-out in a CPC Collector Fitted with CTR Tubes and a CPC Collector Fitted with Heat Pipes . . 41

14. Temperature Distributions in a CPC Collector . . . . . . . . . . . 44

15. $\left(U_{r / e} A_{r}\right)$ versus $\left(\bar{T}_{r}-\bar{T}_{e}\right)$ Curve for CPC Collectors . . . . . . . 46

16. (U $\left.U_{e / a} A_{e}\right)$ and $\left(U_{a / b} A_{a}\right)$ versus $\left(\bar{T}_{e}-\bar{T}_{a}\right)$ Curves for CPC Collectors . 46

17. $\mathrm{L}_{\mathrm{L}}$ and $\mathrm{U}_{\mathrm{O}}$ versus $\overline{\mathrm{T}}_{\mathrm{r}}$ Curves for CPC Collectors . . . . . . . . . 46

18. $\mathrm{F}^{\prime}$ and $\mathrm{F}_{\mathrm{R}}$ Curves for a Series of CPC Collectors . . . . . . . . . 46

19. Heat Exchanger Penalty Factor for a CPC Collector . . . . . . . 48

20. Useful Heat Gains in a Series of CPC Collectors . . . . . . . . . . 48

21. Total Useful Heat in a Series of CPC Collectors . . . . . . . . . 48

22. Efficiency Curves for a CPC Collector . . . . . . . . . . . 48

23. Validation of Mnalysis Using Test Data . . . . . . . . . . . 50

24. Thermodynamic Circuit and T-s Diagrams . . . . . . . . . . 58

25. A Design Chart for Stean Generation . . . . . . . . . . . . . 61

20. A Simplified System Antysis . . . . . . . . . . . . . . . 61

27. Exit Water Temperature Prediction Chart . . . . . . . . . . . 64 
1. Solar I.PH Demonstration Projects . . . . . . . . . . . . . 3

2. Thermodynamic Properties of Aqueous Solutions of Glyc 1 s . . . . . . 39

3. Input Data for Performance Tests of Collectors in the Collector Loup 42

4. Properties of Heat Pipe Materials at $160^{\circ} \mathrm{C}$. . . . . . . . . 51

5. Heat Pipe Specifications . . . . . . . . . . . . . . 52

6. Heat Pipe Design Details................... 53

7. Summary of Heat Transfer Characteristics of the Designed Heat Pipe - 54

8. Input Data for Performance Tests of Collectors in the Boiler Loop. - 56 


\section{English Alphabet:}

A Area

CR Concentration ratio

C Specific heat

D Hydraulic diameter

d Diameter

e Heat exchanger effectiveness

F Frictiona coefficients, $F^{\prime}=U_{0} / U_{L}, F_{R}$ [Equation (31)] $\Gamma_{x}$ [Equation (46)], $F_{A}$ [Equation (44)]

f Drag coefficient

G $\quad \dot{\mathrm{m}}_{\mathrm{c}} / \mathrm{A}_{\mathrm{a}}$

g Gap, acceleration

H Solar fiux

h Convective coefficient, enthalpy

i Incident angle on cover

j Incident angle on receiver envelope

K Permeability

$k$ Incident angle on receiver jacket, thermal. conductivity

L Length of trough, length of heat plpe and its sections

M Mach number

$\dot{\mathrm{m}} \quad$ Mass flow rate

N Nuniber

Nu Nusselt number

No. of reflections

P Gap, pressure
Heat flow

Heat flux

Thermal resistance, gas constant

Radius

Equation (27)

Tensile stress

T Temperature

Thickness

Loss coefficient, overall heat transfer coefficient, conductance

V Wind speed, flow velocity

W Half width of aperture, shaft work

$\mathrm{x} \quad$ Quality of steam

\section{Greek Alphabet:}

Absorptance

$\gamma \quad$ Specific heats railio

$\varepsilon \quad$ Emittance

n Efficiency

$\theta \quad$ Acceptance ha1f-angle

$\mu \quad$ Viscosicy

$\Sigma \quad$ Surface tension

p I!eflectance, density

o Stefan-Boltzinann Constant

T Transmittance, shear stress

$\phi \quad$ Wick porosity

$\psi \quad$ Tilt angle 

Enclosure absorption

Collector cover, heat exchanger inner radius, annulus, heat pipe adiabatic section

Beam component, ambient, boiler loop

c Convection, collector circulating fluid, capillary, condenser

d Diffuse component

e Receiver envelope, heat pipe evaporator section, effective

conductivity

f Fluid, mean fluid zemperature, back plate

g Receiver wa11

h Hydraulic radius

1 Inside radius, inlet section, inside surface

IR Infrared

L Loss coefficient from receiver surface to ambient

$1 \quad$ Liquid

Nucleus Radius

C Overall loss coefficient

o Outside radius, optical efficiency, stagnation state, exit

p Heat pipe, plpe wall, consiant pressure condition

ph Proheater

$R$ Heat recovery factor

r Recelver

s $\quad$ Sky, static pressure

t Total
Useful heat gain, ultimate tensile strength

Vapor or vapor core

Wick

Heat Exchanger

Mean value 

by

C. K. Hsieh

ABSTRACT

A system has been designed to use CPC collectors to collect solar energy and to generate steam for industrial process heat purposes. The system is divided into two loops with the collectors in the collector loop to operate a preheater and the collectors in the boiler loop to heat water to elevated pressures and temperatures. A flash boiler is used to throttle the heated water to steam. Two types of CPC collectors are chosen. In the collector loop the CPC collectors are fitted with concentric tube receivers. In the boiler loop the collectors employ heat pipes to transmit heat. This design is able to alleviate the scaling and plumbing problems. A fragile receiver tube can also be employed without rupture difficulties.

The thermal processes in the collectors were analyzed using a computer modeling. The results were also used to develop a thermodynamic analysis of the total system. Calculations show that the design ts technically feasible. The CPC coilector is shown to have an efficiency that is very weakly dependent on 1ts operating temperatures, which makes the collector particularly attractive in high temperature applications. 



\section{INTRODUCTION}

The use of compound parabolic concentrator (CPC) to collect solar energy has received much attention in recent years. The CPC is able to offer a concentration ratio that is the highest possible given the acceptance angle of the device [1]. Because the $\mathrm{CPC}$ is not intended to focus sharp images, its mirror reflectors can be fabricated with less precision. Probably most important of all, the CPC does not need to track the sun to be operational, oniy occasional adjustments of tilt angles are needed, which greatly reduces the cost of the system. The present project addresses the design of a system that utilizes CPC to collect energy and to generate low quality steam for meeting industrial process heat (IPH) needs.

An examiration of the ation's solar energy program reveals that the present project fits well into the Department of Energy's plan to commercialize solar energy in the industrial process heat sector. Solar IPH demonstration projects have been funded both by DOE and private industries as shown in Table 1 and Figure 1. Of those projects listed in the table, the great majority uses either a flat-plate collector or a parabolic trough concentrator to collect energy. CPC collectors have yet to make a penetration into this important segment of solar applications.

There are several constraints imposed on the design of the present system. Because of the use of receiver tubes inside a collector, in-situ boiling is handicapped due to the receiver tube strength, scaling problem and plumbing difficulties. On the other hand, the CPC collects energy from the sun that follows definite paths day in and day out. For the $\mathrm{CPC}$ to be economically competitive only occasional tilt adjustments are permitted, and the collector must be mounted alor.g an east-west axis. This orientation limits the selection 


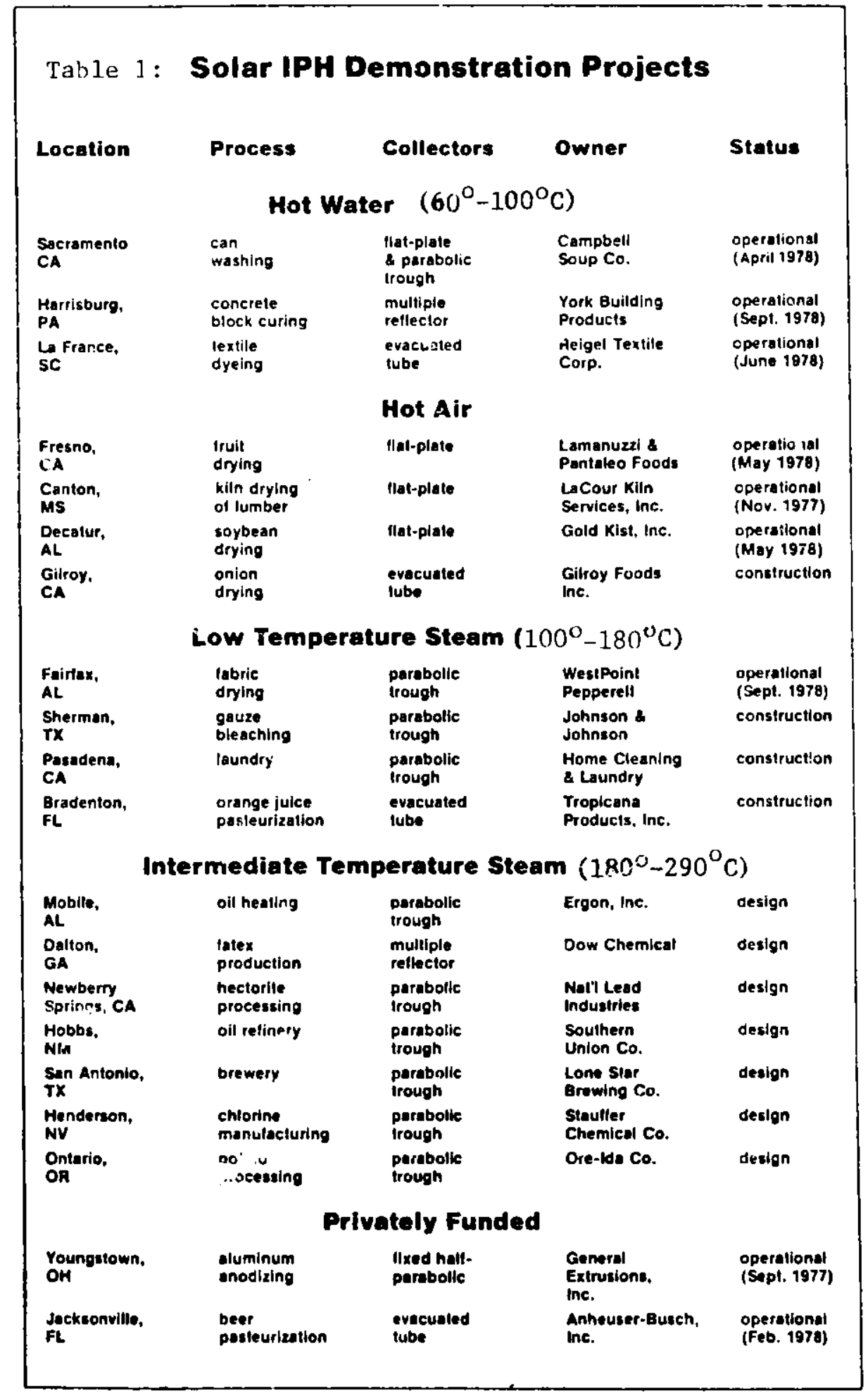




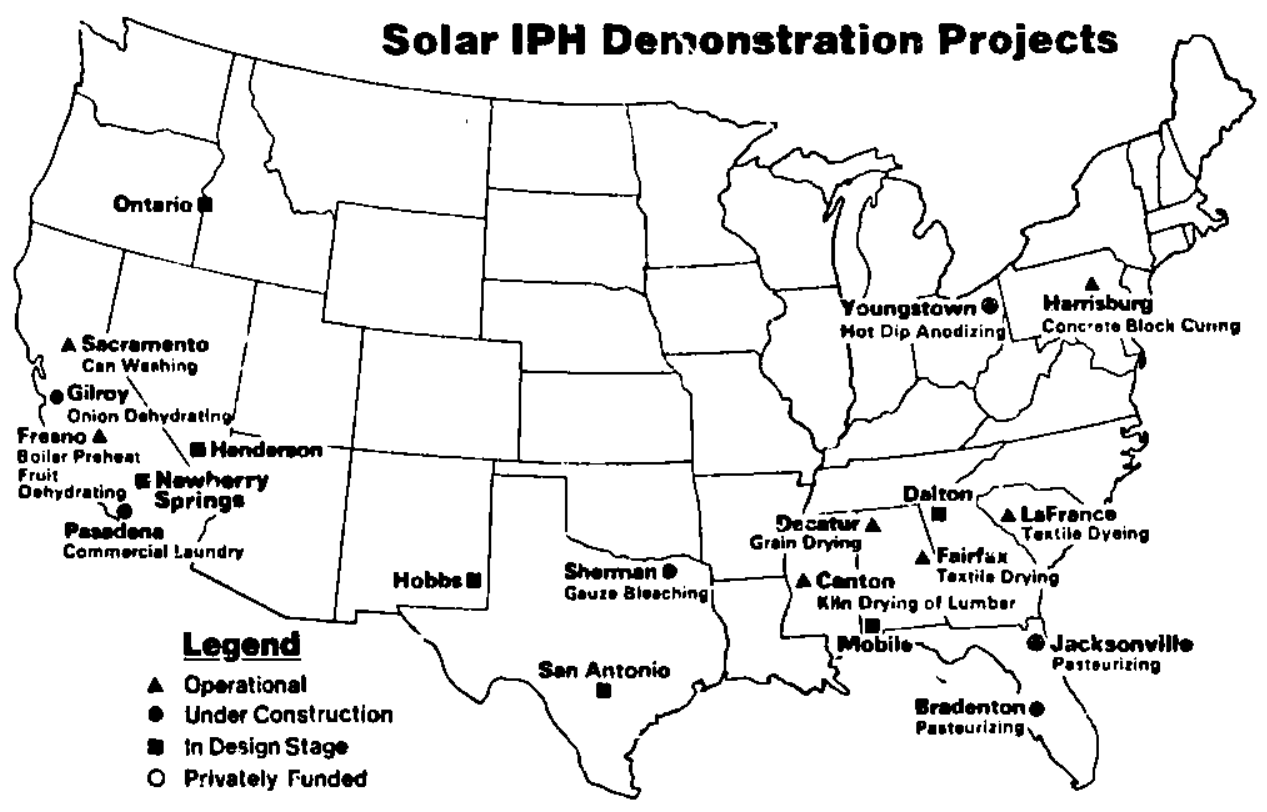

Fig. 1. Geographic Locations of Solar iPH Demonstration Projects 
of heat transmission devices. Furthermore, the sun's energy is highly diluted. To make use of this dilute energy for a relatively energy concentrated application requires special design considerations. The design effort cannot follow the conventional steam generation practice and the project itself presents a real challenge to analysis.

The material presented in this report is divided primarily into two parts. In Section II the theoretical background for analysis is presented. This part consists of three subsections dealing separately with the optical and the thermal analyses of CPC and the heat pipe design theory. Of these three covered, since the optical analysis and the heat pipe design theory have been well documented in the literature [2-5], the materials given in this report are brief, and equations and theories given are limited unly insofar as they are relevant to the present analysis and design of system. As to the thermal analysis of CPC collectors, there is a lack of thorough treatment in the literature. The ones given in [6-8] are incomplete and a full analysis appears in order. The thermal analysis part of this report will address the problem in detail.

Section ITI of this report presents a design of the system. For a detailed analysis of the system performance, two computer programs have been developed. They are used to iimulate the zmal processes of collectors in both collector and boiler loor 3 in the system. The performance of heat pipes is also treated in detail in this section. These analyses permit sizing of the system to meet the need.

The computer programs have been included as appendices to this report. Detailed information is provided to show how these programs can be used for analysis. 
It is not possible to make $i$ transient system analysis in the present project, nor has the economic analysis been treated at this stage. They can be done in the future when specifications of the total system are identified. Nevertheless, the present project is complete to the level where specifications for major components (collectors, heat pipes, pumps) have been determined as given in this report. These informations will be instrumental to make system cost estimatic.1s if necessary. 


\section{ANALYSIS}

The system under investigation is depicted in Figure 2. The CPC collector employs an evacuated tube receiver to intercept concentrated energy. The tube receiver has an evacuated space between the glass envelope and the receiver jacket. This evacuated space serves the purpose of eliminating the convective heat loss from the receiver. The receiver jacket is covered with a selective coating to raise its solar absorptance while minimizing its infrared emittance. The heat absorbed by the receiver jacket is transmitted to the fluid that is flowing inside the receiver tubing via the copper hoat getter (fin) fitted inside the jacket wall. Two receiver tubings occupy the center space with only one tube spot welded to the getter; this is also the tube which delivers fluid to the collector, with the other tibing serving as a return passage of flow.

The collector utilizes a pair of compound parabolje reflectors to reflect sunlight onto the receiver. A clearance is built in between the lower surface of the receiver envelope and the mirror reflector. This clearance is provided to account for any misalignment that can happen to a long receiver tube under ends supported condition. This clearance together with the gap in the evacuated tube constitutes a loss to the intercepted energy as will be examined later.

\section{Optical Analysis of CPC Collectors}

It has been shown in the literature that the geometric concentration ratio (CR) of a CPC is [9]

$$
\mathrm{CR}=\frac{1}{\sin \theta_{\max }}
$$

where $\theta_{\max }$ is the acceptance half-angle. Physically, because of the geometry 


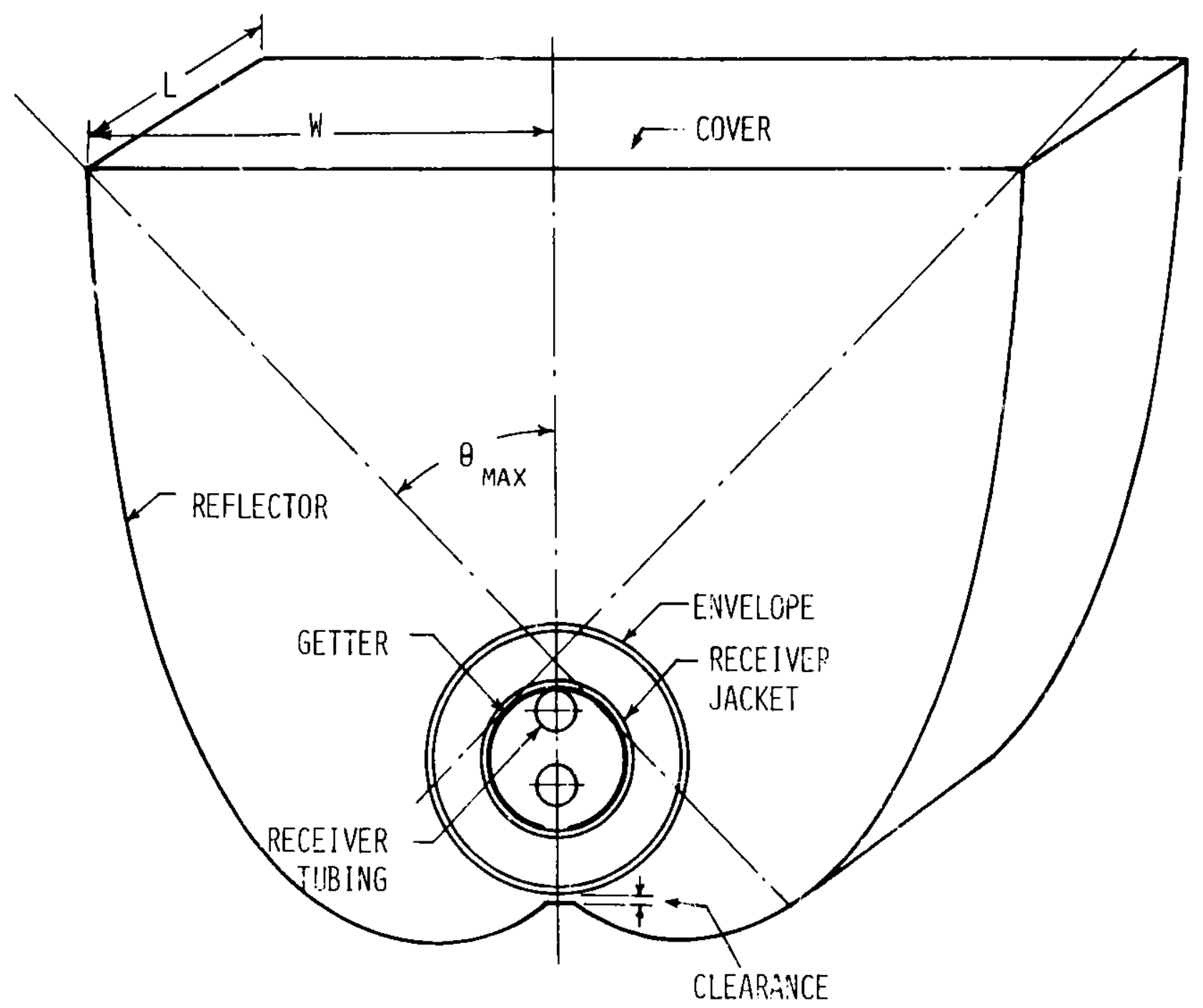

FIGURE 2. A SCHEMATIC DIAGRAM SHOWING A CPC COLLECTOR FITTED NITH A CTR TUBE 
of the mirror reflector, any beam radiation incident on the collector cover that is contained withiin $|i| \leq \theta_{\max }$ is able to reach the receiver. The concentration ratio used in this wor'k is a geometric quantity and is defined on the basis of the total receiver area.

Unlike a flat-plate collector that is able to receive all the diffuse radiation that is incident on its aperture, the $\mathrm{CPC}^{\prime}$ s capability to intercept diffuse radiation is limited and is governed by the acceptance angle concept described above. Although the CPC cover can receive all the diffuse radiation, the fraction of energy that is transmitted through the cover and reaching the receiver is reduced by a factor of $\left(A_{r} / A_{a}\right)=(1 / C R)$ for a two-dimensional CPC trough of interest in this study. By the same token, because of the geometry of the CPC mirror, all the energy leaving the receiver can, with the help of the mirror, reach the cover. Conversely, only a fraction $\left(\mathrm{A}_{r} / \mathrm{A}_{a}\right)$ of the total energy leaving the cover can reach the receiver. This difference in shape factor relations gives rise to different formulations for energy exchanges as will be seen later in the analysis.

The reflection of energy in a CPC collector is also important. For incoming rays located in the central region of the aperture these rays undergo no reflection between the aperture and the receiver. This is not so, however, for edge rays, which undergo one or more reflectiuns before reaching the receiver. The average number of reflections for all the rays filling the aperture can be found using a ray tracing technique, and its use greatly simplifies the analysis. The attenuation or loss of radiation due to mirror reflection can be expressed in terms of the average number of reflections $\bar{n}$ as

$$
\text { Reflection Loss }=1-\rho_{m}^{\bar{n}}
$$

where $\rho_{m}$ is the mirror reflectance. Values for $\bar{n}$ have been documented in the 
literature, for example $[6,10]$. In general, the average number of refl.ctions $i s$ a function of the incidence angle, concentration ratio, receiver configuration and gap size. For most engineering designs the variation of $\overrightarrow{\mathfrak{n}}$ with the CPC incidence angle can be neglected for practical purposes [11].

As noted earlier, thers is a gap between the receiver jacket and the mir this gap the energy received by the absorber is reduced by a factor of $p$, given as [12]

$$
\mathrm{p}=1-\frac{\mathrm{g}}{2 \pi \mathrm{r}_{\mathrm{r}, \mathrm{o}}}
$$

where $g$ is the total gap thickness (clearance plus evacuated gap); $r_{r, o}$ is the receiver jacket radius, see Figure 3 .

\section{Thermal Analysis of CPC Collectors}

In order to simulate the thermal processes in the $\mathrm{CPC}$, it is necessary to establish energy balance for various components in the collector. The interaction of the beam and diffuse radiation with the collector cover, receiver envelope and jacket will be treated first. A two-band model will be used in the analysis.

The beam radiation incident on the cover and absorbed by it can be expressed as

$$
q_{b, a}=H_{b}(i)\left[\alpha_{a}(i)+\bar{\alpha}_{a} \tau_{a}(i) \bar{p}_{e} \rho_{m}^{2 \bar{n}}\right] \frac{A_{a}}{A_{r}}
$$

where the heat flux $q$ has been written on the basis of a unit receiver-jacket aren $A_{r}\left(=2 \pi r r_{r, o} L\right), L$, collector length. $H_{b}$ represents beam radiation flux. $\therefore \rho$ and $\tau$ denote the radiative properties in the solar spectrum and have their usual meanings (notations are defined in the Nonenclature). Subscripts $a, e, m$ and $r$ refer to cover, envelope, mirror and receiver, respectively. 


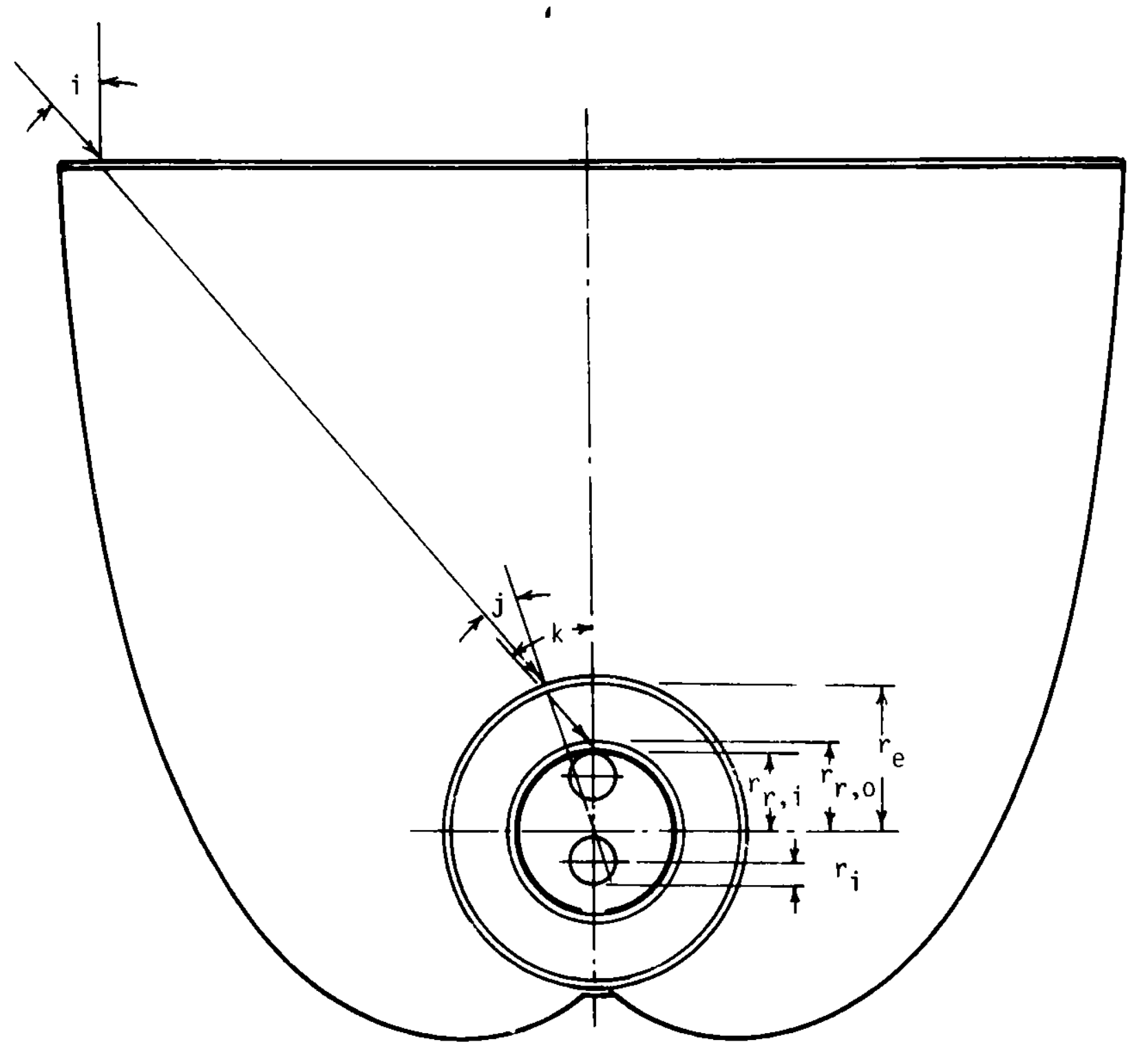

FIG!'RE 3. A DIAGRAM SHOWING INCIDENCE ANGLES AND RADII OF RECEIVER TUBE. 
$H_{b}, \alpha_{a}$ and $\tau_{a}$ are functions of the beam incident angle $i$ and have been so identified by appending parantheses. Overbars abc ve properties designate mean values which remove the angular dependency. $A_{a}$ is the aperture area of the collector, $A_{a}=2 w L, w$, half-width of aperture. The second term in the bracket accounts for the reflested energy from the envelope that is absorbed by the cover, a second-order effect.

The beam radiation transmitted through the cover and absorbed $b y$ the receiver envelope is

$$
q_{b, e}=H_{b}(i) \tau_{a}(i) \rho_{m}^{\bar{n}}\left[\alpha_{e}(j)+\bar{\alpha}_{e} \bar{\rho}_{e} \bar{\rho}_{a} \rho_{m}^{2 \bar{n}} \frac{A_{e}}{A_{a}}+\bar{\alpha}_{e} \bar{\rho}_{r} \tau_{e}(j)\right] \frac{A_{a}}{A_{r}}
$$

where $A_{e}=2 \pi r_{e}{ }^{L}$. The second term in the bracket accounts for that part of the beam radiation reflected from tha envelope and rereflected from the cover and finally absorbed by the envelope. The third term takes into consideration the reflected energy from the receiver jacket that is incident on the envelope. This last contribution is small if the receiver jacket has a selective surface. They are included to account for second order effects.

The beam radiation transmitted through the cover and envelope and absorbed by the receiver $j$ acket is

$$
q_{b, r}=H_{b}(i) \tau_{a}(i) \rho_{m}^{\bar{n}} \tau_{e}(j) p\left[\alpha_{r}(k)+\bar{\alpha}_{r} \bar{\rho}_{r} \bar{\rho}_{e} \frac{A_{r}}{A_{e}}\right] \frac{A_{a}}{A_{r}}
$$

where $p$ has been defined in Equation (3). The second term in the bracket accounts for the beam radiation that is not absorbed on its first impingement on the receiver but reflected from the jacket and rereflected from the envelope ani eventually absorbed by the jacket, again a second order correction term. 
The formulation $f \backslash r$ contributions of beam radiation is now complete; attention is now directed to the diffuse contributions. The diffuse radiation absorbed by the collector cover is

$$
q_{d, a}=H_{d} \bar{\alpha}_{a}\left(1+\bar{\tau}_{a} \bar{\rho}_{e} \rho_{m}^{2 \bar{n}}\right)_{A_{r}}^{A_{a}}
$$

where $\mathrm{H}_{\mathrm{d}}$ is the diffuse component of solar flux. Again the equation is written on the basis of a unit receiver-jacket area $A_{r}$. The second term in the parenthesis represents the second order effect due to reflection of diffuse radiation by the envelope and aisorbed by the cover.

The contribution of diffuse radiation $t$, the absorption in the envelope is

$$
q_{d, e}=H_{d} \bar{\tau}_{a} \rho_{m}^{\bar{n}} \bar{\rho}_{e}\left(\bar{I}+\bar{\rho}_{e} \bar{\rho}_{a} \rho_{m}^{2 \bar{n}} \frac{A_{e}}{A_{a}}+\bar{\rho}_{r} \bar{\tau}_{e}\right) \frac{A_{r}}{A_{a}} \frac{A_{a}}{A_{r}}
$$

The second and the third terms in the parenthesis have the same physical significance as the corresponding terms in Equation (5).

The diffuse contribution to absurption in the receiver jacket is

$$
q_{d, r}=H_{d} \bar{\tau}_{a} \tau_{e} \alpha_{r} \rho_{m}^{\bar{n}} p\left(1+\bar{\rho}_{r} \bar{\rho} \frac{A_{r}}{A_{e}}\right) \frac{A_{r}}{A_{a}} \frac{A_{a}}{A_{r}}
$$

Once again, the second term in the parenthesis plays the same role as the corresponding term in Equation (6). p accounts for correction for gar loss.

Solar radiation incldent on a $\mathrm{CPC}$ will rais: the tomperature of the collector, giving rise to an infrared ener`y exchange. This mode of heat transfer can be formulated in terms of surface infrared emittances and analyzed using an electric allalog as follows. 
For infrared exchange between the receiver jacket and the envelope, the radiant flux is

$$
\mathrm{q}_{I R, r / e}=\frac{\sigma\left(\mathrm{T}_{r}^{4}-\mathrm{T}_{e}^{4}\right)}{\frac{1}{\varepsilon_{r}}+\frac{\mathrm{A}_{r}}{\mathrm{~A}_{e}}\left(\frac{1}{\varepsilon_{e}}-1\right)}
$$

where $\sigma$ is the Stefan-Boltzmann constant. The factor $\left(A_{r} / A_{e}\right)$ for the second term in the denoninator accounts for the view factor between the envelope and the receiver jacket. $\varepsilon$ denotes the infrared emittance. This equation is written again on the basis of a unit receiver-jacket area.

The infrared exchange between the envelope and the collector cover is

$$
\mathrm{q}_{\mathrm{IR}, \mathrm{e} / \mathrm{a}}=\frac{\left(\frac{\mathrm{A}_{\mathrm{e}}}{\mathrm{A}_{\mathrm{r}}}\right) \mathrm{a}\left(\mathrm{T}_{\mathrm{e}}^{4}-\mathrm{T}_{\mathrm{a}}^{4}\right)}{\frac{1}{\varepsilon_{\mathrm{e}}}+\frac{\mathrm{A}_{\epsilon}}{\mathrm{A}_{\mathrm{a}}}\left(\frac{1}{\varepsilon_{\mathrm{a}}}-1\right)}
$$

The heat loss from collector cover to sky is

$$
\mathrm{q}_{I R, a / s}=\varepsilon_{a} \sigma\left(T_{a}^{4}-T_{s}^{4}\right) \frac{A_{a}}{A_{r}}
$$

where the sky temperature $T_{s}$ can be related to the ground-level ambient temperature $\mathrm{T}_{\mathrm{b}}$ by $[13]$

$$
T_{s}=T_{b}-6
$$

In the above equation both $\mathrm{T}_{\mathrm{s}}$ and $\mathrm{T}_{\mathrm{b}}$ are in ${ }^{\circ} \mathrm{C}$.

There are other modes of energy exchange inside the ccllector. The convective heat loss from the recciver envelope is

$$
q_{c, e / a}=h_{e / a} \Delta T \frac{A_{e}}{A_{r}}
$$


which is written again based on a unit receiver area. In the equation the convective coefficient $h_{e / a}$ is a function of temperaturas and can be expressed in an empirical formula [14]

$$
h_{e / a}=1.32\left(\frac{\Delta T}{2 r_{e}}\right)^{1 / 4}
$$

where $\Delta \mathrm{T}$ and $\mathrm{r}_{\mathrm{e}}$ are in untts ${ }^{\circ} \mathrm{C}$ and $\mathrm{m}$, respectively. This equation, having a $1 / 4$ power temperature dependency, is inconvenient to use in the iterative solution. Attempt is thus made to linearilize this equation using the following:

$$
r_{e / a}=3.25+0.0085 \frac{T_{e}-T_{a}}{4 r_{e}}
$$

where the sink temperature in the equation has been taken to be the mean of those of cover and envelope. Equation (16) provides a good approximation to the nonlinear equation (15) over the temperature range that is commonly encountered in CPC collectors, see Figure 4.

For convection loss from cover to ambient the equation to be used is

$$
q_{c, a / b}=h_{a / b}\left(T_{a}-T_{b}\right) \frac{A_{a}}{A_{r}}
$$

where $T_{b}$ designates ambient temperature and $h_{a / b}$ is relatec to wind speed by [14]

$$
\mathrm{h}_{\mathrm{a} / \mathrm{b}}=5.7+3.8 \mathrm{~V}
$$

where $V$ is wind speed in uniLs of $\mathrm{m} / \mathrm{s}, \mathrm{h}_{\mathrm{a}} / \mathrm{b}$ in $\mathrm{W} / \mathrm{m}^{2}{ }^{\circ} \mathrm{C}$

It is noted that in a CPC collector the useful energy is extracted in the form of heat by flowing liquid inside the receiver tubing. If the contact resistance between the recelver jacket and the heat getter (fin) is ignored, the following equation can be written: 


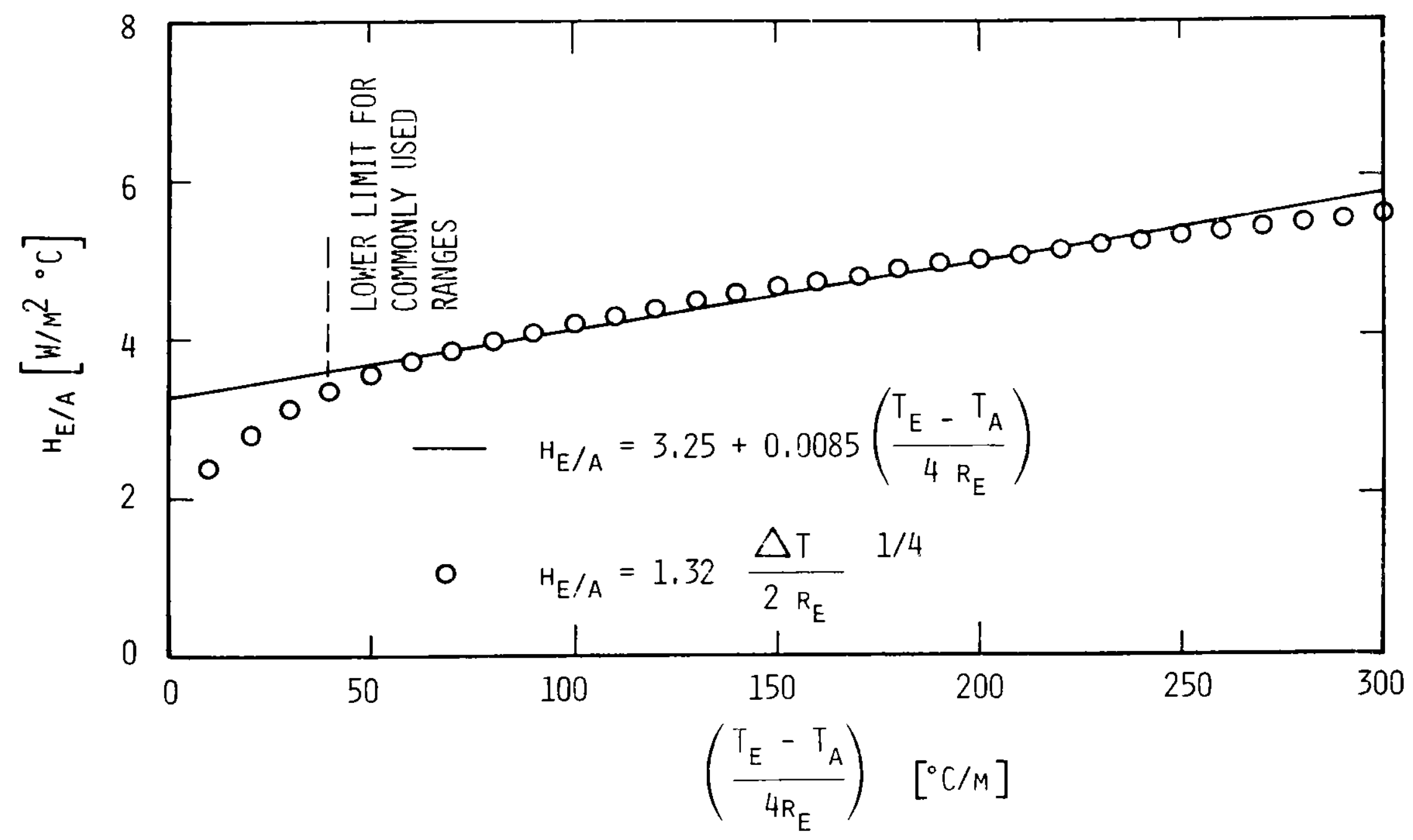

FIGIJRE 4, FREE CONVECTION COEFFICIENT FOR THE RECEIVER ENVELOPE 


$$
\dot{m}_{c} c_{p c}\left(T_{o}-T_{i}\right)=U_{r / 1} A_{r}\left[T_{r}-\frac{\left({ }_{i}+T_{0}\right)}{2}\right]=Q_{u}
$$

where $\dot{m}_{c} c_{p c}$ refers to the thermal capacitance rate of the collector circulating fluid; subscripts $i$ and o for $T$ designate inlet and outlet sections respectively. $A_{r}$ refers to the outside surface of the receiver jacket. The heat transfer coefficient $U_{r / 1}$ accounts for both conduction across the receiver -jacket wall and convection inside the receiver tubing. It follows that

$$
\mathrm{u}_{\mathrm{r} / 1}=\left[\frac{\mathrm{r}_{\mathrm{r}, \mathrm{o}}}{2.182 \mathrm{k}_{\mathrm{f}}}+\frac{\mathrm{r}_{\mathrm{r}, \mathrm{o}} \ln \left(\mathrm{r}_{\mathrm{r}, \mathrm{o}} / \mathrm{r}_{\mathrm{r}, \mathrm{i}}\right)}{\mathrm{k}_{\mathrm{g}}}\right]
$$

where subscripts $\mathrm{f}$ and $\mathrm{g}$ for $\mathrm{k}$ (thermal conductivity) refer to liquid and jacket wall, respectively. In the above equation the convective heat transfer between the fluid and the receiver tubing has been modeled using a constant heat flux condition. Its Nusselt number is [15]

$$
\mathrm{Nu}=4.364
$$

The equations given above provide the basis for establishing energy balance for various components in the coliector. An electric analog circuit depicting energy interactions between components can now be constructed as shown in Fig. 5. Based on this figure the energy balance equation for the collector cover under steady state condition can be derived as

$$
q_{b, a}+q_{d, a}+q_{I R, e / a}+q_{c, e / a}-q_{I R, a / s}-q_{c, a / b}=0
$$

where each term in this equation has been defined previously.

For the envelope the energy balance equation is

$$
q_{b, e}+q_{d, e}+q_{I R, r / e}-q_{I R, e / a}-q_{c, e / a}=0
$$

For the receiver jacket, the following energy balance relation can be established

$$
q_{b, r}+q_{d, r}-q_{I R, r / e}-\frac{Q_{u}}{A_{r}}=0
$$




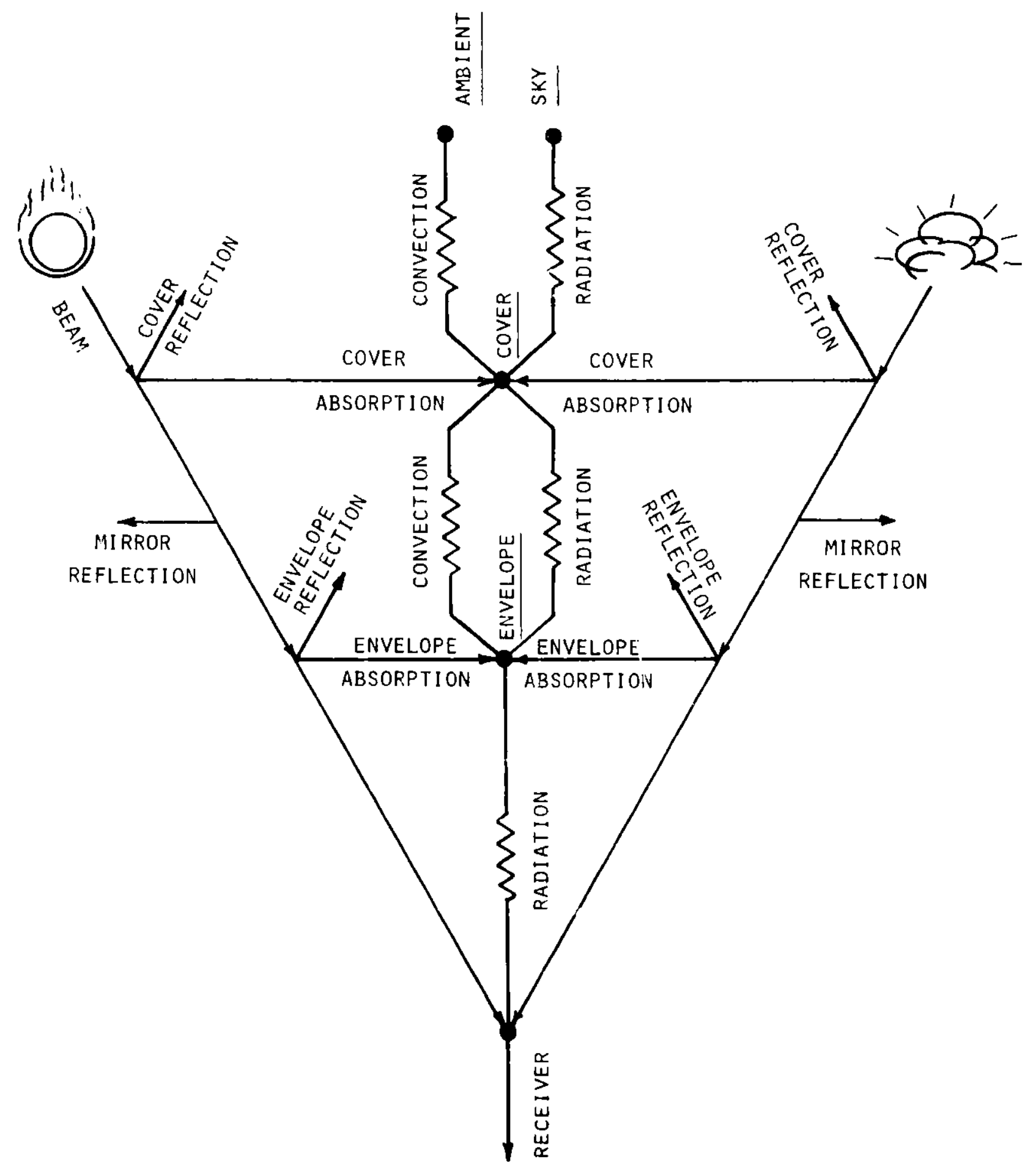

USEFIL ENEREY EXTRACTION

FIGURE 5. ELECTRIC ANALDG CIRCUIT FOR A CPC CILLLECTOR 
Note that there is no convective heat loss from the receiver jacket because the tube is evacuated.

Equations (22), (23) and (24) can be used together with (19) to form a set of four, nonlinear, algebraic equations to solve for four unkowns $\mathrm{T}_{\mathrm{a}}, \mathrm{T}_{\mathrm{e}}$, $\mathrm{T}_{r}$ and $\mathrm{T}_{0}$ if $\mathrm{T}_{i}$ is given. A computer program developed based on a combination of Newton-Raphson method and iteration solution is included as Appendix A to this report.

It is worthy of note that in the foregoing analysis the CPC mirror was not treated as a separate floating potential for the adiabatic surface role it plays. In fact, the computer data show that, because of the construction of the receiver, the vacuum surrounding the receiver jacket as well as the selective surface on the jacket provides good insulation of the receiver. As it turned out, the anvelope has a fairly low temperature; and inclusion of the mirror analysis is certainly unnecessary for the collector.

Anot:her question arises in connection with the rationale of omitting the back loss in the analysis. T'his can be justifled by examining the models illustrated in Figure 6 . The CPC mirror can be simulated as a flat radiation shield between the receiver envelope (e) and the back plate (f). For the system under consideration the heated surfaces are located above; convection is t arefor negligible. The equivalent thermal resistances can he derived for various parts of heat flow and be formulated as shown. Tests have shown that the back loss is negligibly small for all CPC collectors.

The analysis presented above 1 - complete in the sense that it can be used to predict collector performance and sizing collectors, if necessary. However, there will be a hect exchanger in the collector loop in the final design of syster:s. For such an arrangement the system performance will he a function of the heat exchanger penalty factor which is, in turn, a function of the heat 


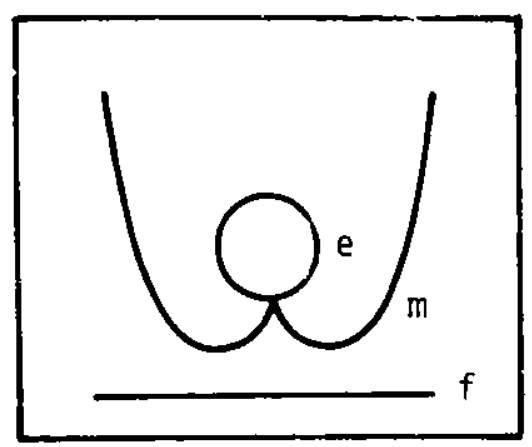

C -..- ENVELOPE

m - . Ni RROR

f -.- BACKPLATE

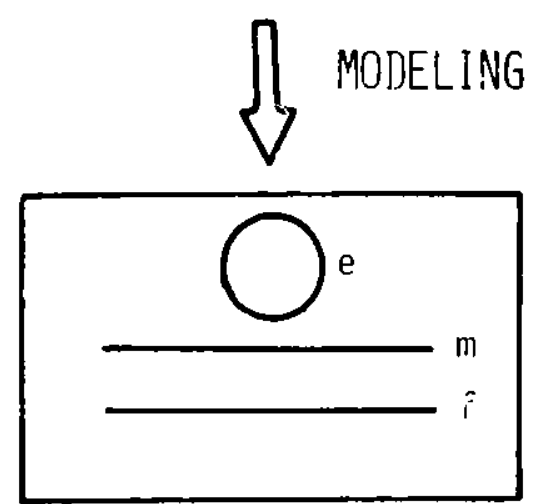

m - - - RADIATION SHIELD

$\mathrm{F}_{\mathrm{e}-\mathrm{m}} \cdots$ SHAPE FACTOR, $\mathrm{F}_{\mathrm{e}-\mathrm{m}}=0.5$

$\left\{\begin{array}{l}\text { ENUIVALENT } \\ \text { NETWORK }\end{array}\right.$

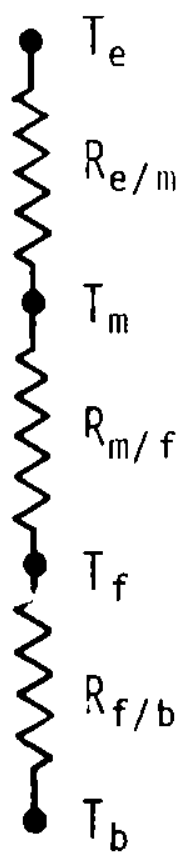

$R_{e / m}=\frac{\frac{\rho_{e}}{A_{e} \varepsilon_{e}}+\frac{2}{A_{e}}+\frac{\rho_{m}}{A_{m}^{\varepsilon_{m}}}}{4 a\left(\frac{{ }^{\top}{ }^{\top} T_{m} j^{3}}{2}\right)^{3}}$

$R_{m / f}=\frac{\frac{\rho_{m}}{A_{m} \varepsilon_{m}}+\frac{1}{A_{m}}+\frac{\rho_{f}}{A_{m}^{E_{f}}}}{4 \sigma\left(\frac{T_{m}+T_{f}}{2}\right)^{3}}$

$R_{f / b}=\frac{1}{h \hat{A}_{f}}$

FIGLIRE 6, IODELING OF HEAT TRANSFER THROUGH THE BACK PLATE DF A CPC COLLECTOR 
removal factor, among others. A separate analysis is thus in order to derive this heat removal factor.

The analysis to be developed follows the Hottel-Whillier-Woertz-Blizz (HWWB) furmulation that was originally derived for analyzing flat-plate collectors [16-18]. The useful energy extracted from the CPC collector can be written as

$$
Q_{u}=H_{t} \bar{\tau}_{a} \rho_{\pi}^{\bar{n}} \bar{\tau}_{e} \bar{\alpha}_{r} p A_{a}-U_{L} A_{r}\left(T_{r}-T_{b}\right)
$$

where $H_{t}$ is the total solar flux defined as

$$
H_{t}=H_{b}(i)+H_{d}
$$

$U_{L}$ is the receiver surface loss coefficient.

Equation (25) appears to be quite simple. However, the analysis does not accuunt for multireflections as what has been afforded in the previous analysis. Hence, using Equation (25) to predict useful heat gain could result in an underestination because of the omission of second order effects. This point can be verified by data as will be shown later in this report.

Equat:on (25) can be recast in a simpler form by introducing

$$
S^{-}=H_{t} \bar{\tau}_{a} \rho_{m}^{\bar{n}} \bar{\tau}_{e} \bar{\alpha}_{r} p \frac{A_{a}}{A_{r}}
$$

thus giving

$$
Q_{u}=A_{r}\left[S^{-}-U_{L}\left(T_{r}-T_{b}\right)\right]
$$

Another way to write $Q_{u}$ equation is to express $Q_{u}$ in terms of the mean fluid temperature $\mathrm{T}_{\mathrm{f}}$ inside the receiver tubing. If toth conductive resistance inside the receiver-jacket wall and the convect1 - resistance inside the receiver tubing are accounted for, there is dertved 


$$
Q_{u}=F^{\prime} A r\left[S^{\prime}-U_{L}\left(T_{f}-T_{U}\right]\right.
$$

where $F^{\prime}$ is the ratio of the overall loss coefficient to the receiver surface loss coefficient, given as

$$
F^{\prime}=\frac{U_{O}}{U_{L}}=\frac{\left(1 / U_{L}\right)}{\left(1 / U_{L}\right)+r_{r, o} \ln \left(r_{r, o} / r_{r, i}\right) / k_{g}+r_{r, o} /\left(r_{i} h_{i}\right)}
$$

Physically, $F^{\wedge}$ represents the ratio of the useful heat gain to the heat gain of a hypothetical case if the receiver jacket surface had been at the fluid "mean" temperature.

A third way to write Equition (28) is to introduce the heat removal factor defined as

$$
F_{R}=\frac{G c_{p c}(C R)}{U_{L}}\left[1-\exp \left(-\frac{U_{L^{\prime}} F^{\prime}}{G c_{p c}(C R)}\right)\right]
$$

where $G=\dot{\mathrm{m}}_{\mathrm{c}} / \mathrm{A}_{\mathrm{a}}$. This permits rewriting $Q_{\mathrm{u}}$ as

$$
Q_{U}=F_{R} A_{r}\left[S^{\prime}-U_{L}\left(T_{i}-T_{b}\right)\right]
$$

Note that the $\mathrm{T}_{\mathrm{r}}$ in Equation (28) [or $\mathrm{T}_{\mathrm{f}}$ in Equation (29)] has been changed to $\mathrm{T}_{i}$ in the above equation. Physical1y, $\mathrm{F}_{\mathrm{R}}$ can be interpreted in a similar way as $F^{\prime}$. More specifically, $F_{R}$ represents the "atio of the useful heat gain to the heat gain if the receiver jacket had been at the "inlet" fluid termperature.

The analysis developed above follows the HWWB formulation for flat-plate collectors. The formulations given here are more general in the sense that, when

$$
\text { (CR) }=\rho_{m}^{\bar{n}}=\bar{\tau}_{e}=p=1
$$

the three $Q_{u}$ equations given above can all be reduced to the similar equations for flat-plate collectors. 
Another point of interest is that, if $F_{R} / F^{\prime}$ is plotted versus $\mathrm{Gc}_{\mathrm{pc}} / \mathrm{F}^{\prime} \mathrm{U}_{\mathrm{L}^{\prime}}$, a family of curves is obtained as shown in Figure 7. For CPC collectors the curves reach the asymtotic value of unity earlier than flat-plate collectors (labeled $\mathrm{CR}=1$ ). The small $\mathrm{U}_{\mathrm{L}}$ typical for a CPC collector will also raise the value of $G c_{p} / F^{\prime} U_{L}$ which is plotted as abscissa in the figure. These cumulative effects will lead to a higher $F_{R}$, a desirable feature from the heat gain point of view.

The $Q_{u}$ equations [Equations (28), (29) and (32)] derived above all share a common simplification - the energy absorbed in the cover and the receiver envelope has been ignored. In fact, the equivalent thermal circuit is the one shown in the left of Figure 8 . A way to improve this analysis is to include the absorption as shown in the right of the figure. Physically, absorption in the cover and envelope will raise the temperature of these components, thereby reducing the receiver losses. Consequently, the useful energy output from the collector can also be increased. The derivation is quite tedious, but the result can be presented in a relatively simple formula as follows:

$$
Q_{u}=F_{R} A_{r}\left\{S^{\prime}+H_{t}\left[\bar{\tau}_{a}\left(1-\bar{\tau}_{e}\right) \frac{U_{L}^{A} r}{U_{e} A^{A} e}+\left(1-\bar{\tau}_{a} \bar{\tau}_{e}\right) \frac{U_{L} A_{r}}{U_{a} / b_{a}}\right]-U_{L}\left(T_{1}-T_{a}\right)\right\}
$$

where

$$
\begin{aligned}
& U_{r / e}=\frac{\sigma\left(T_{r}^{2}+T_{e}^{2}\right)\left(T_{r}+T_{e}\right)}{\frac{1}{\varepsilon_{r}}+\frac{A_{r}}{A_{e}}\left(\frac{1}{\varepsilon_{e}}-1\right)} \\
& U_{e / a}=\frac{\sigma\left(T_{e}^{2}+T_{a}^{2}\right)\left(T_{e}+T_{a}\right)}{\frac{1}{\varepsilon_{e}}+\frac{A_{e}}{A_{a}}\left(\frac{1}{\varepsilon_{a}}-1\right)}+h_{e / a} \\
& U_{a / b}=\varepsilon_{a} \sigma \frac{T_{a}^{4}-T_{s}^{4}}{T_{a}-T_{b}}+h_{a / b}
\end{aligned}
$$




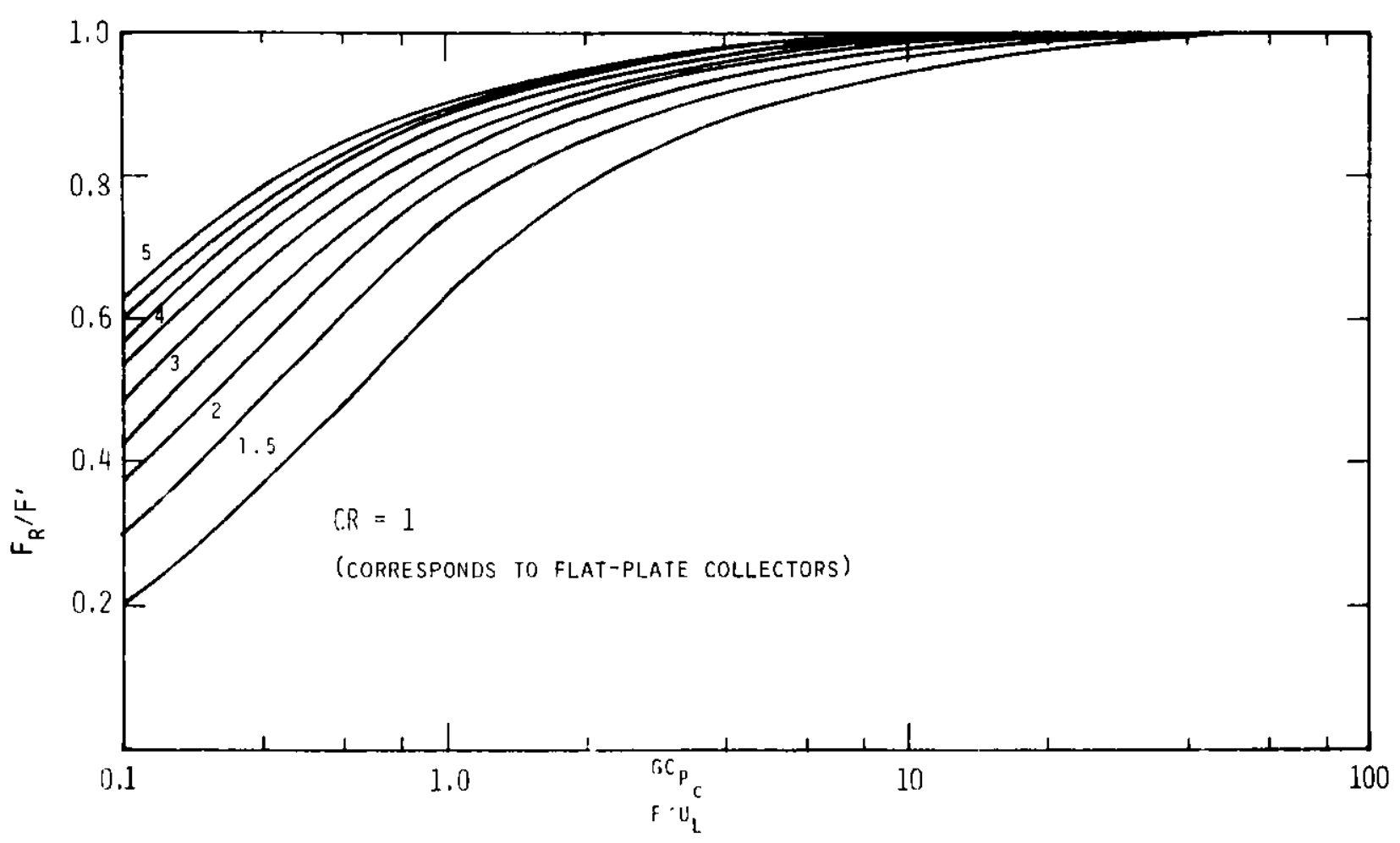

FIGIIRE 7. $F_{R} / F^{\prime}$ CIRVVES FOR CPC COLLECTORS

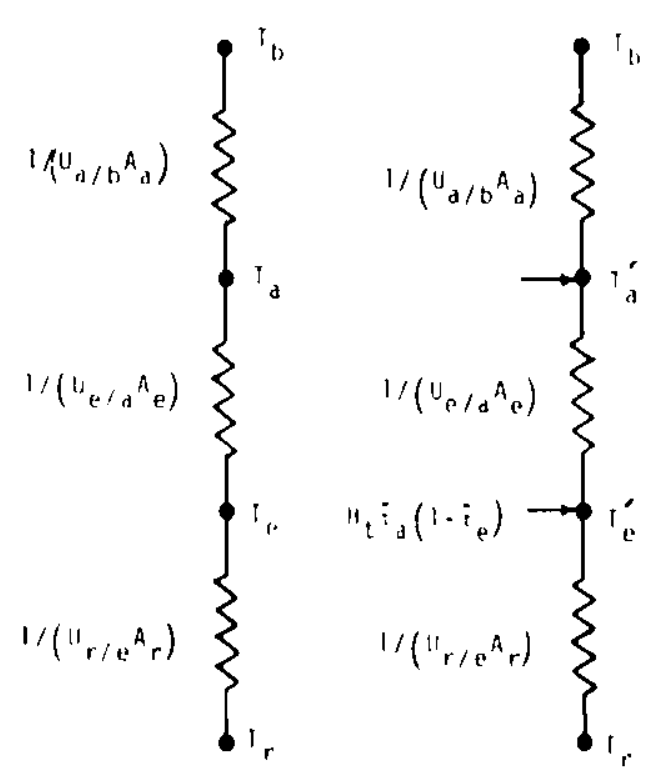

FIGIIRE 8. EOIIVALEIIT ELLCTRIC CIRCUITS FOR A SIIPLIFICD THERMAL A'MLYSIS OF CPC. COLLECTIRS 


$$
U_{L}=\frac{1}{A_{r}}\left(\frac{1}{U_{r / G^{A}}}+\frac{1}{U_{e / a^{A}}}+\frac{1}{U_{a / b}{ }^{A}}\right)^{-1}
$$

A. comparison between Equations (32) and (34) reveals that the improvement in the analysis results in the appearance of the correction (second) term in the braces of Equation (34).

It is now possible to write four efficiency equations based on Equations (28), (29), (32) and (34). By divsciing $Q_{u}$ by $H_{t} A_{a}$, it can be derived that

$$
\begin{aligned}
& n=\eta_{0}-\frac{U_{L}}{H_{t}(C R)}\left(T_{r}-T_{b}\right) \\
& \eta=n_{o} F^{\prime}-\frac{U_{L} F^{\prime}}{H_{t}(C R)}\left(T_{f}-T_{b}\right) \\
& n=n_{o} F_{R}-\frac{U_{L} F_{R}}{H_{t}(C R)}\left(T_{i}-T_{b}\right) \\
& n=n_{o} F_{R}+F_{R} F_{A}-\frac{U_{L} F_{R}}{H_{t}(C R)}\left({ }^{i} i-T_{b}\right)
\end{aligned}
$$

where $n_{0}$ is optical efficiency defined as

$$
n_{0}=\bar{\tau}_{a} \rho_{m}^{\bar{n}} \bar{\tau}_{e} \bar{\alpha}_{r}
$$

$F_{A}$ in Equation (42) can be termed as an enclosure absorption factor, defined as

$$
F_{A}=\frac{1}{(C R)}\left[\bar{\tau}_{a}\left(1-\bar{\tau}_{e}\right) \frac{U_{L} A_{R}}{U_{e} / a^{A}}+\left(1-\bar{\tau}_{a} \bar{\tau}_{e}\right) \frac{U_{L} A_{R}}{U_{a} / b^{A}}\right]
$$

In addition, based on the actual tests of CPC collectors, one can measure $\dot{\mathrm{m}}_{c}, \mathrm{~T}_{1}, \mathrm{~T}_{0}$ and $\mathrm{H}_{t}$ and derive another efficlency equation as follows.

$$
n=\frac{\dot{m}_{c} C_{p c}\left(T_{o}-T_{1}\right)}{H_{t} A_{a}}
$$


Clearly, Equations (39), (40) and (.r1) are all based on the same basic formulation and are expected to yield identical results. n calculated based on Equation (42) should be slightly higher because of the consideration of enclosure absorptions in the analysis. On the other hand, if Equation (45) is used for prediction, in which $T_{0}$ is "computed" based on the solution of simultaneous nonlinear equations given earlier, this computed $n$ will be the highest of all. This is because of the fact that the second order effects including multireflections and absorptions ha.e al.l been included in this final analysis.

The analysis of CPC collector is now complete; attention is now directed to the penalty resulting from the use of a heat exchanger in the collector 10.3.

DeWinter [19] has derived a heat-exchanger penalty factor defined as the ratio of the actual heat ga, $n$ for a system installed with a heat exchanger to a hypothetical heat gain if the exchanger was not there. The analytical expression for the penalty factor is

$$
F_{x}=\frac{1}{1+\frac{F_{R} U_{L}}{G c}\left[\frac{\left(\dot{m} c_{p c}\right)_{c}}{\left(\dot{m} c_{p}\right)_{m i n} \varepsilon_{x}}-1\right]}
$$

where $\left(\dot{m}_{\mathrm{p}}\right)_{\mathrm{c}}$ refers to the heat capacitance rate for the clrcuiating fluid in the collector. $\left(\dot{\mathrm{m}}_{\mathrm{p}}\right)_{\text {min }}$ refers to the smaller of the two fluids circulating in the heat exchanger. $\varepsilon_{x}$ is, the heat exchanger effectiveness, which is related to the overall heat transfer coefficient $\left.{ }^{(U A)}\right)_{x}$ in the heat exchanger according to:

$$
\varepsilon_{x}=\frac{(U A)_{x} /\left(\dot{m c}_{p}\right)_{\min }}{1+(U A)_{x} /\left(\dot{m c}_{p}\right)_{\min }}
$$


A counterflow heat exchanger is most effective from the heat transfer point of view. $e_{x}$ for a counterflow heat exchanger is plotted in Figure 9. The heat exchanger penalty factor is plotted in Figure 10. As expected, a large $(U A)_{x}$ will raise $e_{x}$ which, in turn, diminishes the penalty using a heat exchanger.

\section{Heat Pipe Design Theory}

Heat pipes will be used to transmit heat in the boiler in the final design of systems. Heat pipe design theory is briefly reviewed here.

The selection of materials in the heat pipe design is governed by several considerations. In order to maximize the heat that can be carried by a heat pipe the working fluid should be selected that has a high liquid transport factor $\mathrm{N}_{\ell}$, defined as

$$
\mathrm{N}_{1}=\frac{\xi \rho_{1} \mathrm{~h}_{\mathrm{fg}}}{\mu_{1}}
$$

where $\xi$ refers to the surface tension coefficient, $\rho$ density, $\mu$ dynamic viscosity and $h_{f g}$ heat of vaporization. Subscript 1 refers to liquid for all properties. On the other hand, to minimize the temperature drop across the wick material the working fluid should be selected that has a large liquid conductance factor defined as

$$
\mathrm{N}_{\mathrm{k}_{1}}=\mathrm{k}_{1} \mathrm{~N}_{1}
$$

where $k_{1}$ denotes the thermal conductivity of 1iquid.

The selection of wick material is important to the development of capillary pressure in the wick. To raise the heat transport capability, the wick must have large permeability $k$ defined as

$$
K=\frac{2 \phi r_{h}^{2}}{\left(f_{1,} \operatorname{Re}_{1}\right)}
$$




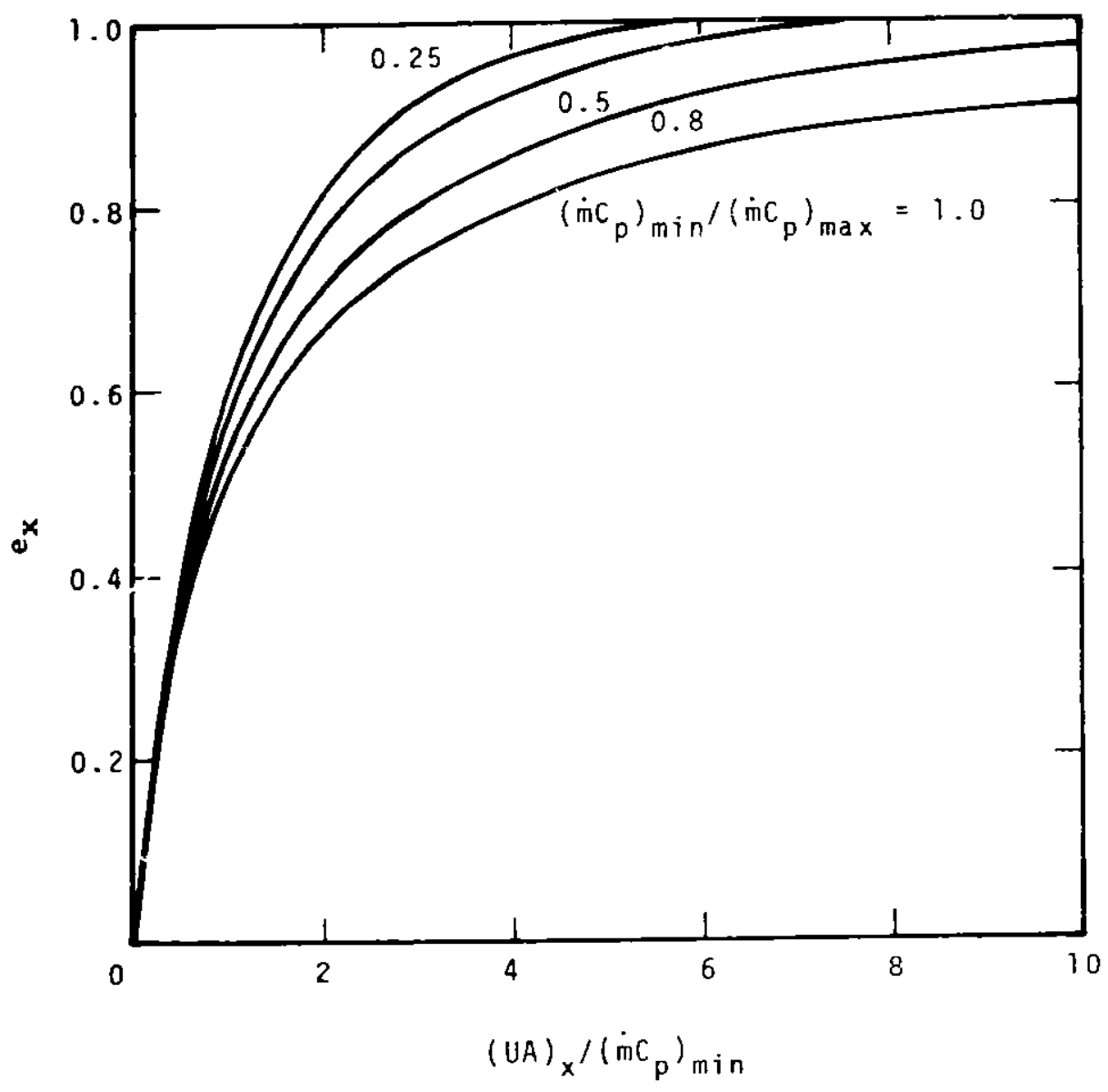

FIGUIRE 9. HEAT EXCHANGER EFFECTIVENESS CURVES

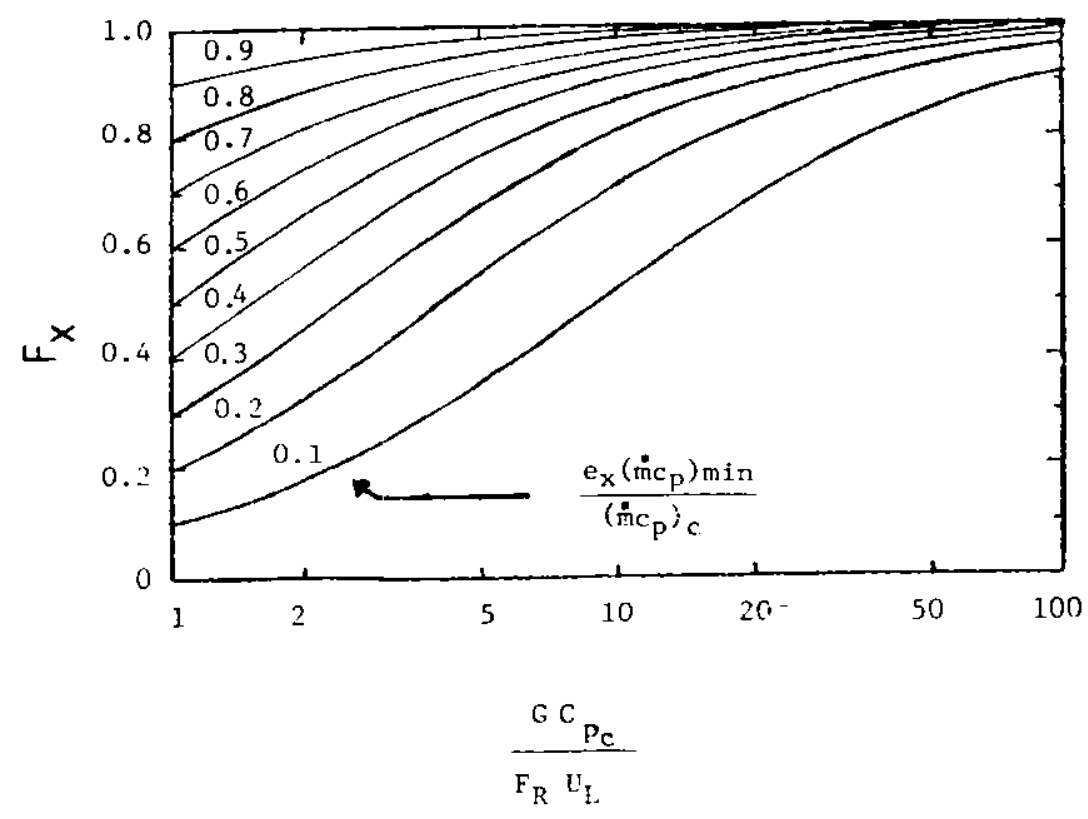

Figure 10. Heat Exchanger Penalty Curves 
where $\phi$ is the wick porosity, $r_{h}$ is the hydraulic radius of wick. Drag coefficient $\mathrm{f}_{1}$ and Reynolds number $\mathrm{Re}_{1}$ in the above equation are given respectively as

$$
\begin{aligned}
\mathrm{f}_{1} & =\frac{2 \tau_{1}}{\rho_{1} \mathrm{v}_{1}^{2}} \\
\operatorname{Re}_{1} & =\frac{\rho_{1} \mathrm{v}_{1} 2 \mathrm{r}_{\mathrm{h}}}{\mu_{1}}
\end{aligned}
$$

where $\tau_{1}$ is the shear stress at the liquid-solid (wall) interface, $v_{1}$ is the liquid velocity in wick. It is noted that, while the capillary pumping pressure is inversely roportional to the pore size, the liquid-flow resistance is inversely proportional to the wick permeability.

In choosing materials for heat pipe containers, consideration must be given to the compatibility hetween the working fluid and pipe wall. Only tests can show if two media are truly compatible. For the present application of heat pipes in a CPC collector, the heat pipe weight is of minor importance. However, the pipe wall conductance is important and the wall material chosen must have high conductance factor, defined as

$$
\mathrm{N}_{\mathrm{p}}=\mathrm{k}_{\mathrm{p}} \mathrm{s}_{\mathrm{u}}
$$

where $k_{p}$ denotes the thermal conductivity of the pipe wall. $s_{u}$ is the $u 1: 1 m a t e$ tensile stress of the wall material. A strong material having a large thermal conductivity will lead to a large $N_{k_{p}}$. Such a heat pipe will result in a small temperature drop for heat flow.

For heat pipes operatirig under elevated temperatures and vapor pressures the strength of the pipe container must be given special consideration. The ASME code for unfired pressure vessels should be consulted in the design of pipe containers. According to this code, the maximum illowable stress in the wall is taken to be one-fourth of the material ultimate strength $\left(s_{u}\right)$ at the 
same temperature. For a circular heat pipe, this stress limitation permits a design of pipe radius as follows

$$
\frac{r_{p, i}}{r_{p, 0}}=1-\frac{4(\Delta p)}{s_{u}}
$$

where $\Delta p$ designates the pressure difference across the pipe wall. Equation (54) is derived based on a static force balance and is valid if the wall thickness is less than $10 \%$ of the diameter of the pipe.

In a like manner, the end cap thickness $t$ can be calculated. For a heat. pipe fitted with a flat cap, the cap thickness can be calculated using

$$
t=\left[\frac{2(\Delta \mathrm{p}) \mathrm{r}_{\mathrm{p}, \mathrm{o}}^{2}}{\mathrm{~s}_{\mathrm{u}}}\right]^{1 / 2}
$$

Probab1y one of the most important considerations in the design of heat pipes is to determine if the designed heat pipe is capable of carrying the heat load as intended. It is common practice to evaluate this heat transfer limit using a capillary pressure analysis. Once this limit is found, the heat pipe must be further checked to see if this capillary limitation stays within the heat loads computed at other operating limitations. Specifically, heat loads at sonic linitation, entrainment limitation and boiling limitation must be separately computed and the smallest load found to be considered the operating limit of the pipe. In the paragraphs that follow, these limitations will be individually analyzed. The capillary limitation is treated first. One of the functions a wick performs is to develop a capillary pressure inside the pipe such that the capillary pumping pressure is greater than the sum of all viscous pressure losses and gravity losses. For a heat pipe operating in the heat pipe mode the capillary limitation on heat load can be evaluated using 


$$
\int_{0}^{L_{t}} Q d x=\frac{P_{c}-P_{s}}{F_{1}+F_{v}}
$$

where $Q$ refers to the "axial" heat flow, $L_{t}$ is the total length of the heat pipe. $P_{c}$ is the maximum capillary pressure, which is a function of the surface tension coefficient and the effective capillary radius. The capillary pressure varies with the wick design. $p_{s}$ in Equation (56) designates the static pressure. For a tilted heat pipe as shown in Figure 11, this hydrostatic pressure can be expressed as

$$
\mathrm{p}_{\mathrm{S}}=\rho_{1} g\left(2 \mathrm{r}_{\mathrm{p}, \mathrm{i}} \cos \psi \pm \mathrm{L}_{\mathrm{t}} \sin \psi\right)
$$

where $\phi$ is the tilt angle. The sign in front of the body force is determined by its direction and is positive (negative) if the direction of the component of gravity along the heat pipe is opposite to (the same as) the direction of integration of Q [Equation (56)].

$F_{1}$ and $F_{V}$ in Equation (56) designate liquid and vapor frictional coefficients. $F_{1}$ is related to wick permeabilicy $\mathrm{K}$ [Equation (50)] by

$$
\mathrm{F}_{1}=\frac{\mu_{1}}{\mathrm{KA}_{\mathrm{w}} \mathrm{h}_{\mathrm{fg}_{\mathrm{g}}} \rho_{1}}
$$

where $A_{w}$ denotes the wick cross-sectional area. This frictional coefficient accounts for the friction the liquid experiences when it is flowing inside the wick and was derived on the basis of a control volume analysis of force balance on th= wick material.

For a screen-mesh wick of interest in this project, the permeability $\mathrm{K}$ can be related to wick porosity $\phi$ by

$$
K=\frac{\mathrm{d}_{\mathrm{m}}^{2} \phi}{122(1-\phi)^{2}}
$$




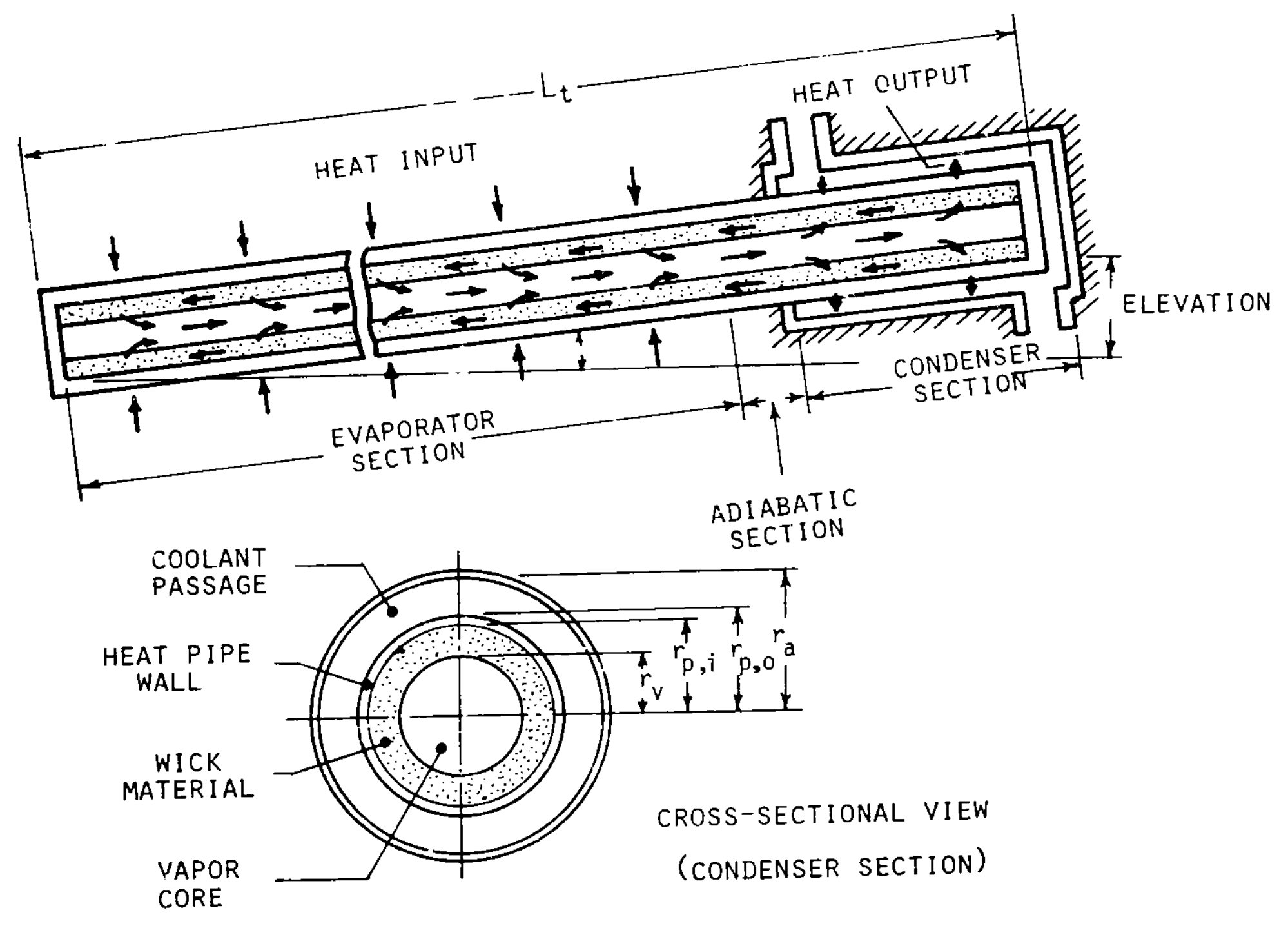

FIGURE 11. A SCHEMATIC DINGRAM SHOWING HEAT PIPE OPERATIONS AND VARIOIS DIMENSIONS 
This porosity is related to the mesh number $N$ and mesh-wire diameter $d_{m}$ by

$$
\phi=1-\frac{1.05 \pi \mathrm{Nd}}{4}
$$

$\mathrm{F}_{\mathrm{v}}$ in Equation (56) is the counterpart of $\mathrm{F}_{\ell}$ in the same equation. This $\mathrm{F}_{\mathrm{v}}$ accounts for frictions in the vapor core. For conventional heat pipes operating at cryogenic or moderate temperatures, the vapor flow in the core is mostly incompressible (Mach number $\leq 0.2$ ) and laminar (Reynold number $\leq 2,300)$. Under these conditions, $F_{\ell}$ and $F_{v}$ are independent of $Q$. This not only makes the derivation of Equation (56) possible, but also leads to a smaller vapor temperature gradient desirable from the heat transfer point of view. For incompressible laminar flow inside a circular core, $F_{v}$ can be expressed as

$$
F_{v}=\frac{8 \mu_{v}}{\pi r_{v}^{4} \rho_{v} h_{f g}}
$$

where Hagen-Poiseuille solution for laminar flow has been used in the simplification.

For a heat pipe exposed to uniform heat fluxes, the left hand side of Equation (56) can be related to the naximum axial heat flow as follows.

$$
\int_{0}^{L_{t}} Q d x=\frac{L_{e}+2 L_{a}+L_{c}}{2} Q_{\max , \text { capillary }}
$$

where $L_{e}, L_{a}$ and $L_{c}$ designate evaporator, adiabatic section and condenser lengths, respectively. Equation (62) can be used together with Equation (56) to find the heat load at capillary limitation.

The heat pipe designed on the basis of the capillary limitation must be tested of its heat carrying capacity at sonic limitation. This sonic limitation 1s the condition when the vapor velocity at the evaporator exit reaches a Mach 
number of unity. The vapor flow inside a heat pipe resembles in many ways flows inside a convergent-divergent nozzle. Once this "chocking" occurs, a further decrease of the sink temperature will not result in a further increase of the total heat flow. Levy's equation can be used to predict this sonic limitation, which is given as

$$
Q_{\max , \text { sonic }}=A_{v} \rho_{o} h_{f g}\left[\frac{\gamma_{v} R_{v} T_{o}}{2\left(\gamma_{v}+1\right)}\right]^{1 / 2}
$$

where $\gamma_{v}$ is the specific heats ratio for vapor, $R_{v}$ is the vapor gas constant. Subscript $\circ$ for $\rho$ and $\mathrm{T}$ refers to a stagnation condition. *

The entrainment limit deals with a total different state of affairs. Inside the heat pipe both vapor and liquid are moving in opposite directions. Because of the low density and, therefore, the high velocity of vapor, liquid at the wick surface tends to be torn apart by vapor and entrained in the vapor stream. This results in an added circulation and upsetting the flow. Eventually the returned liquid may fail to catcl up with the vapor flow rate; dryout then occurs.

l'he heat load at the entrainment limitation can be derived by equating the shear force at the liquid-vapor interface and the suriace force that holds the liquid in place and expressed as

$$
Q_{\max } \text {, entrainment }=A_{v} h_{f g}\left(\frac{\xi \rho_{v}}{2 r_{h, p o r e s}}\right)^{I / 2}
$$

where $r_{h \text {,pores }}$ refers to the hydraulic radius of the wick surface pores. This radius is equal to half of the wire spacing for screen-mesh wicks.

\footnotetext{
* Keaders are cautioned against the difference between the stagnation condition In fluld dynamics and the stagnation condition in testing of solar collectors. The former is referred to in Equation (63).
} 
The bolling limitation also deals with the dry-out phenomenon but in a different perspective. In heat pipe operations, the liquid pressure at the evaporator is equal to the difference between the saturation pressure of the wick fluid at the temperature of the liquid-vapor interface and the capillary pressure at the same location. The saturation vapor pressure is therefore higher than the liquid pressure. Under high heat flux conditions, vapor bubbles may form in the evaporator wick. These bubbles obstruct the flow and may cause hot spots in pipes. The boiling limitation adiresses this operation problem and the following equation can be used to predict the heat load.

$$
Q_{\max } \text {, boiling }=\frac{4 \pi \mathrm{L}_{\mathrm{e}} \mathrm{k}_{\mathrm{e}} \mathrm{T}_{\mathrm{v}} \xi}{\mathrm{r}_{\mathrm{n}} \rho_{\mathrm{v}} \mathrm{h}_{\mathrm{fg}} \ell_{\mathrm{n}}\left(\mathrm{r}_{\mathrm{p}, \mathrm{i}} / \mathrm{r}_{\mathrm{v}}\right)}
$$

where $k_{e}$ denotes the effective thermal conductivity of the wick material. For the wire-mesh wick of interest in this sicudy, $k_{e}$ can be formulated as

$$
k_{e}=\frac{k_{l}\left[\left(k_{1}+k_{w}\right)-(1-\phi)\left(k_{1}-k_{w}\right)\right]}{\left(k_{1}+k_{w}\right)+(1-\phi)\left(k_{1}-k_{w^{\prime}}\right)}
$$

where $k_{1}$ and $k_{w}$ refer to liquid and wick thermal conductivities, respectively. $r_{n}$ in Equation (66) designates critical radius for nucleate boiling. For a conservative design, this radius can be taiken as

$$
\left.r_{n}=2.54 \times 10^{-7} \mathrm{~m} \text { (or } 10^{-5} \mathrm{in.}\right)
$$

The theory for design of heat pipes is now complete. A final note is in order to formulate the overall heat transfer coefficient between the evaporator and the condenser section of the heat pipe. This coefficient is needed later to evaluate the performance of CPC collectors fitted with heat pipe.

For the heat pipe shown in Figure 11, the overall heat transfer coefficient between the evaporator surface and the condenser surface can be expressed, 
based on the pipe's cross-sectional area, as

$$
U_{p}=\left(R_{p, e}+R_{w, e}+R_{v}+R_{w, c}+R_{p, c}\right)^{-1}
$$

where $R_{p, e}, R_{w, e}, R_{v}, R_{w, c}$ and $R_{p, c}$ designate thermal resistances in the evaporator side of the pipe wall, evaporator side of the wick naterial, vapor core, condenser side of the wick material and condenser side of the pipe wall, respectively. They can be separately formulated as follows.

$$
\begin{aligned}
& R_{p, e}=\frac{r_{p, o}^{2}}{2 L_{e} k_{p}} \\
& R_{w, e}=\frac{r_{p, o}^{2} \ln \left(r_{p, i} / r_{v}\right)}{2 L_{e} k_{e}} \\
& R_{v}=\frac{\pi r_{p, o}^{2} T_{v}\left(p_{v, e}-p_{v, c}\right)}{\rho_{v} h_{f g} Q} \\
& \mathrm{R}_{\mathrm{w}, \mathrm{c}}=\frac{\mathrm{r}_{\mathrm{p}, \mathrm{O}} \ln \left(\mathrm{r}_{\mathrm{p}, 1} / \mathrm{r}_{\mathrm{v}}\right)}{2 \mathrm{~L}_{\mathrm{c}} \mathrm{k}_{\mathrm{e}}} \\
& R_{p, c}=\frac{r_{p, o}^{2} \ln \left(r_{p, o} / r_{p, i}\right)}{2 L_{c} k_{p}}
\end{aligned}
$$

where $k_{e}$ is the effective thermal conductivity of the wick material, which has been defined earlier as Equation (66). Equation (71) was derived on the basis of the Clausius-Clapeyron equation. The vapor pressure drop between the evaporator and the condenser can be related to the axial heat flow. For a laminar incompressible flow of vapor with a negligible dynamic effect and under the condition when the pipe wall is exposed to a uniform heat flux, this pressure drop can be expressed as

$$
p_{v, e}-p_{v, c}=F_{v} Q \frac{L_{e}+6 L_{a}+L_{c}}{6}
$$


Substitution of Equation (74) into (71) ylelds

$$
R_{v}=\frac{\pi r_{p, o}^{2} T_{v} F_{v}\left(L_{e}+6 L_{a}+L_{c}\right)}{6 \rho_{v} h_{f g}}
$$

Finally, attention is directed to the convective coefficient on the surface of the condenser. For the arrangement shown in Figure 11, flow is confined inside an annulus at the condenser section, and the outside surface of the heat exchanger is insulated. Lundberg, et al. [20] have studied the problem analytically. For the system given, the Nusselt number at the outside surface of the annulus is zero, while that for the inside surface,

$$
\mathrm{Nu}_{i}=\frac{\mathrm{h}_{\mathrm{c}} \mathrm{D}_{\mathrm{a}}}{\mathrm{k}}=5.663
$$

where $D_{a}$ is hydraulic diameter for the annulus, defined as

$$
D_{1}=2\left(r_{a}-r_{p, o}\right)
$$

Equ tion (76) can be used together with Equation (68) to develop a U equation for heat transfer from the surface of the evaporator to the fluld at the condenser side of the heat exchanger. Once this $U$ is found, the thermal analysis given in the preceding subsection can be reused to determine the system performance for CPC collectors fitted with heat-pipe receivers. 
III. WESIGN OF SYSTEM AND PREDICTION OF PERFORMANCE

A design of the total system is shown in Figure 12. The design meets all the constraints described in the INTRODUCTION section of this report. It also possesses several features as discussed below.

The total steam-generation system is divided into two loops: the collector loop and the boller loop. In the collector loop the CPC collectors are fitted with concentric tube receivers (CTR). Collectors of this design have been extensively tested with several types of CTR receivers here at Argonne, and their performance records have been established. Because of the use of a heat exchenger (preheater) in this loop, antifreezes can be used for collector circulation. This arrangement alleviates the collector freezing problem while it raises the bolling point of the circulation liquid as desired. A sumnary of glycol properties is listed in Table 2 . $80 \%$ by weight of ethylene glycol in an aqueous solution has been found to be satisfactory for the present project.

The use of a heat exchanger in the collector loor also permits the use of a more fragile CTR (e.g., Owen-Illinois tubes) for heat collection. As long as the tubings in the heat exchanger are leak-proof, the slightly pressurized water in the boller loop is separated from the circulating antifreeze and will not endanger the safe operation of the tubes.

[n the boller loop water leaving the preheacer enters an array of CPC collectors that are fitted with heat pipes. In these collectors neating takes place outside the heat pipe; scaling becomes of minor concern. These heat pipes will heat the circulating water "near" bolling at elevated pressures. Then, once the water is discharged through a throttling valve, part of the water will flash into steam. The flash boller serves primarily as a separator to direct 
Table 2. Thermodynamic Properties of Aqueous Solutions of Glycols

(22)

Ethylene Cilycol
(80\% by weight)

Diethylene Glycol ( $80 \%$ by Weight)
Trlethylene Glycol ( $80 \%$ by We1ght)
Propylene Glycol ( $80 \%$ by Welght)

Thermal

conductivity

at $120^{\circ} \mathrm{C}$

0.2768

0.2595

0.2422

$0.2249 \mathrm{~W} / \mathrm{m}^{\circ} \mathrm{C}$

Constant

Pressure

Specific Hoit

at $120^{n} \mathrm{C}$

322

3140

3120

$3475^{\star} \mathrm{J} / \mathrm{kg}^{\circ} \mathrm{C}$

Freszing

Polnt

$-45$

$-37^{\star}$

$-38.5$

(not avallable)

Bolling

Polnt

124

117

113

119

Specifie:

lirivits.

$1.02 !$

1.032

1.037

0.962

*he extrapolat ion

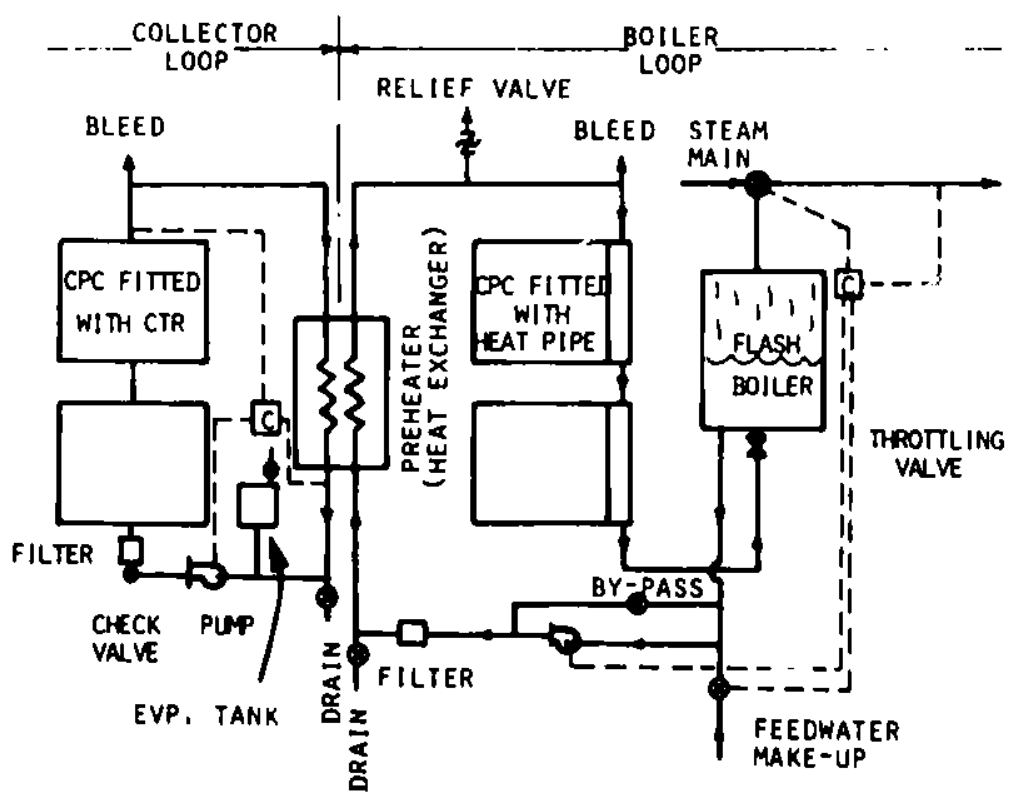

FIGURE 12. DIAGRAM OF A SYSTEM USING CPC COLLECTORS TO 
steam upward for delivery, while the saturated liquid is flowing downward and is circulated to the preheater and boiler for recycling. Feed water is also provided to the pump inlet to make up the fraction of the circulated water that is flashed into steam. A continuous steam generation is thus made possible. The diagram also illustrates numerous valves, tanks, filters and controls which are necessary for a satisfactory operation of the system.

\section{Performance of Collectors in the Collector Loop}

The CPC collector chosen for analysis in the present project is a prototype $1.5 \mathrm{X}$ collector designed and built by the Argonne National Laboratory. The collector is a ten trough collector module consisting of two banks in parallel with each bank made up of five troughs in series, see a schematic diagram shown in Figure 13(a). The tubular absorber used for collecting heat is designed by the General Electric, which has been 11 lustrated in Figure 2. Input data relevant to the collector analysis are summarized in Table 3.

The computer program used for performance analysis is given in Appendix A. The program was designed to calculate temperatures $\left(\mathrm{T}_{\mathrm{a}}, \mathrm{T}_{\mathrm{e}}, \mathrm{T}_{\mathrm{r}}\right.$ and $\left.\mathrm{T}_{0}\right)$ separately for each CPC trough. Since these troughs are connected in series, the exit temperature from one trough was used as the inlet temperature for the second trough. In calculating the loss coeffictents, these $T_{a}, T_{e}$ and $T_{r}$ values were averaged for flve troughs in each collector module, and these mean temperatures were used to calculate all the performance parameters of interest in this study. These computations were repeated for the collectors in the array. Hence, a computer run was able to generate a large body of data sufficlent for performance analysis and sizing systems. Computer results are presented below.

Figure 14 shows various temperatures for each collector (module). The 


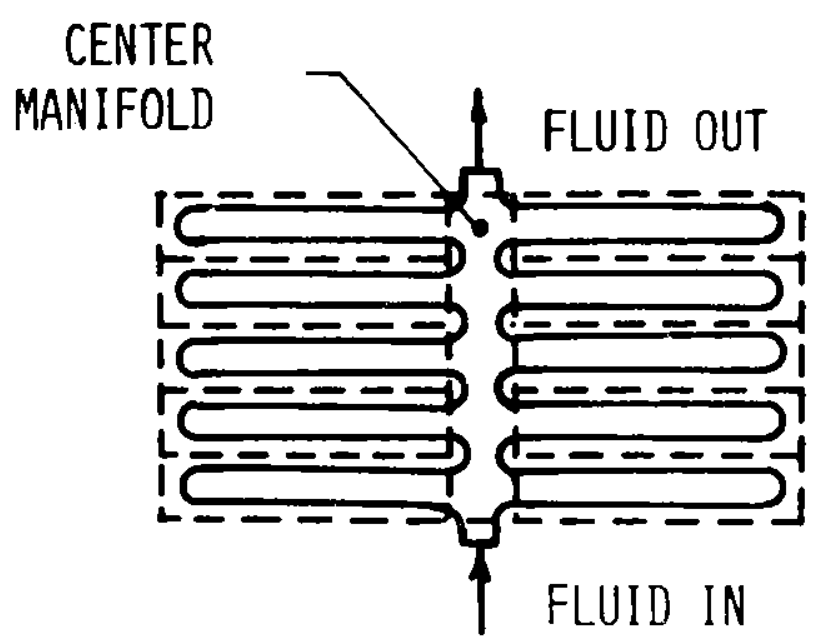

(a)

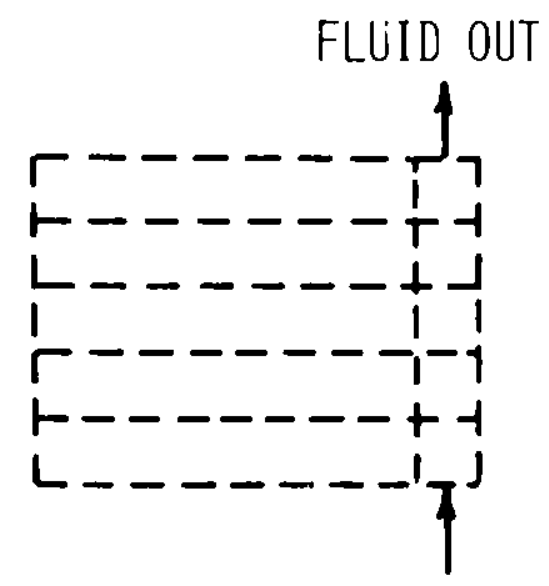

FLUID IN

(b)

FIGURE 13. A SCHEMATIC DIAGRAM SHOWING TROUGHS LAY-OUT IN A CPC COLLECTOR FITTED WITH CTR TUBES AND A CPC COLLECTOR FITTED WITH HEAT PIPES 
Table 3. Input Data for Performance Tests of Collectors in the Collector Loop Collector Specifications (refer to Figures 2 and 3 for notations):

See Figure 13(a) for troughs lay-out.

$$
\begin{aligned}
& \mathrm{W}=0.1128 \mathrm{~m} \\
& \mathrm{~L}=1.1271 \mathrm{~m} \\
& \mathrm{r}_{\mathrm{e}}=0.0264 \mathrm{~m} \\
& \mathrm{r}_{\mathrm{r}, \mathrm{i}}=0.0211 \mathrm{~m} \\
& \mathrm{r}_{\mathrm{r}, 0}=0.0222 \mathrm{~m} \\
& r_{i}=0.0030 \mathrm{~m} \\
& \text { Gap }=\text { clearance }+\mathrm{r}_{\mathrm{e}}-\mathrm{r}_{\mathrm{r}, 0}=0.0050+0.0264-0.0222=0.0092 \mathrm{~m}
\end{aligned}
$$

Solar Radiation Data:

$$
\begin{aligned}
& H_{b}(i)=966 \mathrm{~W} / \mathrm{m}^{2} \\
& H_{d}=100 \mathrm{~W} / \mathrm{m}^{2}
\end{aligned}
$$

Ambient Conditions:

$$
\begin{aligned}
\mathrm{T}_{\mathrm{b}} & =20^{\circ} \mathrm{C} \\
\mathrm{T}_{i} & =25^{\circ} \mathrm{C} \\
\mathrm{V} & =5 \mathrm{~m} / \mathrm{s}
\end{aligned}
$$

\section{Material Properties:}

$$
\begin{aligned}
& \alpha_{a}(i)=\bar{\alpha}_{a}=0.05 \\
& \bar{\rho}_{a}=0.05 \\
& \tau_{a}(1)=\bar{\tau}_{a}=0.9 \\
& \alpha_{e}(j)=\bar{\alpha}_{e}=0.05 \\
& \bar{\rho}_{e}=0.05
\end{aligned}
$$


Table 3. (continued)

$$
\begin{aligned}
& \tau_{\mathrm{e}}(\mathrm{j})=\bar{\tau}_{\mathrm{e}}=0.9 \\
& \alpha_{\mathrm{r}}(\mathrm{k})=\bar{\alpha}_{\mathrm{r}}=0.85 \\
& \bar{\rho}_{\mathrm{r}}=0.15 \\
& \rho_{\mathrm{m}}=0.85 \\
& \overline{\mathrm{n}}=0.6 \\
& \varepsilon_{\mathrm{a}}=0.85 \\
& \varepsilon_{\mathrm{e}}=0.85 \\
& \varepsilon_{\mathrm{r}}=0.05 \\
& \mathrm{k}_{\mathrm{g}}=0.779 \mathrm{~W} / \mathrm{m}{ }^{\circ} \mathrm{C}
\end{aligned}
$$

Data for Heat Exchanging Media:

$$
\left.\begin{array}{l}
\mathrm{k}_{\mathrm{f}}=0.28 \mathrm{~W} / \mathrm{m}^{\circ} \mathrm{C} \\
\dot{\mathrm{m}}_{\mathrm{c}}=0.0162 \mathrm{~kg} / \mathrm{s} \\
\mathrm{c}_{\mathrm{pc}}=3224 \mathrm{~J} / \mathrm{kg}^{\circ} \mathrm{C}
\end{array}\right\}(80 \% \text { Ethylene Glycol) }
$$

Heat Exchanger (Preheater) Data:

$$
{ }^{(\mathrm{UA})}{ }_{\mathrm{x}}=50 \mathrm{~W} /{ }^{\circ} \mathrm{C}
$$




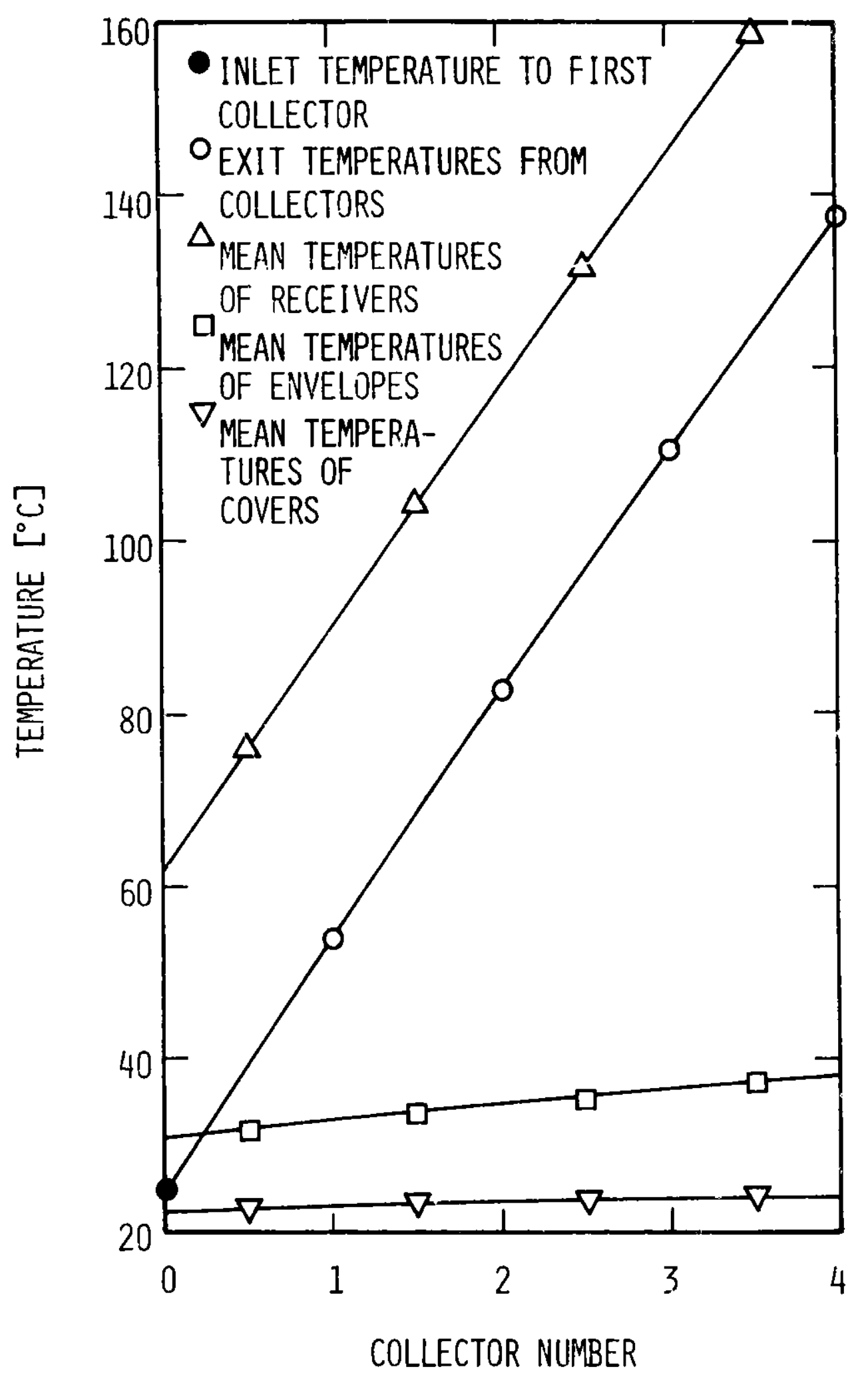

FIGURE 14. TEMPERATURE DISTRIBUTION IN A CPC COLLECTOR 
The exit temperature rise in the array appears to be nearly linear. The receiver jacket, envelope and cover temperatures given in the figure are mean values for each collector; these data are therefore plotted at the mid-point for each unit. The change in the envelope temperatures is very small. As a result, the difference between the receiver and the envelope temperatures is large, signifying that the receiver loss is insignificant.

This point can be further substantiated by examining Figures 15 and 16 . Here the heat loss factors (UA products) are plotted against $\Delta \overline{\mathrm{T}}$ for the surfaces in heat transfer. The $\left(U_{r / e} A_{r}\right)$ value is very small in Figure 15, indicating that the receiver is well insulated by the vacuum jacket. It is also seen in these figures that the heat losses increase with both $\Delta \overline{\mathrm{T}}$ and $\overline{\mathrm{T}}$ (values of $\overline{\mathrm{T}}$ have been identified near symbols). While the latter trend is expected, the former is a result of the rate of temperature rise in Figure 14 . There is a reverse of trend, however, for the $\mathrm{U}_{\mathrm{a}} / \mathrm{b}_{\mathrm{a}} \mathrm{A}$ curve in Figure 16 . This can be ascribed to the way the $U_{a / b}$ is defined in Equation (37), where the fourth power temperatures in the numerator are in absolute units while those in the denominator are not. Hence, a small rise in $T_{a}$ tends to have little effect on the quantity in the numerator while that in the denominator rises steadily with $\mathrm{T}_{\mathrm{a}}$. This results in a steady decline of $\mathrm{U}_{\mathrm{a} / \mathrm{b}}$ as shown in Figure 16.

Both the receiver surface and the overall loss coefficients increase with $\overline{\mathrm{T}}_{\mathbf{r}}$ as shown in Figure 17 . The ratio of these coefficients gives the value of $F^{\prime}$ as plotted in Figure 18. Both $F^{-}$and $F_{R}$ in this figure desrease as the mean receiver temperature is incieased. It is noted that the abscissa in this figure is again plotted as the collector number with the mean receiver tempe:atures Identified for each collector near the data points. The trend of these curves is primarily a risult of the rate of increase of $\mathrm{J}_{\mathrm{L}}$ with temperatures. 


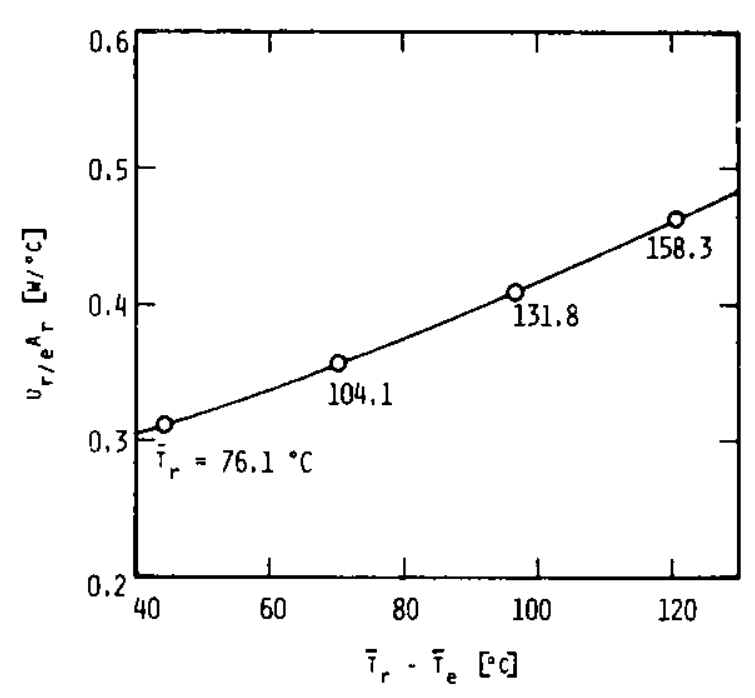

FIGURE 15. (U $\left.U_{r / e} A_{r}\right)$ VERSUS $\left(\bar{T}_{r}-\bar{T}_{e}\right)$ CURVE FOR CPC COLLECTORS

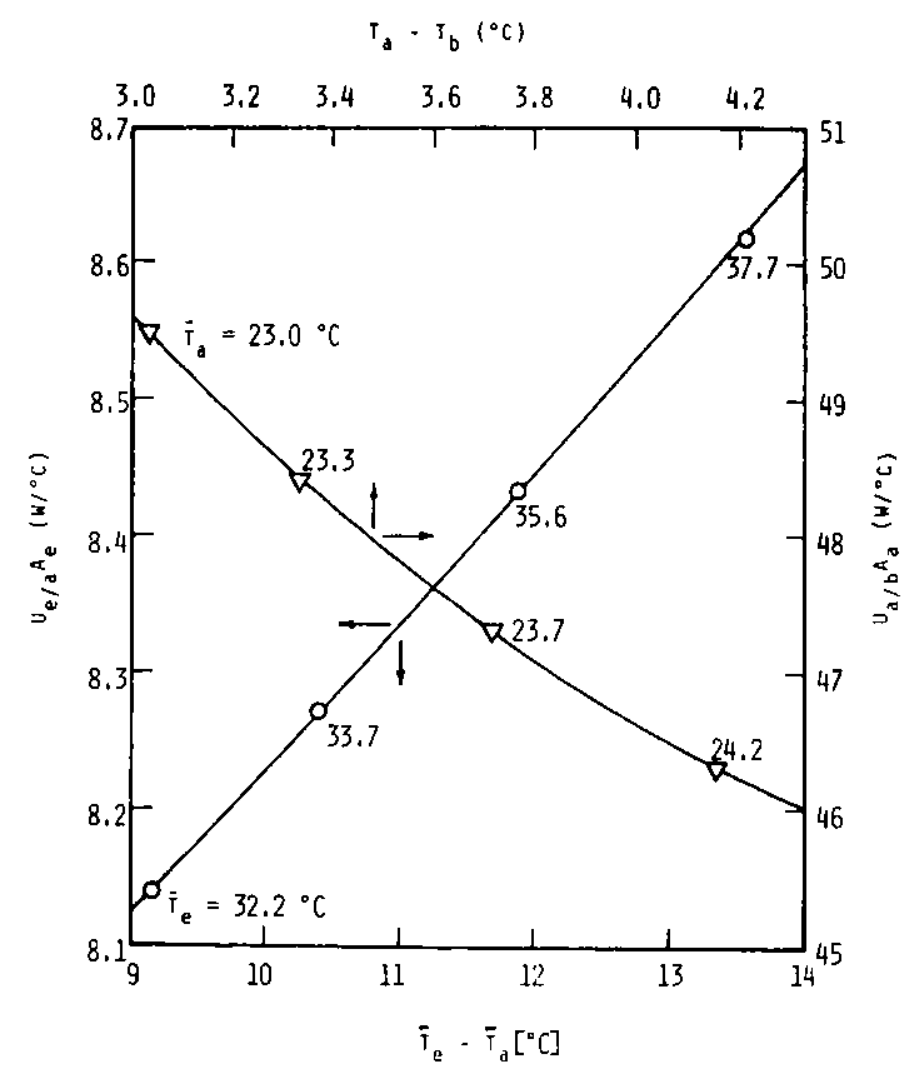

FIGURE 16, $\left(U_{e} / a A_{e}\right)$ AND $\left(U_{a} / b A_{a}\right)$ VERSUS $\left(\bar{i}_{e}-\bar{i}_{a}\right)$ CURVES FOR CPC COLLECTORS
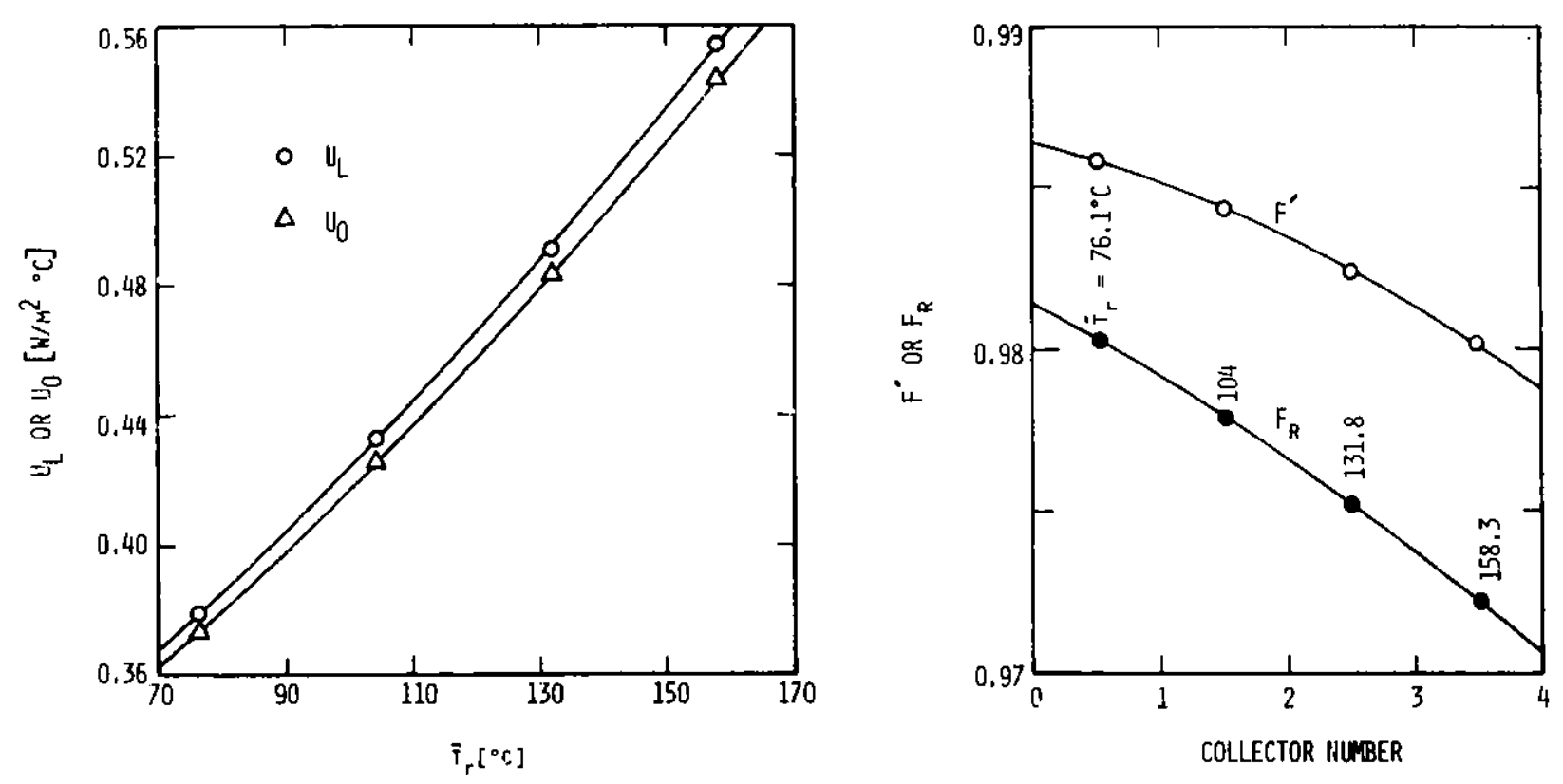

FIGURE 17. UL AND U VERSUS $i_{r}$ CURVES FOR CPC COLLECTORS

FIGUIRE 18. F' AND F $F_{R}$ CURVES FOR A SERIES OF CPC COLLECTORS 
The heat exchanger penalty factor was also computed and plotted for each collector shown in Figure 19. The drop of $\mathrm{F}_{\mathrm{x}}$ is a result of $\mathrm{U}_{\mathrm{L}}$ which values have been identified near the data points. The $F_{x}$ data in Figure 19 can be used to construct Figure 20 where $Q_{u}$ has been calculated for each collector using Equation (19). $Q_{u_{p h}}$ represents the useful heat in the preheater and was obtained by multiplying the $Q_{u}$ just calculated by $F_{x}$. The decline of $Q_{u}$ with $\overline{\mathrm{T}}_{\mathrm{r}}$ is a result of the increased heat loss when the fluid temperature is raised.

The data given in Figure 21 provides an estimation of totai useful heat if several collectors are connected in series. Again two curves are given, one represents the useful heat in the collector $\left(\Sigma Q_{u}\right)$, the other useful heat in the preheater $\left(\Sigma Q_{u_{p h}}\right)$. Because of the large scale used for plotting the $Q_{u}$ axis, the difference in $Q_{u}$ values appears to be deceptively small.

Finally, the collector efficiency can be computed and plotted as shown in Figure 22. Here $\eta$ and $\eta_{\mathrm{ph}}$ designate the efficiencies based on the collector circulating fiuid and the heated water in the preheater, respectively. The salient point with these two curves is the weak dependency of $n$ on $T$, indicating that a CPC collector is particularly attractive in high temperature applications.

It was discussed in the preceding section that the numerical value of the efficiency was dependent on which efficiency equation was used in the prediction. Computer data substantiate this observation. A plot of the efficiencies based on Equations (39), (40), (41), (42) and (45) is shown in Figure 22 (using the right expanded scale). As expected, Equation (45) gives the highest prediction. This is followed by Equation (42). Equations (39), (40) and (41) give the lowest values. The reason for this has been explained previr. sly (see the text following Equation (45)). 


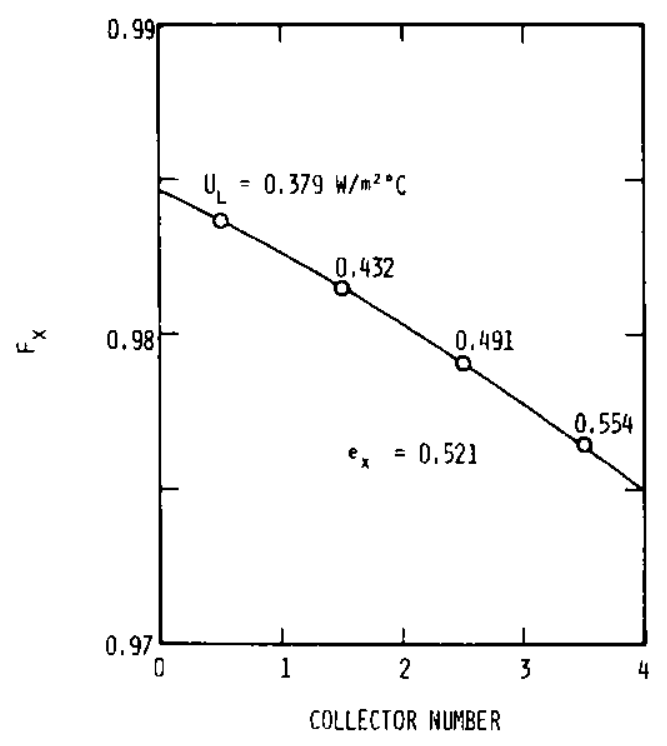

FIGURE 19. HEAT EXCHANGER PENALTY FACTOR FOR A CPC CJLLECTOR

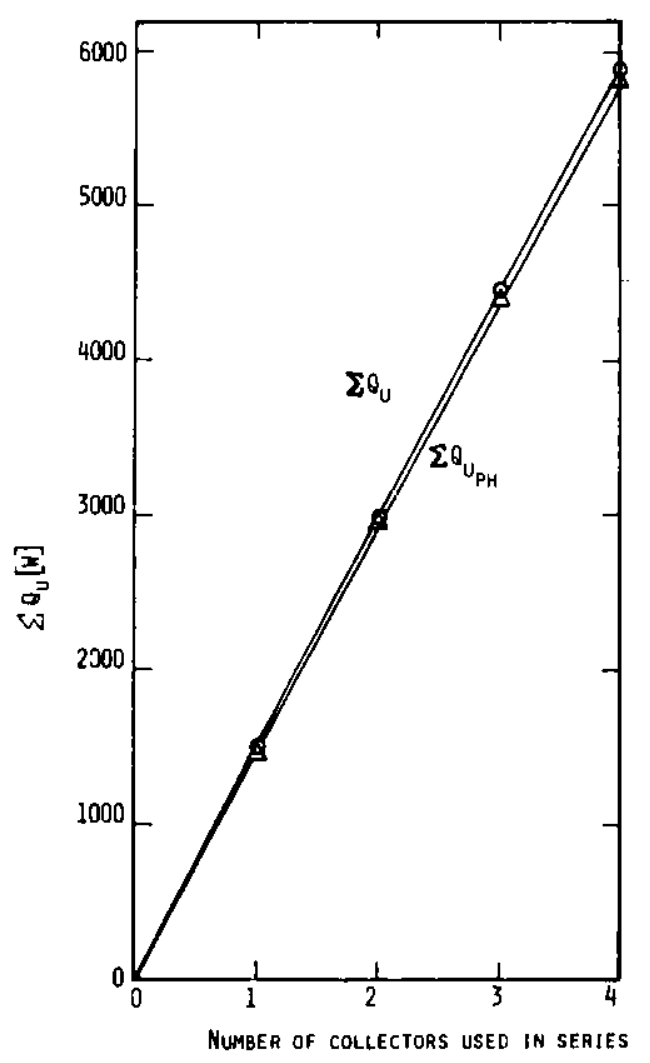

figure 21. Total Useful heat in a Serjes of cPC Collectors

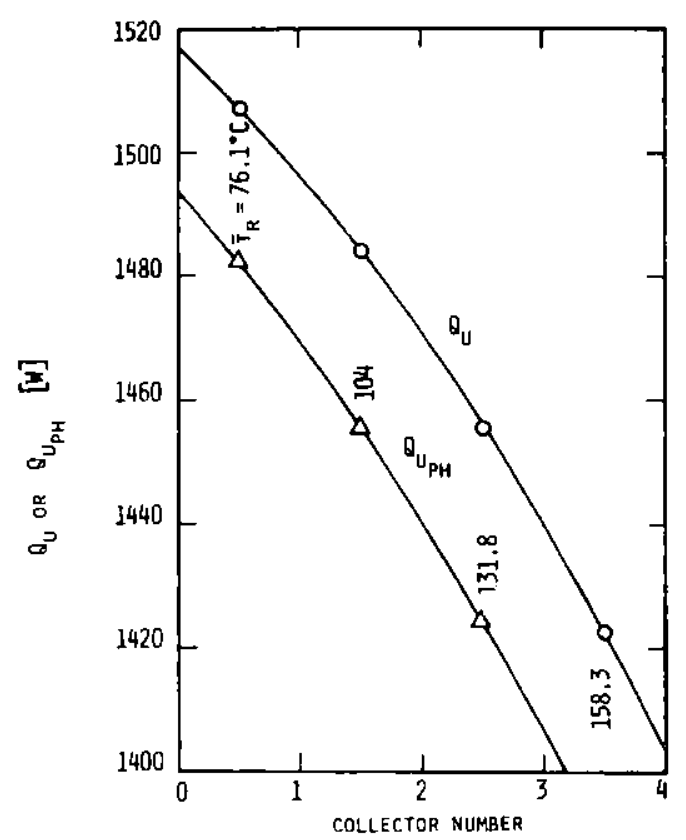

Figure 20. Useful heat gains in a Series of CPC COllectors

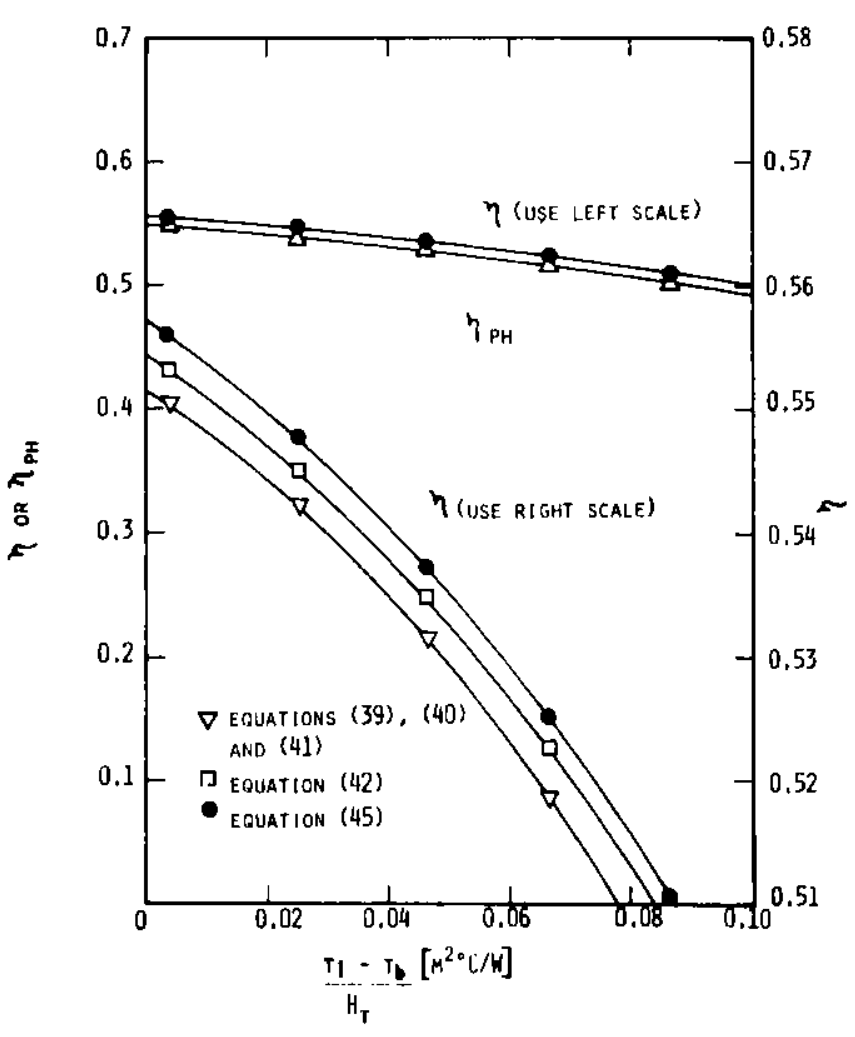

Figuae 22. Efficiency Curves for a cPC Collector 
The analysis presented in this subsection was validated by using experimental data as shown in Figure 23. Water was taken as the collector circulation fluid because of the availability of 1ts test data. The prediction appears to be in good agreement with experiments.

\section{Boiler Loop Analysis}

The CPC collectors in the boiler loop employ heat pipes to transmit heat. These pipes were designed based on the analysis given in the preceding section. Property values used in the design are sumnarized in Table 4. A detailed heat pipe analysis yields a set of specifications as shown in Table 5 . In order to characterize the heat pipe performance some design parameters were also computed and listed in Table 6. For the CPC collectors chosen to use in the boiler loop, the maximum heat load to be carried by each heat pipe is $164 \mathrm{~W}$. The heat loads at capillary, sonic, entrainment and boiling limitations are found to be $389,84027,2635$ and $406 \mathrm{~W}$, respectively. They are far greater than needed; a safe operation of the pipe can be assured.

In order to evaluate the performance of collectors in the boiler loop, it is necessary to determine the heat transfer characteristics of heat pipes. This was done by using Equations (68) to (75), and the results are listed in Table 7. The major resistance to heat flow appears in the wick, which is typical for a heat pipe. The overall conductance based on the cross-sectional. area of the pipe is calculated to be about 25 times that of a solid copper bar of the same cross section and length. The reason to use heat pipes to transmit heat is thus obvious.

The computer program previously used for collector loop analysis was modifled to use in the boiler loop. There is a minor simplification in the new program. Since the water at the condenser section was treated as flow 


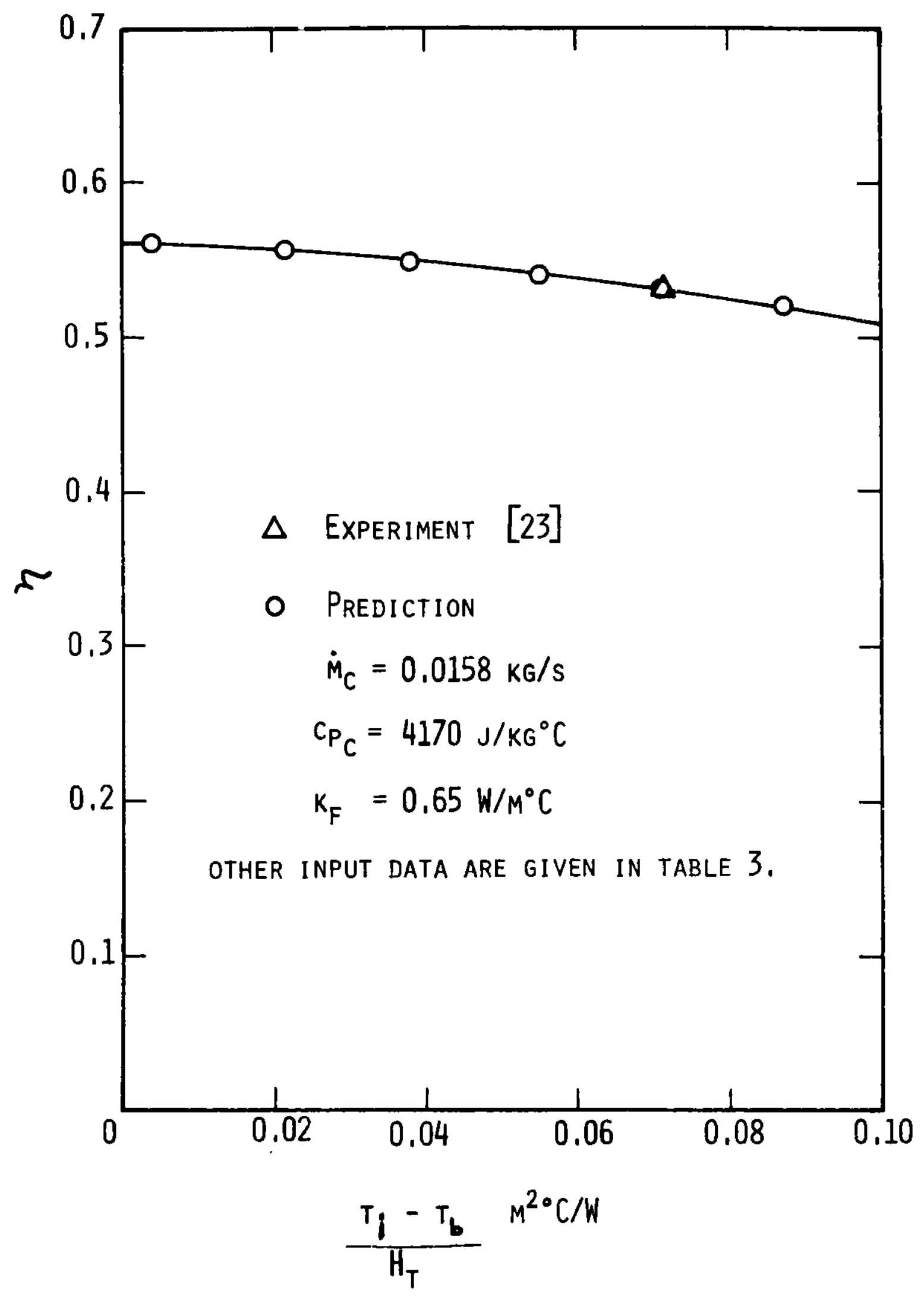

Figure 23. Validition of analysis Using Test Data 
Table 4. Properties of Heat Pipe Materials at $160^{\circ} \mathrm{C}$

Container and Cap - Copper

$$
\begin{aligned}
& k_{p}=372 \mathrm{~W} / \mathrm{m}^{\circ} \mathrm{C} \\
& s_{u}=1.38 \times 10^{8} \mathrm{~N} / \mathrm{m}^{2}
\end{aligned}
$$

Working Fluid - Water

$$
\begin{aligned}
& \mathrm{P}_{\mathrm{v}}=6.81 \times 10^{5} \mathrm{~N} / \mathrm{m}^{2} \\
& \mathrm{~h}_{\mathrm{fg}}=2074 \mathrm{kj} / \mathrm{kg} \\
& \gamma_{\mathrm{v}}=1.33 \\
& \xi_{1}=4.66 \times 10^{-2} \mathrm{~N} / \mathrm{m} \\
& \rho_{1}=909 \mathrm{~kg} / \mathrm{m}^{3} \\
& \rho_{\mathrm{v}}=3.27 \mathrm{~kg} / \mathrm{m}^{3} \\
& \mu_{1}=0.17 \mathrm{cP} \\
& \mu_{\mathrm{v}}=1.49 \times 10^{-2} \mathrm{cp} \\
& \mathrm{k}_{1}=0.679 \mathrm{~W} / \mathrm{m}^{\circ} \mathrm{C}
\end{aligned}
$$


Table 5. Heat Pipe Specifications

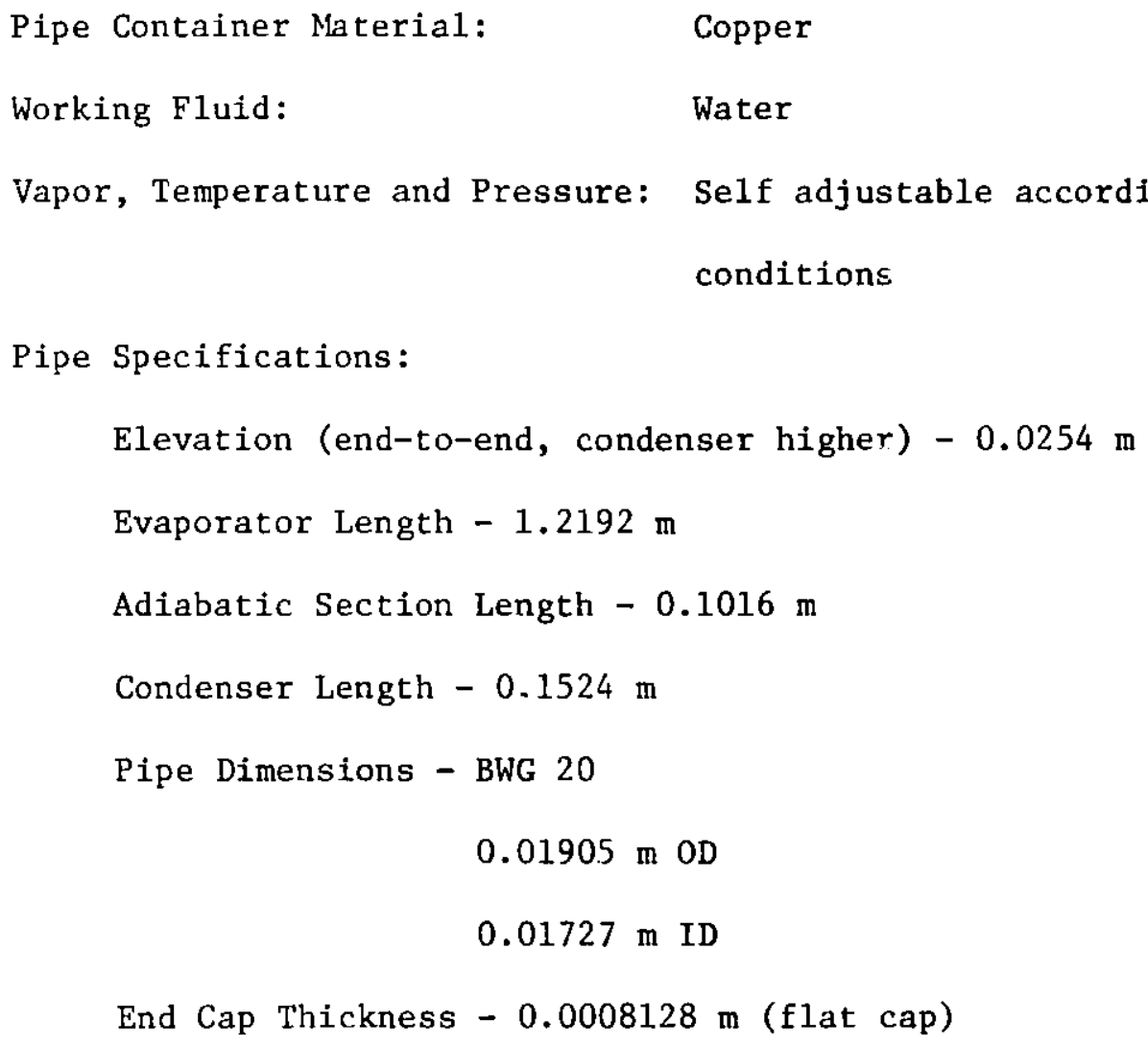

Pipe Specifications:

Wick Specifications:

Wick Thickness - 0.004572 'm

Wire-screen Mesh

Mesh Number $=50$

Wire Diameter $=0.000254 \mathrm{~m}$

Wick Material $=$ Copper 
Table 6. Heat Pipe Design Details

Maximum Heat Load to be Carried by Each Heat Pipe $=\left(H_{b}(i)+H_{d}\right) 2 W L_{e} \eta_{0}$

$=1.64 \mathrm{~W}$

Parameters Relating to Fluid Selection:

$$
\text { (Fluid - water) } \quad \begin{aligned}
\mathrm{N}_{1} & =5.17 \times 10^{11} \mathrm{~W} / \mathrm{m}^{2} \\
\mathrm{~N}_{\mathrm{k}_{1}} & =3.51 \times 10^{11} \mathrm{~W}^{2} / \mathrm{m}^{3{ }^{\circ} \mathrm{C}}
\end{aligned}
$$

Parameters Relating to Container Selection:

$$
\text { (Container - Copper) } \quad \mathrm{N}_{\mathrm{k}_{\mathrm{p}}}=4.17 \times 10^{10} \mathrm{~J} \mathrm{~kg} / \mathrm{sec}^{3} \mathrm{~m}^{2}{ }^{\circ} \mathrm{C}
$$

Wick Data:

$$
\begin{aligned}
\phi & =0.5877 \\
K & =6.31 \times 10^{-10} \mathrm{~m}^{2} \\
r_{c} & =0.3937 \mathrm{~m}
\end{aligned}
$$

Friction Coefficients:

$$
\begin{aligned}
& F_{1}=0.783 \mathrm{~N} \mathrm{sec} / \mathrm{Jm}^{3} \\
& F_{v}=0.658 \mathrm{~N} \mathrm{sec} / \mathrm{Jm}^{3}
\end{aligned}
$$

Operating Limitations:

$$
\begin{array}{ll}
Q_{\max } \text { capillary } & =389 \mathrm{~W} \\
Q_{\max } \text { sonic } & =84,027 \mathrm{~W} \\
Q_{\max } \text { entrainment } & =2,635 \mathrm{~W} \\
Q_{\max , \text { boiling }} & =406 \mathrm{~W}
\end{array}
$$

Comments :

A11 $Q_{\max }>164 \mathrm{~W}$, safe operation is assured.

Check Reynolds and Mach Numbers for Vapor Flow:

$$
\begin{aligned}
& R_{e}=831 \quad(<2,300) \\
& M=9 \times 10^{-4}(<0.2)
\end{aligned}
$$


Table 7. Summary of Heat Transfer Characteristics of the Designed Heat Pipe

$$
\begin{aligned}
& R_{p, e}=9.28 \times 10^{-9} \mathrm{~m}^{2}{ }^{\circ} \mathrm{C} / \mathrm{W} \\
& R_{w, e}=1.21 \times 10^{-5} \mathrm{~m}^{2 \circ} \mathrm{C} / \mathrm{W} \\
& R_{v}=1.62 \times 10^{-9} \mathrm{~m}^{2 \circ} \mathrm{C} / \mathrm{W} \\
& R_{w, c}=9.67 \times 10^{-5} \mathrm{~m}^{2 \circ} \mathrm{C} / \mathrm{W} \\
& R_{p, c}=7.44 \times 10^{-8} \mathrm{~m}^{2 \circ} \mathrm{C} / \mathrm{W} \\
& U_{p}=9.18 \times 10^{3} \mathrm{~W} / \mathrm{m}^{2}{ }^{\circ} \mathrm{C}
\end{aligned}
$$


in an annulus, and the convective coefficient of water has been incorporated into the overall heat transfer coefficient from the receiver surface to water (discussed previously in Section II, 3), a separate evaluation of the heat exchanger penalty is no longer needed. This new computer program has been included as Appendix $B$ to this report. A sample run was also made using the data given in Table 8 as inputs.

An examination of the data output reveals that the trends of data are quite similar to the ones seen in Figures 14 to 18 . There is one exception the collector efficiency in the boiler loop is about $25 \%$ lower than before. This can be ascribed to the fact that the gap loss for these boiler collectors is much higher. Using data given in Tables 3 and 8 , it is easy to show that, for the collectors in the collector 1oop, $p=0.933$, whereas those in the boiler loop, $\mathrm{p}=0.782$. The gap loss is thus important to the collector performance. The computer data for boiler collectors have been given in the appendix following the computer program, a separate data plot is not attempted.

The analysis made above provides a means of evaluating the performance of the total system. Use is made of the equivalent thermodynamic circuit shown in Figure 24. Here the collectors in both collector and boiler loops are represented by a blackbox and $\left(Q_{u_{p h}}+Q_{u_{b}}\right)$ is used to denote the constantpressure heat input to the boiler water. Process 2-3 represents a throttling process. This process enables a portion of the subcooled (or saturated) liquid at elevated pressures and temperatures to flash into steam. The flash boiler behaves much like a separator to direct the saturated steam upward to point 5 while the saturated water at lower pressures settles down and discharges at point 4. The portion of the water that is flashed into steam is replenished by the makeup feedwater which mixes with the water at state 4 
Table 8. Input Data for Performance Tests of Collectors in the Bofler Loop

Collector Specifications (refer to Figures 2 and 11 for notations):

See Figure 13 (b) for troughs lay-out.

$$
\begin{aligned}
& \mathrm{W}=0.1128 \mathrm{~m} \\
& \mathrm{~L}=1.2192 \mathrm{~m} \text { (Corresponds to heat pipe evaporator length) } \\
& \mathrm{r}_{\mathrm{e}}=0.0174 \mathrm{~m} \\
& \mathrm{r}_{\mathrm{p}, \mathrm{o}}=0.0095 \mathrm{~m} \\
& \mathrm{r}_{\mathrm{a}}=0.0127 \mathrm{~m} \\
& \mathrm{~L}_{\mathrm{e}} / \mathrm{L}_{\mathrm{c}}=8 \\
& \text { Gap }=\text { Clearance }+\mathrm{r}_{\mathrm{e}}-\mathrm{r}_{\mathrm{p}, \mathrm{o}}=0.0050+0.0174-0.0095=0.0129 \mathrm{~m}
\end{aligned}
$$

Solar Radiation Data:

$$
\begin{aligned}
& \mathrm{H}_{\mathrm{b}}(\mathrm{i})=966 \mathrm{~W} / \mathrm{m}^{2} \\
& \mathrm{H}_{\mathrm{d}}=100 \mathrm{~W} / \mathrm{m}^{2}
\end{aligned}
$$

Ambient Conditions:

$$
\begin{aligned}
& \mathrm{T}_{\mathrm{b}}=20^{\circ} \mathrm{C} \\
& \mathrm{T}_{i}=137.39^{\circ} \mathrm{C} \text { (Assume four collectors in series in the collector 1oop) } \\
& \mathrm{V}=5 \mathrm{~m} / \mathrm{s}
\end{aligned}
$$

Material Properties:

$$
\begin{aligned}
& \alpha_{a}(i)=\bar{\alpha}_{a}=0.05 \\
& \bar{\rho}_{a}=0.05 \\
& \tau_{a}(i)=\bar{\tau}_{a}=0.9 \\
& \alpha_{e}(j)=\bar{\alpha}_{e}=0.05 \\
& \bar{\rho}_{e}=0.05
\end{aligned}
$$


Table 8 (Continued)

$$
\begin{aligned}
& \tau_{e}(j)=\bar{\tau}_{e}=0.9 \\
& \alpha_{r}\left(k ; \bar{\alpha}_{r}=0.85\right. \\
& \bar{\rho}_{r}=0.15 \\
& \rho_{m}=0.85 \\
& \bar{n}=0.6 \\
& \varepsilon_{a}=0.85 \\
& \varepsilon_{e}=0.85 \\
& \varepsilon_{r}=0.05
\end{aligned}
$$

Data for Water in the Boiler Loop:

$$
\begin{aligned}
& \mathrm{k}_{\mathrm{f}}=0.65 \mathrm{~W} / \mathrm{m}^{\circ} \mathrm{C} \\
& \dot{\mathrm{m}}_{\mathrm{b}}=0.017 \mathrm{~kg} / \mathrm{s} \\
& { }_{\mathrm{C}_{\mathrm{P}}}=4170 \mathrm{~J} / \mathrm{kg}^{\circ} \mathrm{C}
\end{aligned}
$$

Heat Pipe Data:

$$
\mathrm{U}_{\mathrm{p}}=9180 \mathrm{~W} / \mathrm{m}^{2} \mathrm{C}
$$



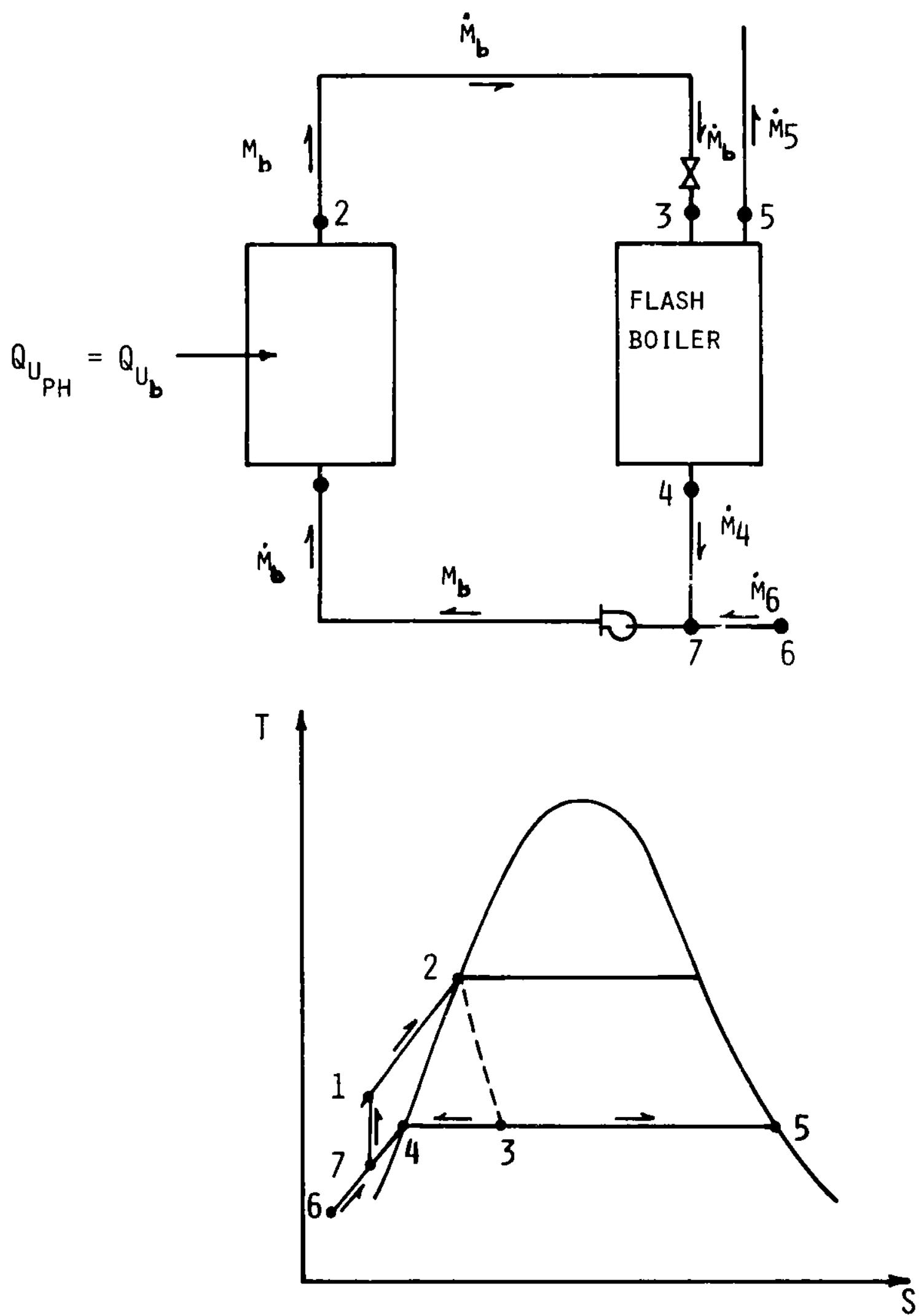

Figure 24, Thermodynamic Circuit and T-S Diagrams 
to form state 7 . The pumping process can be modeled as isentropic and is used to pressurize water in the boiler loop. The total thermodynamic cycle can be plotted using a temperature-entropy diagram and shown in the lower half of the figure. A thermodynamic analysis follows below.

It is easy to show by using the continuity equation that

$$
\dot{\mathrm{m}}_{5}=\dot{\mathrm{m}}_{6}
$$

By using the first law of thermodynamics, it can be derived that the quality of steam at point 3 is

$$
x_{3}=\frac{h_{3}-h_{4}}{h_{5}-h_{4}}
$$

where $h^{\prime}$ s are enthalpies.

Using the same law, the system at the T-joint at pump inlet can be analyzed as follows:

$$
h_{7}=\left(1-x_{3}\right) h_{4}+x_{3} h_{6}
$$

Similarly for the pump itself,

$$
h_{1}=h_{7}+v_{7}\left(p_{1}-p_{7}\right)
$$

where $\mathrm{v}$ is the specific volume. Equations (78) to (81) can be used together to predict the steam flow rate.

For illustration purposes, a sample calculation is provided below. It is assumed that

$$
\begin{aligned}
& \mathrm{p}_{3}=\mathrm{p}_{4}=\mathrm{p}_{5}=\mathrm{p}_{6}=\mathrm{p}_{7}=1 \mathrm{~atm} \\
& \mathrm{~T}_{6}=20^{\circ} \mathrm{C} \\
& \mathrm{p}_{2}=3.08 \times 10^{5} \mathrm{~N} / \mathrm{m}^{2} \doteq 3 \mathrm{~atm}
\end{aligned}
$$

and point 2 is a saturated liquid. The analysis given above can be used to predict

$$
\begin{aligned}
& \mathrm{x}_{3}=6.5 \% \\
& \mathrm{~h}_{1}=4 \times 10^{5} \mathrm{~J} / \mathrm{kg} \\
& \mathrm{h}_{7}=3.98 \times 10^{5} \mathrm{~J} / \mathrm{kg}
\end{aligned}
$$


and

$$
\begin{aligned}
Q_{p h}+Q_{b} & =\left(h_{2}-h_{1}\right) \dot{m}_{b} \\
& =1.644 \times 10^{5} \times \dot{m}_{b} W
\end{aligned}
$$

Since $\dot{\mathrm{m}}_{\mathrm{b}}$ has been chosen to be $0.017 \mathrm{~kg} / \mathrm{s}$ in the computer simulation (see Table 8)

$$
Q_{p h}+Q_{b}=2.79 \times 10^{3} \mathrm{~W}
$$

which represents the total heat input needed for the circulating water.

There are several ways by which this heat demand can be met, see Figure 25. If there is no collector in the collector 1cop, it takes about 4.5 boilers to supply this amount of heat. If there is one collector in the collector loop, then 2.1 boilers must be used. Of course, if two collectors are available in the collector loop, then these collectors will be sufficient to meet the need. In practice, the boiler numbers cited here will be rounded upward to account for system heat losses. Figure 25 is seen to be an excellent tool for design purposes.

The analysis given above also provides a means for predicting the anount of steam generation. Since $\dot{\mathrm{m}}_{6}$ has been chosen as $0.017 \mathrm{~kg} / \mathrm{s}$ in the computer simulation, the amount of steam generation can readily be calculated as

$$
\dot{\mathrm{m}}_{5}=0.065 \times 0.017=1.1 \mathrm{~g} / \mathrm{s}
$$

where 0.065 on the right of the equation comes from Equation (82).

This steam generation rate can be checked by considering the entire briler loop as a system, which is identified by its system boundary shown in Figure 26 . For this system the interactions between the system and the surroundings Include the heat transfer $\left(Q_{p h}+Q_{b}\right)$, the shaft work to drive the pump, i.e.

$$
\mathrm{w}=\mathrm{h}_{1}-\mathrm{h}_{7}
$$



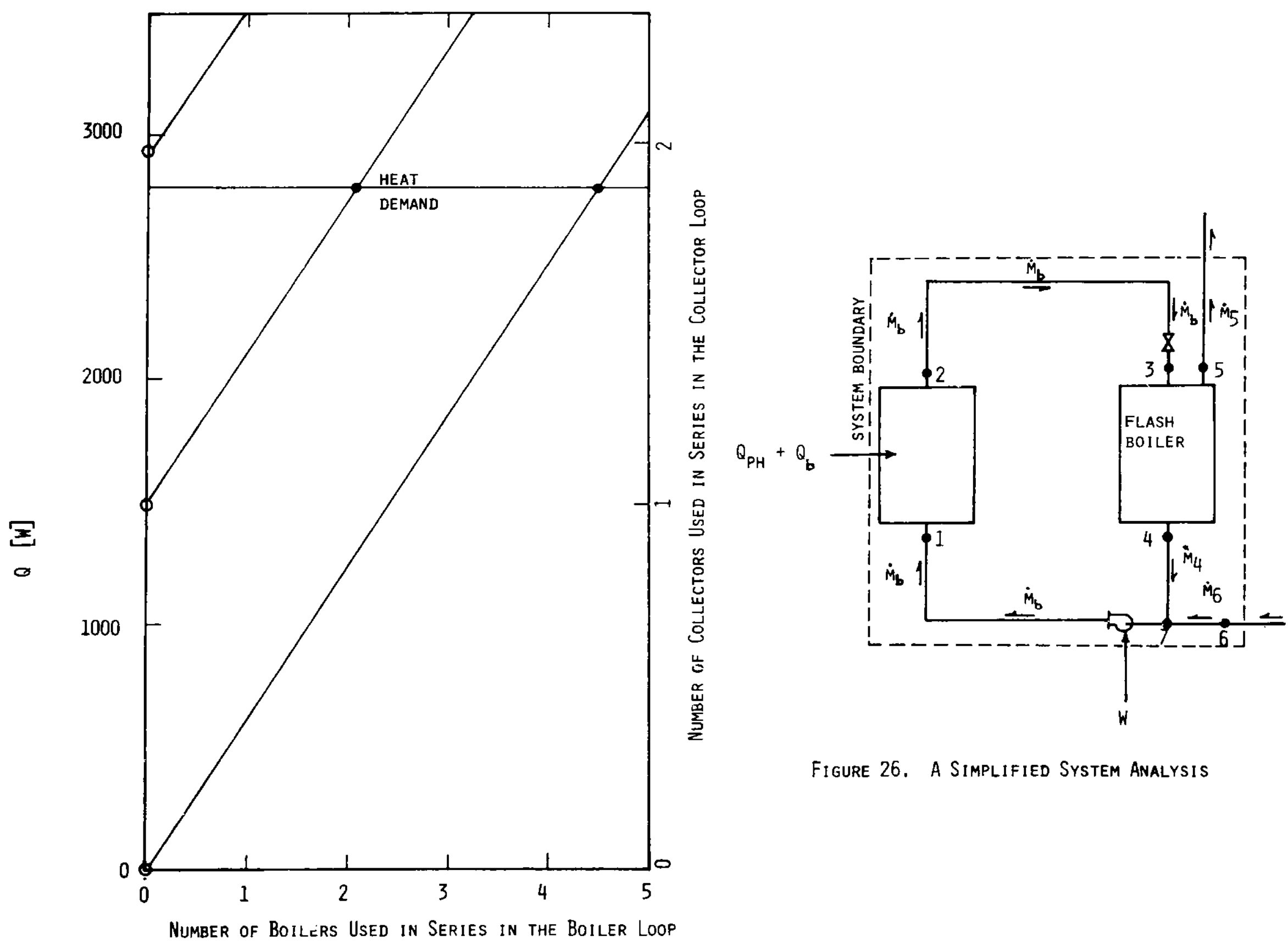

Figure 25. a design Chart for Steam generation 
and fluid flowing in and out of the system. According to the previous analysis the total energy (heat and work) input to the system is

$$
Q_{\text {total }}=2790+0.02 \times 10^{5} \times 0.017=2824 \mathrm{~W}
$$

This value is in close agreement with the energy required to convert $1.1 \mathrm{~g} / \mathrm{s}$ of water at $20^{\circ} \mathrm{C}$ to steam at $100^{\circ} \mathrm{C}$, which is $2847 \mathrm{~W}$. ${ }^{*}$ The error of $0.8 \%$ can be ascribed to the fact that the specific heat of water has been treated as a constant in the simple analysis (see footnote). The numerical error also contributes to the difference.

\section{Discussion}

It should be noted that in the present design, the system uses a doubleloop circuit for energy collection. As has been shown, a total heat input is a11 that is needed to convert the feed water to steam. As such, the use of double-1oop appears to be unnecessary. Indeed, if the system is designed to produce hot "water" for industrial process heat applications, the collectors in the collector loop, with ethylene glycol used as collector circulating fluid, should be adequate to provide the heat demand. It will be a different state of affairs, however, if the system is designed to produce steam. Then, various constraints should be considered. A one-step heating in the collector loop may be impossible because of the low boiling points of glycols.

\footnotetext{
${ }^{*}$ Energy required to raise the temperature of water from 20 to $100^{\circ} \mathrm{C}$ is

$$
Q_{20-100^{\circ} \mathrm{C}}=1.1 \times 4.7 \times(100-20)=367 \mathrm{~W}
$$
}

To convert this water to steam requires

$$
Q_{100^{\circ} \mathrm{C} \text { water }-100^{\circ} \mathrm{C} \text { steam }}=1.1 \times 2254.6=2480 \mathrm{~W}
$$


As a point of further interest, the use of the present system for supplying hot water in the industrial process heat applications is also analyzed as shown in Figure 27. Here the figure was constructed on the basis of two collectors in series and the family of curves is parameterized by the water inlet temperature. As is totally expected, an increase of the water flow rate as well as a lowering of the water inlet temperature depresses the water exit temperature.

The heat pipes inside the boiler loop collectors use water as a working fluid. Water is known to have a high freezing point, which makes the collector susceptible to freeze damage at low temperatures. It should be noted that the decision of using water as a working fluid in heat pipes is solely dictated by its high liquid transport number [Equation (48)]. Many organic liquids are available and have low freezing points, but they are inferior to water in this respect. There are various factors to be weighed in selecting a working fluid [3-5]. Research on heat pipes for moderate temperatus applications is still active presently.

The analysis given in this report was made based on a negligible heat loss from pipes and accessories. In practice, such a parasatic loss is unavoidable and these losses should be taken into consideration in the f1.al design. On the other hand, in the boiler loop the collectors were analyzed based on a water inlet temperature of $137.39^{\circ} \mathrm{C}$. This temperature was taken based on the assumption that there were four collectors in series in the collector loop. (The resulting preheater exit temperature is of this magnitude). Calculations

\footnotetext{
${ }^{*}$ Philco Italiana uses EHS 112 as a working fluid in their heat-pipe solar collectors. North American Philips Lighting has just developed a heat-pipe receiver tube using lsobutane as a working fluid.
} 
$V A[G A L / M I N]$

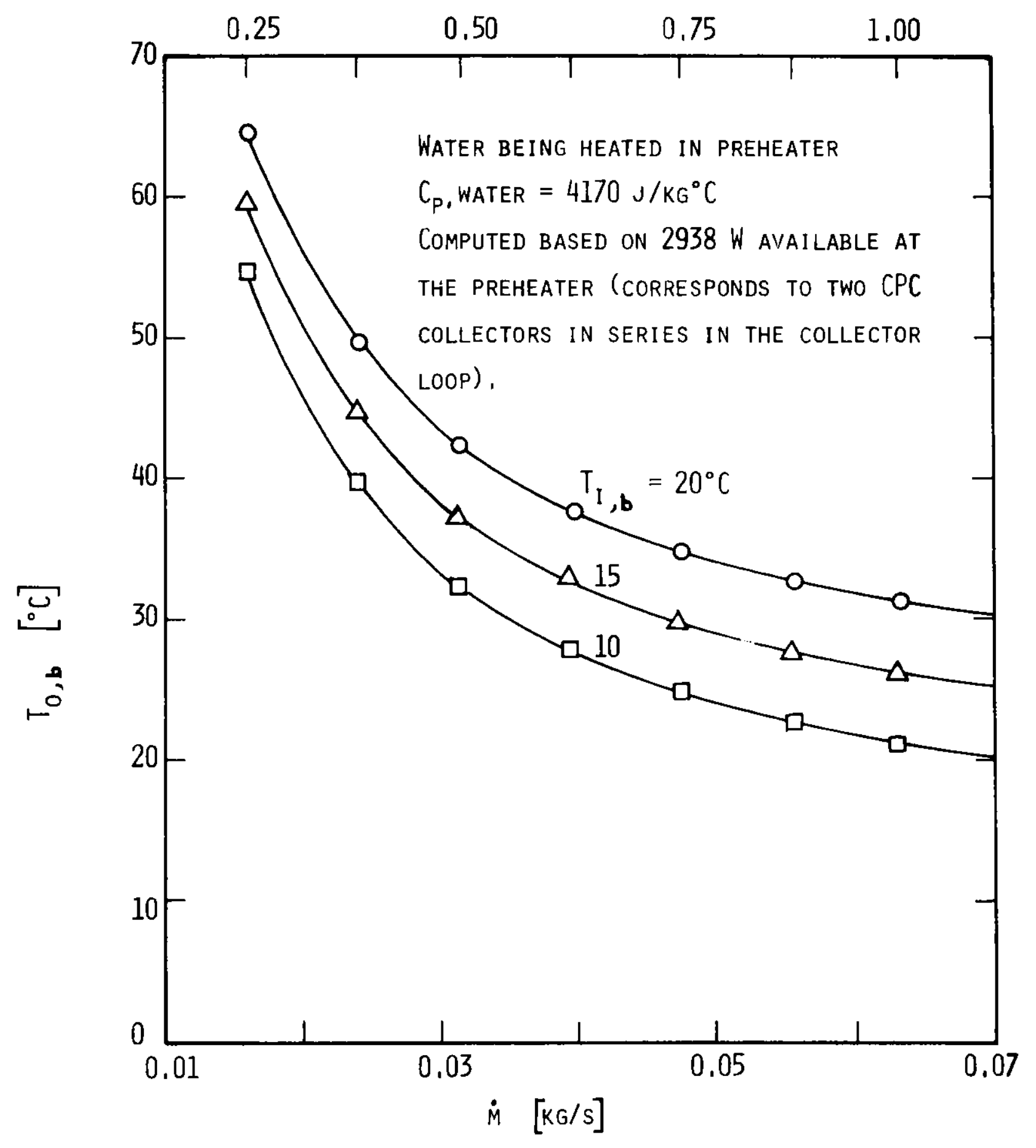

Figure 27. Exit Water temperature Prediction Chart 
based on this inlet temperature are expected to yield a slightly higher heat 1oss. Hence, the actual heat gains are expected to be slightly higher than those given in Figure 25. The difference is, nevertheless, small for the small $\mathrm{U}_{\mathbf{r} / \mathrm{e}}$ occurring in CPC collectors.

Finally, it is noted that, in the installation of collectors in the boiler loop, these collectors are rotated in the sense that the condenser section is slightly higher than the evaporator. The number of collection hours for a rotated $\mathrm{CPC}$ collector has been analyzed and reported in [21]. Tilt angle adjustments can be computed accordingly with the help of this reference. 


\section{CONCLUSIONS}

Based on the study made in this report some conclusions can be drawn and given as follows:

1. It has been shown that the proposed system can be used to produce low quality steam for industrial process heat purposes. The system consists of two series of collectors divided into two loops. The collectors in the collector loop use ethylene glycol for collector circulation fluid which is known for its low freezing point and high boiling point. The collectors in the boiler loop use heat pipes for transmitting heat. These heat pipes enable heating to take place outside its condenser section. The circulating water in the boiler loop is slightly pressurized to raise its boiling point. It is expected that, with these special designs, problems associated with weak receiver tube, scaling and plumbing problems can all be resolved in steam generation.

2. The CPC collectors have shown to be an excellent collector for industrial process heat applications. Not only is its simplicity in design, requiring only occasional adjustments of tilt angles to intercept solar energy, but also is the fact that the CPC collector has an efficiency curve that is very weakly dependent on the receiver temperatures. The CPC collector is thus superior to a constant tracking trough or dish collector and is particularly attractive in high temperature applications.

3. The computer simulations given in this report have shown that the proposed system is technically feasible. Thermodynamic analyses given here also verify the validity of the analysis. The computer program, as wel.1 as the detailed analyses presented in this report, will be helpful to the prediction of thermal processes in a CPC collector and will be instrumental to the future system analysis. 


\section{REFERENCES}

1. Ir..ormation Source: SERI

2. Welford, W. T., and Winston, R., The Optics of Nonimaging Concentrators, Academic Press, 1978.

3. Winter, E. R. F., and Barsch, W. 0., The Heat Pipe, Advances in Heat Transfer 7 (Editors: T. F. Irvine, Jr., and J. P. Hartnett), Academic Press, 1971.

4. Chi, S. W., Heat Pipe Theory and Practice: A Source Book, Hemisphere Publishing, 1976.

5. Dunn, P., and Reay, D. A., Heat Pipes, Pergamon Press, 1975.

6. Rabl, A., Optical and Thermal Properties of Compound Parabolic Concentrators, Solar Energy, Vo1. 18, 497, 1.976.

7. Kreider, J. F., Performance Study of the Compound Parabolic Concentrator Solar Collector, Environmental Consulting Services, Inc., Boulder, Colorado, 1974 .

8. Kreider, J. F., Therma1 Performance of the Compound Parabolic Concentrator Solar Collector - Phase II, Environmental Consulting Services, Inc., Boulder, Colorado, 1975.

9. Winston, R., Principles of Solar Concentrators of a Novel Design, Solar Energy, Vol. 16, 89, 1974.

10. Rab1, A., Radiation Transfer through Specular Passages - A Simple Approximation, International Journal of Heat and Mass Transfer, Vo1. 20, 323, 1977.

11. Rabl, A., Comparison of Solar Concentrators, Solar Energy, Vol. 18, 93, 1975 . 
12. Goodman, N. B., Rabl, A., and Winston, R., Optical and Thermal Design Considerations for Ideal Light Collectors, Sharing the Sun, Vo1. 2, 336, 1976.

13. Whiller, A., Design Factors Influencing Solar Collectors, Low Temperature Engineering Applications of Solar Energy, ASHRAE, 1967.

14. McAdams, W. C., Heat Transmission, Third Edition, McGraw-Hill, 1954.

15. Kays, W. M., Convective Heat and Mass Transfer, McGraw-Hill, 1966.

16. Hottel, H. C., and Woertz, B. B., Performance of Flat-plate Solar-Heat Collectors, Transactions of ASME, Vo1. 64, 91, 1942.

17. Hottel, H. C., and Whillier, A., Evaluation of Flat-plate Collector Performance, Transactions of the Conference on the Use of Solar Energy, Vol. 2, Part 1, 74, 1958.

18. Bliss, R. W., The Derivations of Severa1 Plate Efficiency Factors Useful in the Design of Flat-plate Solar-Heat Collectors, Vol. 3, 55, 1959.

19. deWinter, F., Heat Exchanger Penalties in Double Loop Solar Water Heating Systems, Solar Energy, Vo1. 17, 335, 1975.

20. Lundberg, R. E., McCuen, P. A., and Reynolds, W. C., Heat Transfer in Annular Passages. Hydraudynamically Developed Laminar Flow with Arbitrarily Prescribed Wall Temperature or Heat Flux, International Journal of Heat and Mass Transfer, Vo1. 6, 495, 1963.

21. Miller, C. W., Collection Times for Trough-Type Concentrators Having Arbitrar rientáion, Solar Energy, Vol. 20, 399, 1978.

22. Information Source: Union Carbide

23. Ar, nne National Laboratory Solar Energy Program Annual Report, ANL-79-16. 


\section{APPENDIX A. A COMPUTER PROGRAM TO ANALYZE THERMAL PROCESSES IN A SERIES OF CPC COLLECTORS FITTED WITH CTR TUBES}

The computer program given in this appendix is designed to generate a large body of data relevant to the thermal processes in a CPC collector fitted with a CTR. A single run of the computer program yields data for an array of six collectors in series. Line number 62 can be changed if more collectors are needed. Definitions for input variables are given as follows.

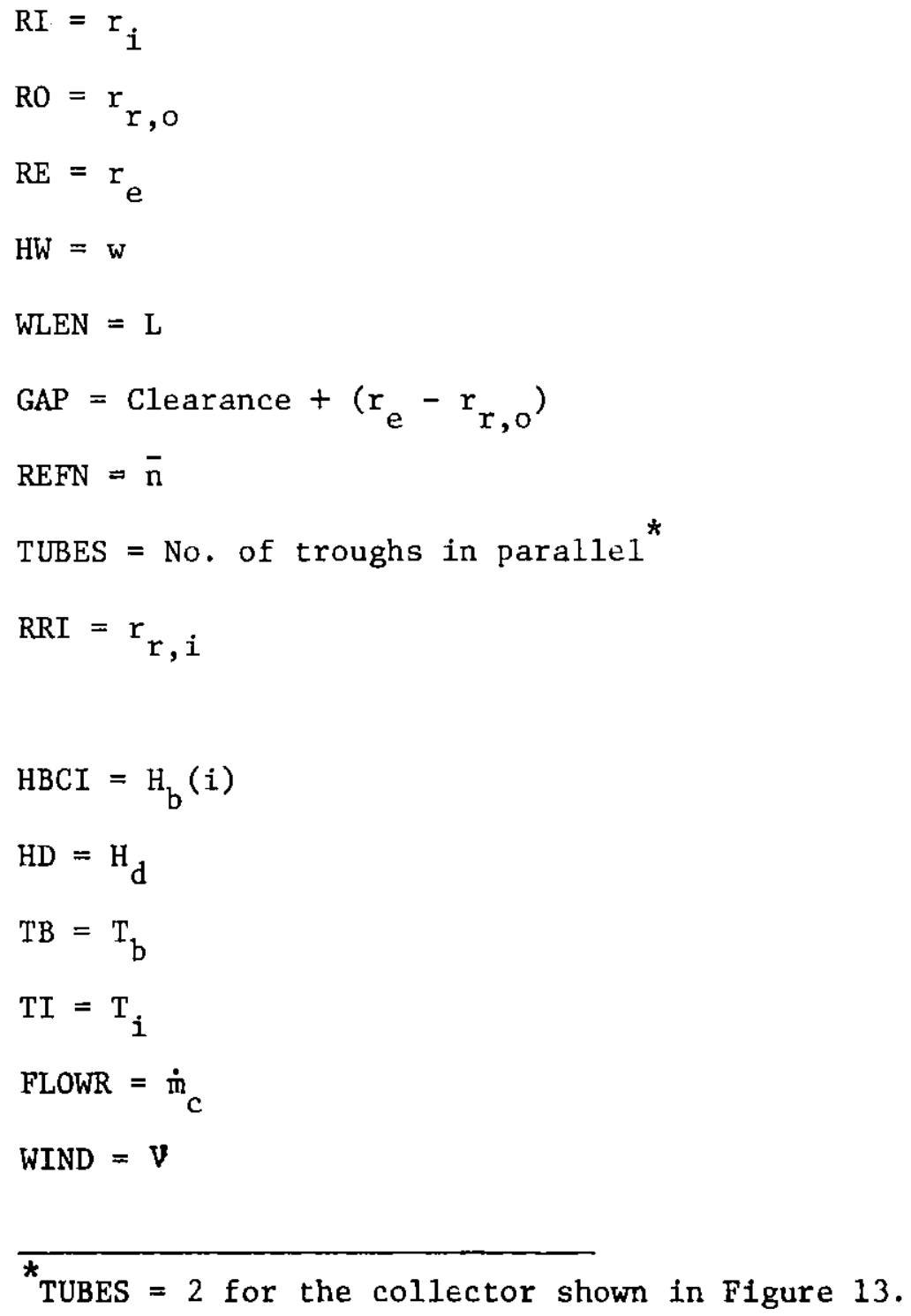




$$
\begin{aligned}
& \mathrm{ER}=\varepsilon_{\mathrm{r}} \\
& \mathrm{EE}=\varepsilon_{\mathrm{e}} \\
& E A=\varepsilon_{a} \\
& \mathrm{CP}=\mathrm{c}_{\mathrm{p}} \\
& \mathrm{TKF}=\mathrm{k}_{\mathrm{f}} \\
& \mathrm{TKG}=\mathrm{k}_{\mathrm{g}} \\
& \mathrm{ARK}=\alpha_{\mathrm{r}}(\mathrm{k}) \\
& \mathrm{ARM}=\bar{\alpha}_{\mathrm{r}} \\
& R R M=\bar{\rho}_{r} \\
& A E J=\alpha_{e}(j) \\
& \mathrm{AEM}=\bar{\alpha}_{\mathrm{e}} \\
& \operatorname{REM}=\bar{\rho}_{\mathrm{e}} \\
& \text { TEJ }=\tau_{e}{ }^{(j)} \\
& \mathrm{TEM}=\bar{\tau}_{\mathrm{e}} \\
& A A I=\alpha_{a}(i) \\
& \mathrm{AAM}=\bar{\alpha}_{\mathrm{a}} \\
& \operatorname{RAM}=\vec{\rho}_{\mathrm{a}} \\
& \text { TAI }=\tau_{a}(i) \\
& T A M=\bar{\tau}_{a} \\
& \mathrm{RMIR}=\rho_{\mathrm{m}}
\end{aligned}
$$

EPS = Convergence criterion for iteration

PASS $=$ No. of troughs in series ${ }^{*}$

${ }^{*}$ PASS $=5$ for the collector shown in Figure 13. 


$$
\begin{aligned}
& \text { FLOWF }=\dot{\mathrm{m}}_{\mathrm{b}} \\
& \mathrm{CPF}=\mathrm{C}_{\mathrm{p}_{\mathrm{b}}} \\
& \mathrm{UA}=(\mathrm{UA})_{\mathrm{x}}
\end{aligned}
$$

Definitions for output variables are given as follows:

$$
\begin{aligned}
& \mathrm{TA}=\mathrm{T}_{\mathrm{a}} \text { or } \overline{\mathrm{T}}_{\mathrm{a}} \\
& \mathrm{TE}=\mathrm{T}_{\mathrm{e}} \text { or } \overline{\mathrm{T}}_{\mathrm{e}} \\
& \mathrm{TR}=\mathrm{T}_{\mathrm{r}} \text { or } \overline{\mathrm{T}}_{\mathrm{r}} \\
& \mathrm{TO}=\mathrm{T}_{\mathrm{o}} \\
& \mathrm{UOP}=\mathrm{U}_{\mathrm{r} / \mathrm{e}^{\mathrm{A}} \mathrm{r}} \\
& \mathrm{UWP}=\mathrm{U}_{\mathrm{e} / \mathrm{a}^{\mathrm{A}} \mathrm{e}} \\
& \text { UTP }={ }^{r} a / b^{A} \\
& \mathrm{ULP}=\mathrm{U}_{\mathrm{L}} \mathrm{A}_{\mathrm{r}} \\
& \mathrm{UL}=\mathrm{U}_{\mathrm{L}} \\
& \mathrm{UO}=\mathrm{U}_{\mathrm{o}} \\
& \mathrm{FPR}=\mathrm{F}^{\prime} \\
& \mathrm{FSR}=\mathrm{F}_{\mathrm{R}} \\
& \mathrm{CN} \cdot \mathrm{IN}=\left(\dot{\mathrm{mC}}{ }_{\mathrm{p}}\right)_{\mathrm{min}} \\
& \operatorname{CMAX}=\left(\dot{m c}_{\mathrm{p}}\right)_{\max } \\
& \text { TUNIT }=(U A)_{x} /\left(\dot{\mathrm{m}}_{\mathrm{p}}\right)_{\text {min }} \\
& \text { EHX }-e_{x} \\
& \mathrm{FHX}=\mathrm{F}_{\mathrm{x}}
\end{aligned}
$$




$$
\begin{aligned}
& \mathrm{QUY}=\mathrm{Q}_{\mathrm{u}} \text {, Equation (28) } \\
& \text { QUZ }=Q_{u} \text {, Equation (29) } \\
& \text { QU1 }=Q_{u} \text {, Equation (32) } \\
& \mathrm{QU2}=\mathrm{Q}_{\mathrm{u}} \text {, Equation (34) } \\
& \text { QU3 }=\text { QU2 times } F_{\mathrm{x}} \\
& \text { QUC }=\dot{\mathrm{m}}_{\mathrm{c}} \mathrm{c}_{\mathrm{p}_{\mathrm{c}}}\left(\mathrm{T}_{\mathrm{o}}-\mathrm{T}_{\mathrm{i}}\right)_{\mathrm{c}} \\
& \text { EFFY }=\eta \text {, Equation (39) } \\
& \text { EFFZ }=\pi \text {, Equation (40) } \\
& \text { EFF1 }=\eta \text {, Equation (41) } \\
& \text { EFF2 }=n \text {, Equation (42) } \\
& \text { EFF3 = EFF2 times } F_{x} \\
& \mathrm{EFFC}=n \text {, Equation (45) }
\end{aligned}
$$

The computer program is given on the next page. 
REQUESTED OPTIONS: NOTERM,

OPTIONS IN EFFECT: NAHE(MAIN) NOOPTIMIZE LINECOU:IT(60) SIZE(MAX) AUTODBL(NONE)

SOLPCE NOANSF NDTERM FLAG(I)

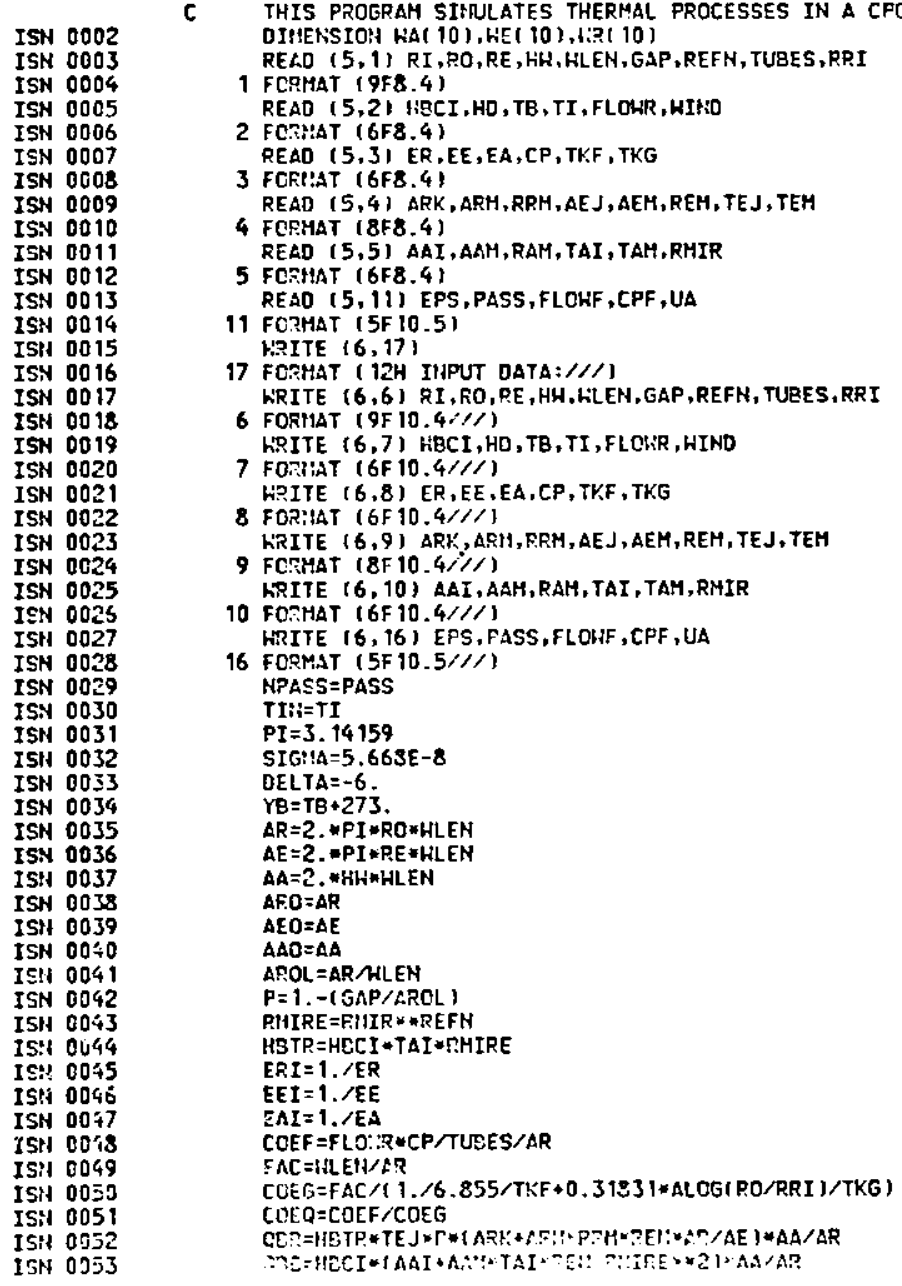




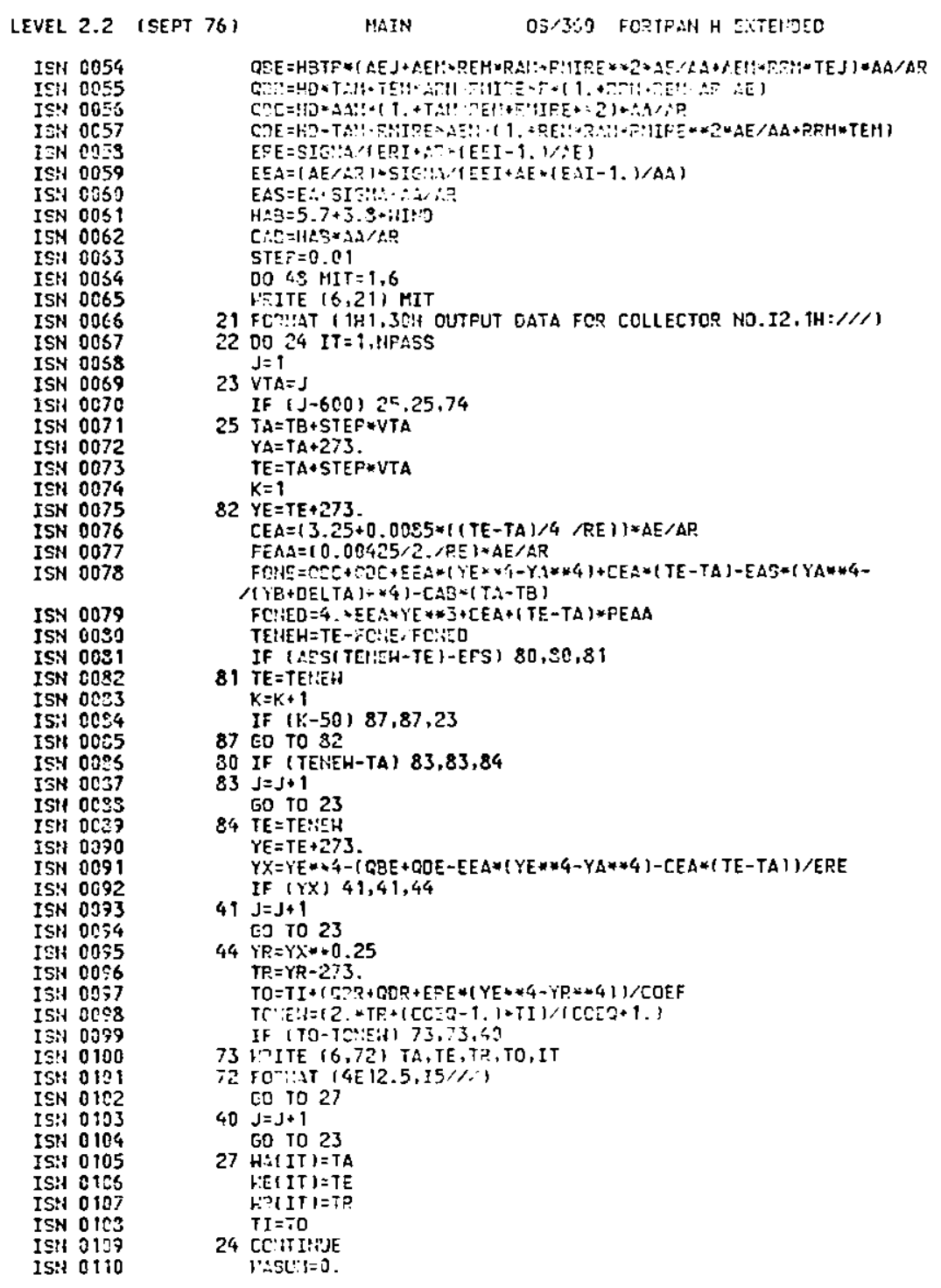


LEVEL 2.2 (SEPT 76)

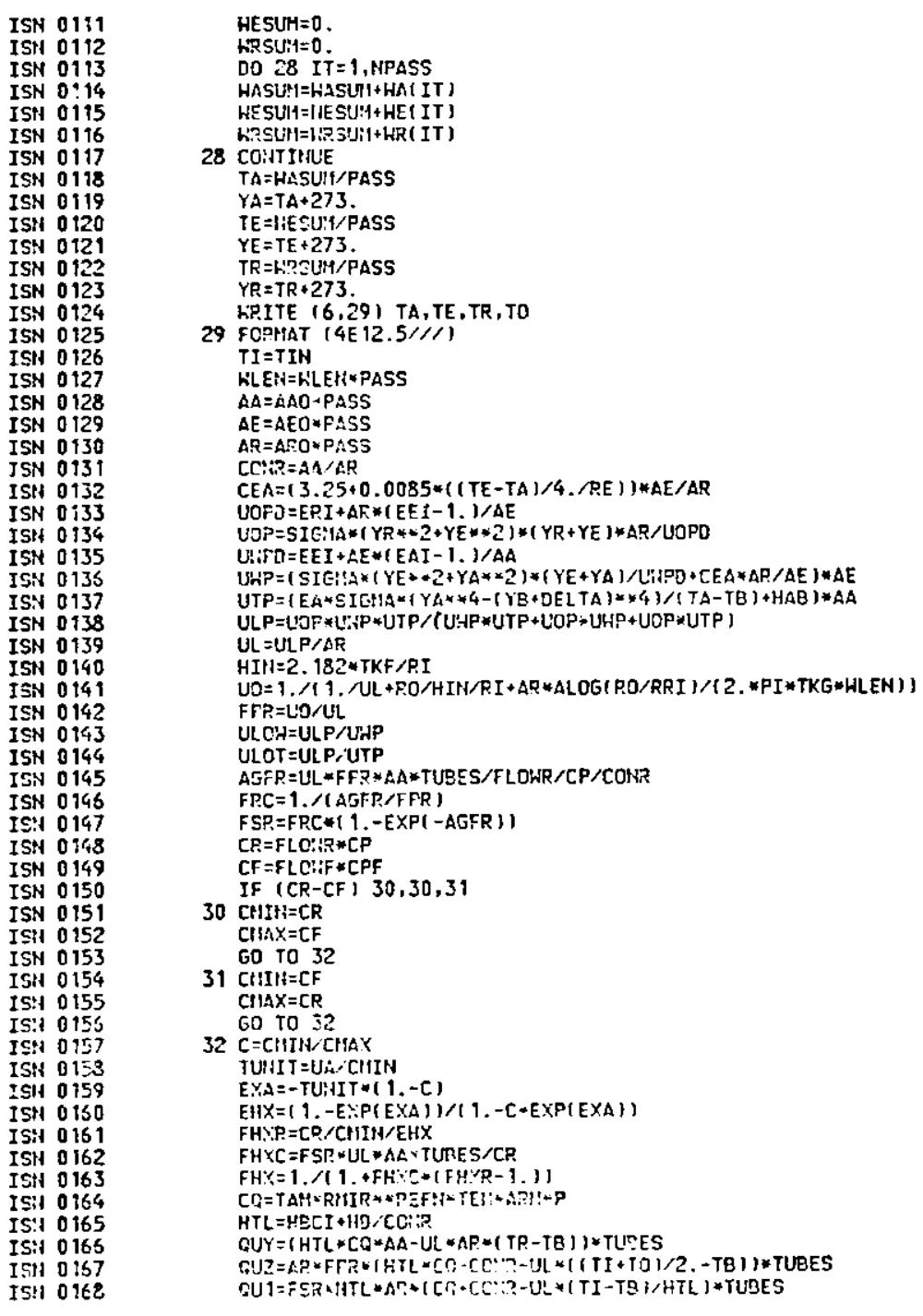




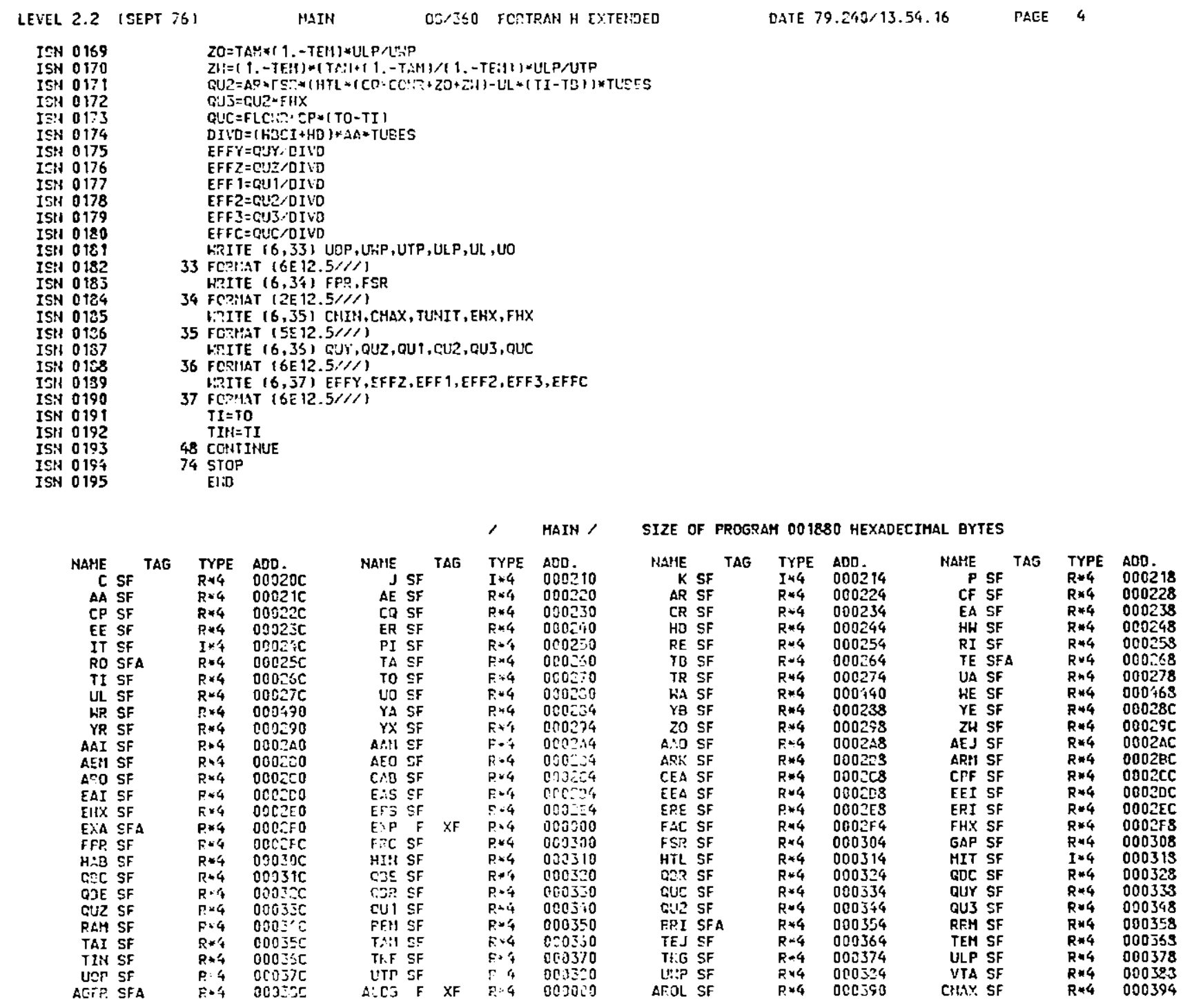




\section{APPENDIX B. A COMPUTER PROGRAM TO ANALYZE THERMAL PRCCESSES IN A SERIES OF CPC COLLECTORS FITTED WITH HEAT PIPES}

The computer program given in this appendix is designed to analyze the thermal processes in a CPC collector fitted with a heat pipe receiver. A single run of the program yields data for ten crllectors in series. Line number 66 can be changed if more collectors are reeded. Definitions for input variables are given as follows.

$$
\begin{aligned}
& \mathrm{RC}=\mathrm{r}_{\mathrm{a}} \\
& \mathrm{RO}=\mathrm{r}_{\mathrm{p}, \mathrm{o}} \\
& \mathrm{RE}=\mathrm{r}_{\mathrm{e}} \\
& \mathrm{HW}=\mathrm{w} \\
& \text { WLEN }=\mathrm{L} \\
& \mathrm{GAP}=\text { Clearance }+\left(\mathrm{r}_{\mathrm{e}}-\mathrm{r}_{\mathrm{p}, \mathrm{o}}\right) \\
& \mathrm{REFN}=\overline{\mathbf{n}} \\
& \text { TUBES }=\text { No. of troughs in parallel } \\
& \mathrm{EVOC}=\mathrm{L}_{\mathrm{e}} / \mathrm{L}_{\mathrm{C}} \\
& \mathrm{HBCJ}=\mathrm{h}_{\mathrm{b}}(\mathrm{i}) \\
& \mathrm{HD}=\mathrm{H}_{\mathrm{d}} \\
& \mathrm{TB}=\mathrm{T}_{\mathrm{b}} \\
& \mathrm{TI}=\mathrm{T}_{i} \\
& \text { FLOWR }=\dot{\mathrm{m}}_{\mathrm{b}} \\
& \text { WIND }=\mathrm{V} \\
& E R=\varepsilon_{r} \\
& \mathrm{EE}=\varepsilon_{\mathrm{e}}
\end{aligned}
$$




$$
\begin{aligned}
& \mathrm{EA}=\varepsilon_{\mathrm{a}} \\
& \mathrm{CP}=\mathrm{C}_{\mathrm{P}_{\mathrm{b}}} \\
& \mathrm{TKF}=\mathrm{k}_{\mathrm{f}} \\
& A R K=\alpha_{r}(k) \\
& A R M=\bar{\alpha}_{r} \\
& \mathrm{RRM}=\bar{\rho}_{\mathrm{r}} \\
& A E J=\alpha_{e}(j) \\
& \mathrm{AEM}=\bar{\alpha}_{\mathrm{e}} \\
& \mathrm{REM}=\bar{\rho}_{\mathrm{e}} \\
& T E J=\tau e^{(j)} \\
& \operatorname{TEM}=\bar{\tau}_{\mathrm{e}} \\
& \mathrm{AAI}=\alpha_{\mathrm{a}} \text { (i) } \\
& A \mathrm{AM}=\bar{\alpha}_{\mathrm{a}} \\
& \operatorname{RAM}=\bar{\rho}_{\mathrm{a}} \\
& \text { TAI }=\tau_{a}(i) \\
& \mathrm{TAM}=\bar{\tau}_{\mathrm{a}} \\
& R M T R=\rho_{m}
\end{aligned}
$$

EPS $=$ Convergence criterion for iteration

PASS $=$ No. of troughs in series

$$
\mathrm{UHP}=\mathrm{U}_{\mathrm{p}}
$$


Definitions for output variables are given as follows:

$$
\begin{aligned}
& \mathrm{TA}=\mathrm{T}_{\mathrm{a}} \text { or } \overline{\mathrm{T}}_{\mathrm{a}} \\
& \mathrm{TE}=\mathrm{T}_{\mathrm{e}} \text { or } \overline{\mathrm{T}}_{\mathrm{e}} \\
& \mathrm{TR}=\mathrm{T}_{\mathbf{r}} \text { or } \overline{\mathrm{T}}_{\mathbf{r}} \\
& \text { TO }=\mathrm{T}_{\mathrm{O}} \\
& \mathrm{UOP}=\mathrm{U}_{\mathrm{r} / \mathrm{e}} \mathrm{A}_{\mathrm{r}} \\
& \text { UWP }=\mathrm{U}_{\mathrm{e} / \mathrm{a}} \mathrm{A}_{\mathrm{e}} \\
& \mathrm{UTP}=\mathrm{U}_{\mathrm{a} / \mathrm{b} \mathrm{A}_{\mathrm{a}}} \\
& \mathrm{ULP}=\mathrm{U}_{\mathrm{L}}{ }_{\mathrm{r}} \\
& \mathrm{UL}=\mathrm{U}_{\mathrm{L}} \\
& \mathrm{UO}=\mathrm{U}_{\mathrm{O}} \\
& \mathrm{FPR}=\mathrm{F}^{-} \\
& \mathrm{FSR}=\mathrm{F}_{\mathrm{R}} \\
& \text { QUY }=Q_{\mathrm{u}} \text {, Equation (28) } \\
& \text { QUZ }=Q_{u} \text {, Equation (29) } \\
& \text { QU1 }=Q_{u} \text {, Equation (32) } \\
& \text { QU2 }=Q_{u} \text {, Equation (34) } \\
& \text { QUC }=\dot{\mathrm{m}}_{\mathrm{b}} \mathrm{C}_{\mathrm{P}_{\mathrm{b}}}\left(\mathrm{T}_{\mathrm{o}}-\mathrm{T}_{\mathrm{i}}\right)_{\mathrm{b}} \\
& \text { EFFY }=n \text {, Equation (39) } \\
& \text { EFFZ }=n \text {, Equation (40) } \\
& \text { EFF1 }=\eta \text {, Equation (41) } \\
& \text { EFE2 }=n \text {, Equation (42) } \\
& \text { EFFC }=\eta \text {, Equation (45) }
\end{aligned}
$$

The computer program is given on the next page. A set of data output is given following the computer program. This is the group of data used in making the system analysis given in Section III, 2. 
REQUESTED OPTIOHS: NOTESM,

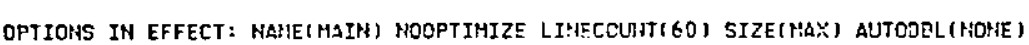
SOLFCE EECOIC HOLIST MOJECK CZIECT MIP NGFCEUHT GOSTMT HOXREF NOALC NOANSF MOTEPM FLATII

c THIS FrCorah SIMULATES thegmal Frocesses IN A CFC

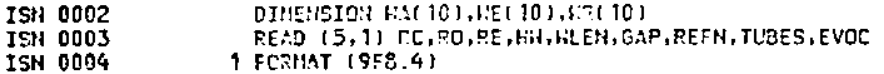

ISN 0005

IS: 0006

ISN 0008

ISH 0010

ISN 0011

ISN 0012

ISN 6013

ISiN 0014

ISII 0015

ISN 0017

ISH 0018

ISH 0019

ISN 0020

ISN 0022

IS: 0024

ISt 0025

ISH 0025

ISH 0027
ISH 0028

ISH 0028

IS: 0030

ISN 0031

ISt 0032

ISN 0053

ISt 0035

ISN 0037

ISH 0038

ISN 0039

ISH 004

ISH 0941
ISI 0042

ISN 0073

ISN $00^{\prime \prime}+7$

ISN 0045

ISN 0045

ISH 0047

ISH 0043

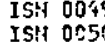

ISt: 035

IEN cos PEAO $(5,2)$ YEECI, HO, TB, TI , FLCHT , HIHO 2 ECPIIAT $16 F 8.4$

3

3 REAMNT (5FS. 4$)$

READ $(5,5)$ AAT

FCOHAT (6ES.4) AAH, PAH, TAI, TAM, FIIIR

PELO (5, 11 ) EPS, PASS, UHP

17 FCTIEAT (12H INFUT DATA://I)

HRITE $(6,6)$ FC, RO, RE, HW, HLEN, GAP, PEEFN, TUSES, EVOC

6 FOTHAT $(9 F 10.4 / 1 /$ )

HPITE (6,7) HECI, HD , TB, TI, FLONO . HIHD

FQTHAT $16 F 10.4 / / / 1$

8CruAT (5F 10, GE, EA, CP, TKF

HRITE $(6,9)$ AF:.,$O O 1$, RPM, AEJ, AEM, PEM, TEJ, TEM

FCSI4AT ISF $10.4 / 1 /$ )

AMH,PAM,TAI, TAM, PMIR

REITE (6, 10) AAI, AaH.

FCSI:AT (6F t0. $4 / / 1)$
HTITE $(5,15)$ ETS, FASS, UHP

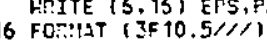

NPASS:FASS

TIH $=$ TI

$P I=3.14159$

SICIA $=5.658 \mathrm{E}-8$

$\mathrm{DELTA} A=-6$.
$Y B=T B+273$.

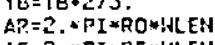

$A E=2$. $* P I \rightarrow ?$ ? E* * iLEEN

$A A=2$. $* H H+H L E N$

$\triangle F . O=A R$
$A E O=A E$

$\triangle F O L=A R / H L E H$

$P=1 .-1 C \cdot C / F O C, 1$

PT TP=ESEI-TAI+FMIFE

$E F I=1$ - $/ E R$

$E S T=1, \angle A$

CAI $=1 . / E A$
CDEF $=F L C:: P \times C P / T U B E S / A R$

$F A C=!: L E: V / \angle R$

$\triangle C C=P I \times C \mathrm{C}+2$

HCC:: = $A$ ASIS:TKF/ $/ F C$-P.

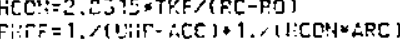




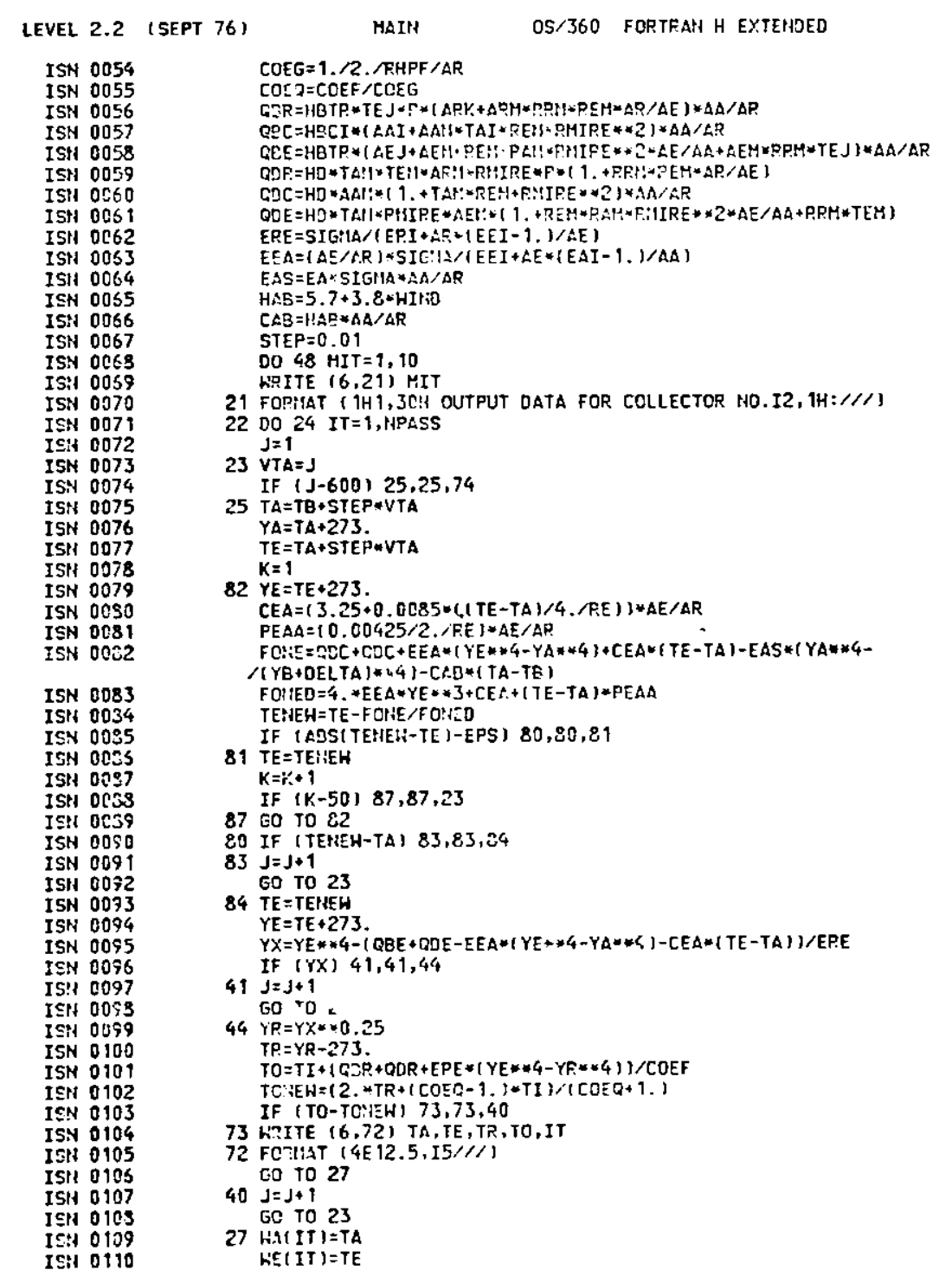




\begin{tabular}{|c|c|c|}
\hline 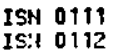 & & $\begin{array}{l}h P(I T)=T P . \\
T I=T O\end{array}$ \\
\hline ISN 0113 & 24 & $\begin{array}{l}\text { TI }=\text { TO } \\
\text { COITIPYUE }\end{array}$ \\
\hline ISN $01 \div 4$ & & 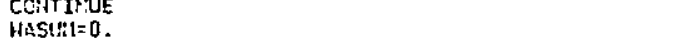 \\
\hline ISN 0115 & & $K=\leq ! H_{i}=0$. \\
\hline ISt 0116 & & h?SL: $1=0$. \\
\hline ISN OIII & & $00 \therefore 3 \quad I T=1$, NPASS \\
\hline ISH 0118 & & H.SUHI=\{ASUYY+HA IT \\
\hline ISN 0119 & & bES!ni=UESU:1+HE IT: \\
\hline ISN 0120 & & 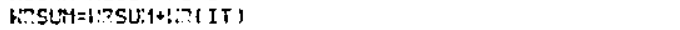 \\
\hline ISN 0121 & 28 & CO:ITINUE \\
\hline ISN 0122 & & $T A=6: 2 S U H 1 / P A S S$ \\
\hline ISN 0123 & & $Y A=T A+273$ \\
\hline ISN 0124 & & TE $=1, E S L: 1 /$ PASS \\
\hline ISN 0125 & & $Y E=T E+273$ \\
\hline ISN 0126 & & TR=!IRSLi1/PASS \\
\hline ISH Q 127 & & $Y R=1 R+273$ \\
\hline ISN 0123 & & WNITE $(6,29)$ TA,TE,TR,TO \\
\hline ISH 0129 & 29 & FC?HAT ( $4 E 12.5 / / /)$ \\
\hline ISN 0130 & & $T I=T I N$ \\
\hline ISN 0131 & & HLEN $=H L E N * P A S S$ \\
\hline ISN 0132 & & $A A=A A D-P A S S$ \\
\hline ISH 0133 & & $A E=A E Q * P A S S$ \\
\hline ISH 0134 & & $\triangle R=A F O * P A S S$ \\
\hline ISH 0135 & & CC:TP=AA/A? \\
\hline ISH 0136 & & $C E A=(3.25+0.0035 *(\{T E-T A) / 4 . / R E)) * A E / A R$ \\
\hline ISN 0137 & & UOFD $=E R I+A R * I E E I-1, J / A E$ \\
\hline ISN 0138 & & $U Q P=S I G+4 A *(Y R *=2+Y E * 2) *(Y R+Y E) * A R / O F D$ \\
\hline ISN 0139 & & USAPD $=[E I+A E *(E A]-1,) / A A$ \\
\hline ISN 0140 & & $(U: P=(S) E H A *(Y E * * 2+Y A * 2 Z) *(Y E+Y A) / U A F D+C E A=A R / A E) * A E$ \\
\hline IS: 0149 & & 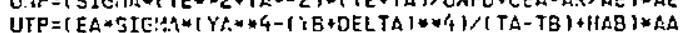 \\
\hline IS: 0142 & & 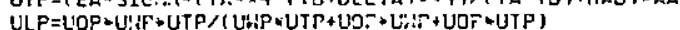 \\
\hline ISN 0143 & & UL=ULP $A$ A \\
\hline IS: 0 O 144 & & $A Z Y=A C C / A P C$ \\
\hline ISN 0145 & & UO= $=1 . / 1 . / U L+A R O / U H P / A C C+E V O C / H C O H I$ \\
\hline ISN 0146 & & $F F F=L O / U L$ \\
\hline ISN 0147 & & ULO':UULP/LISP \\
\hline ISN 0148 & & ULOT $=U U_{-} P$ UTTP \\
\hline ISN 0149 & & LEFP $=U L * F / P=\triangle A / F L O H O / C P / C O: H R$ \\
\hline ISH 0150 & & $F P C=1 . /$ (AGFR/FPR) \\
\hline ISN 0151 & & $F S ?=F P C *(1 .-E X P\{-A E F P\})$, \\
\hline ISH 0152 & & 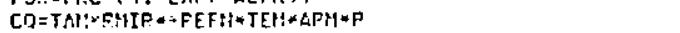 \\
\hline ISit 0153 & & $H T L=H E C I+H I / C O L R$ \\
\hline ISit 0154 & & $Q U Y=H T L * C Q * A A-U L * A Q *(T R-T B)$ \\
\hline $1=10955$ & & 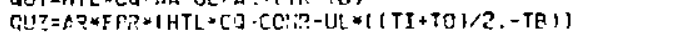 \\
\hline IS: 0155 & & 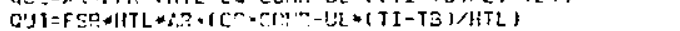 \\
\hline ISN 0157 & & 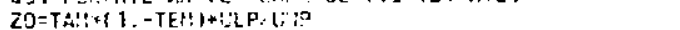 \\
\hline 19110158 & & 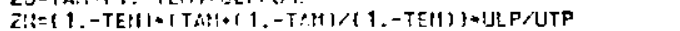 \\
\hline ISt 0159 & & 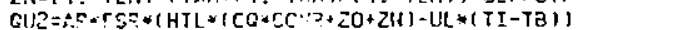 \\
\hline ISN 0150 & & 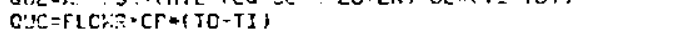 \\
\hline IS: 0161 & & DIVD $=(H I=C I+H D)+2 A D$ \\
\hline I जN 0162 & & ETF $i=$ C.UY $/ O I N D$ \\
\hline Ist 0163 & & $E \div F Z=R: 12 / 01 V 0$ \\
\hline ISH 0164 & & $E F F \bar{J}=G J 1 / O I V D$ \\
\hline ISN 0165 & & EFF $=C I J 2$, OIVD \\
\hline ISt 0166 & & $E F F C=F U C / O I N D$ \\
\hline 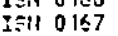 & & $\because$ IE 16.23$)$ (ISP, UHP, \\
\hline ISt 0163 & 33 & FC OCT (GE \\
\hline
\end{tabular}




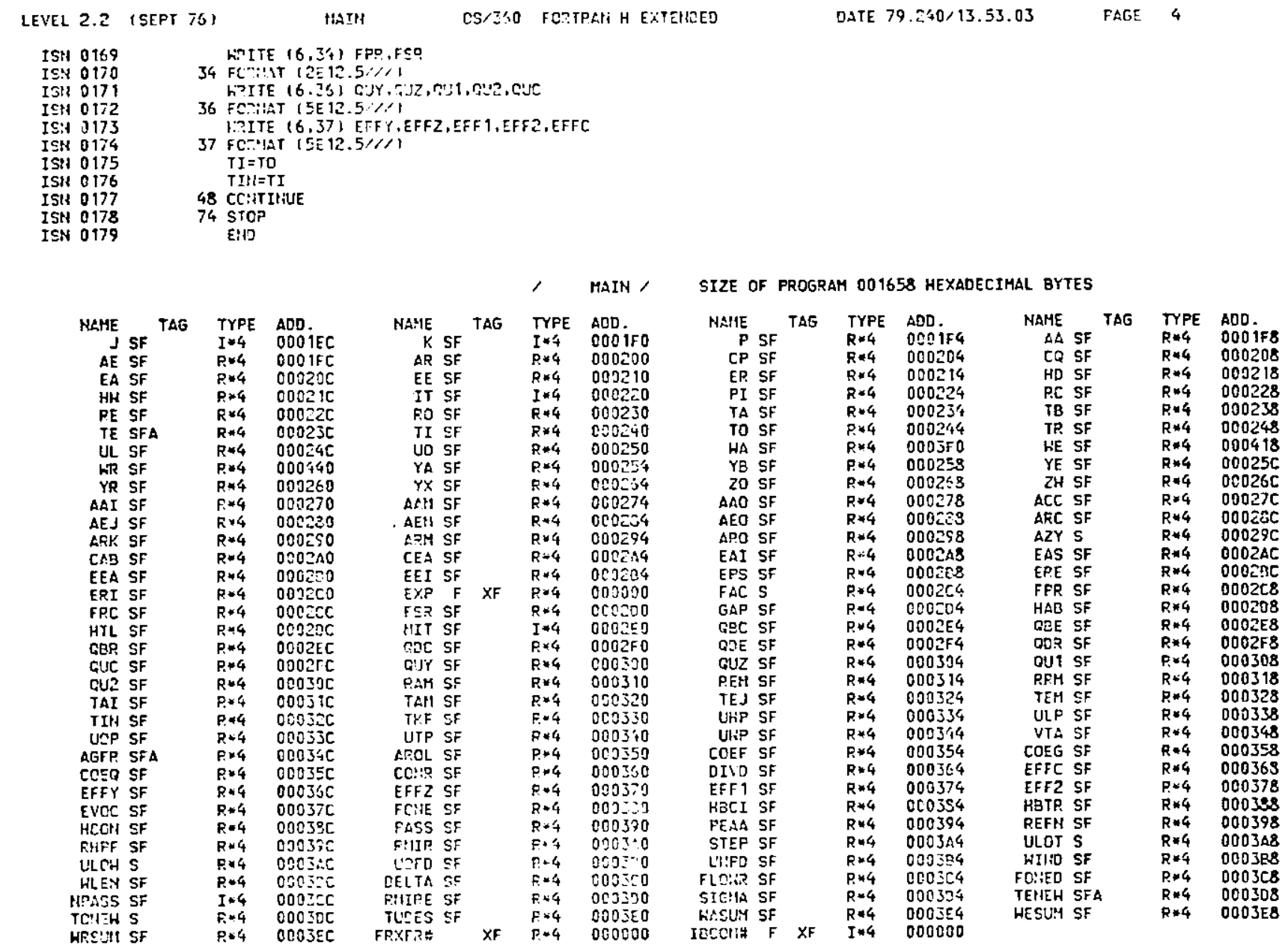

SOUPCE STATEMENT LABELS

\begin{tabular}{|c|c|c|c|c|c|c|c|c|c|c|c|}
\hline $\begin{array}{r}\text { LABEL } \\
22 \\
81\end{array}$ & $\begin{array}{r}\text { ISN } \\
71 \\
86\end{array}$ & $\begin{array}{l}A C D O \\
000 C 2 C N R \\
0000 C C\end{array}$ & $\begin{array}{r}\text { LABEL } \\
23 \\
87\end{array}$ & $\begin{array}{r}\text { ISN } \\
73 \\
89\end{array}$ & $\begin{array}{c}\triangle C O R \\
\text { OS?CIC } \\
\text { CICDEA }\end{array}$ & $\begin{array}{r}\text { LAEEI } \\
2^{2} \\
80\end{array}$ & $\begin{array}{r}\text { ISN } \\
75 \\
90\end{array}$ & $\begin{array}{l}\text { ADOR } \\
\text { O00C62 } \\
\text { O000FO }\end{array}$ & $\begin{array}{r}\text { LABEL } \\
82 \\
83\end{array}$ & $\begin{array}{r}\text { ISN } \\
79 \\
91\end{array}$ & $\begin{array}{c}A 0 D R \\
00092 \\
0000 \mathrm{FE}\end{array}$ \\
\hline
\end{tabular}


INPUT DATA:

$\begin{array}{ccccccccc}0.0127 & 0.0095 & 0.0174 & 0.1128 & 1.2192 & 0.0129 & 0.6000 & 1.0000 & 8.0000 \\ 966.0000 & 100.0000 & 20.0000 & 137.3900 & 0.0170 & 5.0000 & & \\ 0.0500 & 0.8500 & 0.8590 & 4170.0000 & 0.6500 & & & \\ 0.8500 & 0.8500 & 0.1500 & 0.0500 & 0.0500 & 0.0500 & 0.9000 & 0.9000 \\ 0.0500 & 0.0500 & 0.0500 & 0.9000 & 0.9000 & 0.8500 & & \end{array}$

$0.01000 \quad 5.000009180 .00000$ 
OUTPUT DATA FOR COLLECTOR NO. 1:

$0.23740 E+02 \quad 0.39725 E+02 \quad 0.21011 E+03 \quad 0.13915 E+03 \quad 1$

$0.23760 E+02 \quad 0.39840 E+02 \quad 0.21189 E+03 \quad 0.14031 E+032$

$0.23780 E+02 \quad 0.39956 E+02 \quad 0.21366 E+03 \quad 0.14267 E+03 \quad 3$

$0.23800 E+02 \quad 0.40071 E+02 \quad 0.21540 E+03 \quad 0.14443 E+03 \quad 4$

$0.23820 E+02 \quad 0.40186 E+02 \quad 0.21713 E+03 \quad 0.14618 E+03$

$0.23780 E+02 \quad 0.39956 E+02 \quad 0.21364 E+03 \quad 0.14618 E+03$

$0.27542 E+00 \quad 0.68699 E+01 \quad 0.51015 E+02 \quad 0.26344 E+00 \quad 0.72208 E+00 \quad 0.70098 E+00$

$0.97078 E+00 \quad 0.96902 E+00$

$0.61715 E+03 \quad 0.61749 E+03 \quad 0.61749 E+03 \quad 0.61905 E+030.62305 E+03$

$0.42106 E+00 \quad 0.42129 E+00 \quad 0.42129 E+00 \quad 0.42235 E+00 \quad 0.42509 E+00$ 
OUTPU DATA FOR COLLECTOR H. ?:

$0.23840 E \cdot 02 \quad 0.40301 E \cdot 02 \quad 0.21334 E+03 \quad 0.14793 E \cdot 03 \quad 1$

$0.23350 E \cdot 02 \quad 0.40353 E+02 \quad 0.21969 E+03 \quad 0.14968 E+03 \quad 2$

$0.23870 E+02 \quad 0.40473 E+02 \quad 0.22137 E \cdot 03 \quad 0.15143 E+03$

$0.23590 E+02 \quad 0.4058: E \cdot 02 \quad 0.22364 E \cdot 03 \quad 0.15317 E+03 \quad 4$

$0.23910 E+020.40701 E+020.22468 E \cdot 03 \quad 0.15492 E+C 3 \quad 5$

$0.23872 E+02 \quad 0.40484 E+02 \quad 0.22152 E+03 \quad 0.15492 E+03$

$0.28502 E+00 \quad 0.69159 E+090.59775 E+020.27237 E+00 \quad 0.74631 E+000.72379 E+G B$

$0.96983 E \cdot 00 \quad 0.96202 E+00$

$0.61329 E+03 \quad C .61353 E+03 \quad 0.61353 E+03 \quad 0.61513 E+030.61930 E+03$

$0.41842 E+00 \quad 0.41259 E+00 \quad 0.41859 E+00 \quad 0.4155 E E+00 \quad 0.42252 E+00$ 
CUTFT DATA FOR COLLECTOR ND. 3:

$0.23930 E+02 \quad 0.40315 E+02 \quad 0.2253 \pi E+03 \quad 0.15 \leq 6 S E+03$

$0.23950 E \cdot 02 \quad 0.40929 E \cdot 02 \quad 0.22793 E+03 \quad 0.150395 \cdot 03=$

$0.23980 E+02 \quad 0.41099 E+02 \quad 0.23033 E+03 \quad 0.16013 E+03$

$0.24000 E+02 \quad 0.41212 E+02 \quad 0.23191 E+03 \quad 0.16186 E+03 \quad 4$

$0.24020 E+02 \quad 0.41324 E+02 \quad 0.23347 E+03 \quad 0.16359 E+03$

$0.23976 E+02 \quad 0.41076 E+02 \quad 0.22999 E+03 \quad 0.16359 E+03$

$0.29 J \cup 4 E+00 \quad 0.69674 E+01 \quad 0.50516 E+02 \quad 0.28202 E+00 \quad 0.77302 E+00 \quad 0.74 E E S E+00$

$0.96878 E+00 \quad 0.96692 E+00$

$0.60894 E+03 \quad 0.60925 E+03 \quad 0.60926 E+03 \quad 0.61091 E+03 \quad 0.61504 E+03$

$0.41545 E+00 \quad 0.41567 E+00 \quad 0.41558 E+00 \quad 0.41680 E+00 \quad 0.41962 E+03$ 
OUTPUT DATA FOR COLLECTOR NO. 4:

$0.24040 E+02 \quad 0.41437 E+02 \quad 0.23502 E+03 \quad 0.16532 E+03$

$0.24060 E+02 \quad 0.41550 E+02 \quad 0.23656 E+03 \quad 0.16704 E+032$

$0.24080 E+02 \quad 0.41662 E+02 \quad 0.23303 E+03 \quad 0.16877 E+03$

$0.24100 E+02 \quad 0.41774 E+02 \quad 0.23959 E+03 \quad 0.17049 E+05$

$0.24120 E+02 \quad 0.41886 E+02 \quad 0.24105 E+03 \quad 0.17221 E+03$

$0.24030 E+02 \quad 0.41662 E+02 \quad 0.23807 E \cdot 03 \quad 0.17221 E+03$

$0.30604 E+00 \quad 0.70183 E+01 \quad 0.50271 E+02 \quad 0.29955 E+00 \quad 0.759: 4 E+00 \quad 0.77338 E+00$

$0.96776 E+00 \quad 0.96584 E+00$

$0.60458 E+03 \quad 0.60489 E+03 \quad 0.60490 E+03 \quad 0.60660 E+03 \quad 0.61079 E+03$

$0.41248 E+000.41269 E+00 \quad 0.41270 E+00 \quad 0.41306 E+00 \quad 0.41672 i+00$ 
OUTPUT DATA FOR COLLECTOR NO. 5:

$0.24150 E+02 \quad 0.42053 E+02 \quad 0.24330 E+03 \quad 0.17392 E+03$

$0.24170 E+02 \quad 0.42165 E+02 \quad 0.24477 E+03 \quad 0.17564 E+03=$

$0.24190 E+02 \quad 0.42276 E+02 \quad 0.24622 E+03 \quad 0.17735 E+03$

$0.24210 E+02 \quad 0.42357 E+02 \quad 0.24766 E+03 \quad 0.17905 E+03 \quad 4$

$0.24230 E+02 \quad 0.42498 E+02 \quad 0.24909 E+03 \quad 0.18076 E+03$

$0.24190 E+02 \quad 0.42276 E+02 \quad 0.24621 E+03 \quad 0.18076 E+03$

$0.31632 E+00 \quad 0.70717 E+010.50026 E+02 \quad 0.30141 E+00 \quad 0.82616 E+00 \quad 0.79865 E+00$

$0.96671 E+80 \quad 0.96473 E+00$

$0.59993 E+03 \quad 0.60032 E+03 \quad 0.60033 E+03 \quad 0.60207 E+03 \quad 0.60629 E+03$

$0.40934 E+00 \quad 0.40958 E+00 \quad 0.40958 E+30 \quad 0.41077 E+n 90.413 f^{\circ} E+00$ 
OUTPUT DATA FO? TOLLECTCP MO. 6:

$0.24260 E+02 \quad 0.42363 E+02 \quad 0.25120 E+03 \quad 0.192 r, \leqslant E+03$

$0.24280 E+02 \quad 0.42773 E+02 \quad 0.25260 E+03 \quad 0.18416 E+03 \quad 2$

$0.24300 E+02 \quad 0.42833 E+02 \quad 0.25399 E+03 \quad 0.1858 S E+03 \quad 3$

$0.24330 E+02 \quad 0.43048 E+02 \quad 0.25305 E+03 \quad 0.18755 E+03 \quad 4$

$0.24350 E+02 \quad 0.43158 E+02 \quad 0.25741 E+03 \quad 0.13525 E+03$

$0.24304 E+02 \quad 0.42905 E+02 \quad 0.25425 E+03 \quad 0.18925 E+03$

$0.32776 E+00 \quad 0.712 E 4 E+01 \quad 0.49785 E+02 \quad 0.31139 E+00 \quad 0.85352 E+00 \quad 0.82419 E+00$

$0.96564 E+00 \quad 0.96360 E+00$

$0.59522 E+030.59559 E+03 \quad 0.59560 E+03 \quad 0.59739 E+030.60162 E+03$

$0.40509 E+00 \quad 0.40635 E+00 \quad 0.40536 E+00 \quad 0.40759 E+00 \quad 0.41047 E+00$ 
OUTPUT DATA FOR COLLECTOR NO. 7:

$0.24370 E+02 \quad 0.43267 E+02 \quad 0.25876 E+03 \quad 0.1909 f E+03$

$0.24400 E \cdot 02 \quad 0.43431 E+02 \quad 0.26077 E+03 \quad 0.19252 E+03 \quad 2$

$0.24420 E+02 \quad 0.43540 E+02 \quad 0.26210 E+03 \quad 0.19431 E+03$

$0.24440 E+02 \quad 0.43649 E+02 \quad 0.26341 E+03 \quad 0.15599 E+03 \quad 4$

$0.24470 E+02 \quad 0.43812 E+02 \quad 0.265 T^{-} E+03 \quad 0.19767 E+03$

$0.27420 E+02 \quad 0.43540 E+02 \quad 0.2620 \varepsilon E+03 \quad 0.19767 E+03$

$0.33569 E+00 \quad 0.71814 E+01 \quad 0.49552 E+02 \quad 0.32134, E+00 \quad 0.83980 E+00 \quad 0.84960 E+00$

$0.96458 E+00 \quad 0.96248 E+00$

$0.59037 E+03 \quad 0.59073 E+03 \quad 0.59075 E+030.59258 E+03 \quad 0.52685 E+03$

$0.40279 E+00 \quad 0.40303 E+00 \quad 0.40304 E+00 \quad 0.40429 E+00 \quad 0.40723 E+00$ 
OUTPUT DATA FOR COLLECTOP. NO. 8

$0.24490 E+02 \quad 0.43920 E+02 \quad 0.26656 E+03 \quad 0.19934 E+03$

$0.24520 E+02 \quad 0.44032 E+02 \quad 0.26355 E+03 \quad 0.20101 E+03$

$0.24540 E+02 \quad 0.44190 E+02 \quad 0.26995 E+03 \quad 0.20268 E+03$

$0.24560 E+02 \quad 0.44298 E+02 \quad 0.27111 E+03 \quad 3.20435 E+03 \quad 4$

$0.245905+020.444595+020.27299 E+030.20602 E+03$

$0.24540 E+02 \quad 0.44190 E+02 \quad 0.26984 E+03 \quad 0.20602 E+03$

$0.34980 E+00 \quad 0.72378 E+01 \quad 0.49324 E+02 \quad 0.33143 E+00 \quad 0.90845 E+00 \quad 0.87530 E+00$

$0.96351 E+00 \quad 0.96134 E+00$

$0.55536 E+03 \quad 0.58571 E+03 \quad 0.55572 E+03 \quad 0.58760 E+03 \quad 0.59196 E+03$

$0.39937 E+00 \quad 0.3996$ TE+00 0.3996 TE+00 $0.40090 E+00 \quad 0.40397 E+00$ 
OUIPUT DATA FOR COLLECTOR MO. 9:

$0.24510 E+02 \quad 0.44566 E+02 \quad 0.27423 E+03 \quad 0.20768 E+03$

$0.24540 E+02 \quad 0.44727 E+02 \quad 0.27607 E+03 \quad 0.20934 E+03 \quad 2$

$0.24660 E+02 \quad 0.44833 E+02 \quad 0.27729 E+03 \quad 0.21059 E+03 \quad 3$

$0.24690 E+02 \quad 0.44593 E+1 \quad 0.27910 E+03 \quad 0.21265 E+03 \quad 4$

$0.24720 E+020.45153 E+020.23090 E+030.21430 E+03 \quad 5$

$0.24664 E+C 2 \quad 0.44854 E+02 \quad 0.27752 E+03 \quad 0.21430 E+03$

$0.36107 E+00 \quad 0.72954 E+01 \quad 0.49102 E+02 \quad 0.34165 E+00 \quad 0.93646 E+00 \quad 6.90128 E+00$

$0.96243 E+00 \quad 0.96020 E+00$

$0.58018 E+03 \quad 0.58053 E+03 \quad 0.52054 E+03 \quad 0.58247 E+03 \quad 0.58688 E+n 3$

$0.39583 E+00 \quad 0.39607 E+00 \quad 0.39608 E+00 \quad 0.39739 E+00 \quad 0.40041 E+00$ 
OUTPUT DATA FER COLLECTOR RO. 10:

$0.29749 E+02 \quad 0.4525 S E+02 \quad 0.28209 E+03 \quad 0.21574 E+03$

$0.24770 E+02 \quad 0.45418 E+02 \quad 0.28385 E+03 \quad 0.2175,9 E+032$

$0.24790 E+02 \quad 0.45523 E+02 \quad 0.28502 E+03 \quad 0.21923 E+03 \quad 3$

$0.24520 E+02 \quad 0.45682 E+020.28676 E+030.22086 E+03 \quad 4$

$0.24850 E+02 \quad 0.45840 E+02 \quad 0.23848 E+03 \quad 0.22250 E+03$

$0.24794 E+02 \quad 0.45544 E+02 \quad 0.28524 E+03 \quad 0.22250 E+03$

$0.37269 E+00 \quad 0.73551 E+010.42881 E+02 \quad 0.35216 E+00 \quad 0.96527 E+00 \quad 0.927+3 E+00$

$0.96132 E+00 \quad 0.95903 E+00$

$0.57475 E+03 \quad 0.57515 E+03 \quad 0.57516 E+03 \quad 0.57714 E+03 \quad 0.53156 E+03$

$0.39213 E+00 \quad 0.39740 E+00 \quad 0.39241 E+000.39376 E+00 \quad 0.39678 E+00$ 